Aus der Klinik für Unfallchirurgie, Orthopädie und Plastische Chirurgie

(Prof. Dr. med. W. Lehmann)

der Medizinischen Fakultät der Universität Göttingen

\title{
Der Einfluss des selektiven Androgenrezeptor- Modulators Enobosarm auf die Skelettmuskulatur im Modellorganismus der osteoporotischen Ratte
}

\author{
INAUGURAL-DISSERTATION \\ zur Erlangung des Doktorgrades \\ der Medizinischen Fakultät der \\ Georg-August-Universität zu Göttingen
}

\author{
vorgelegt von \\ Danny Henkies \\ aus \\ Göttingen
}

Göttingen 2020 
Dekan:

Referent/in

Ko-Referent/in:

Drittreferent/in:
Prof. Dr. rer. nat. H. K. Kroemer

Prof. Dr. med. S. Sehmisch

Prof. Dr. Dr. Stephan von Haehling

Prof. Dr. Martin Oppermann

Datum der mündlichen Prüfung: 03.03.2020 
Hiermit erkläre ich, die Dissertation mit dem Titel "Der Einfluss des selektiven Androgenrezeptor-Modulators Enobosarm auf die Skelettmuskulatur im Modellorganismus der osteoporotischen Ratte" eigenständig angefertigt und keine anderen als die von mir angegebenen Quellen und Hilfsmittel verwendet zu haben.

Göttingen, den .............. 


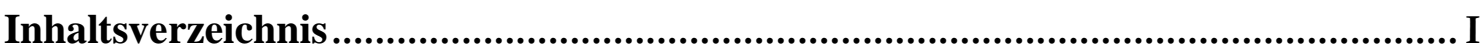

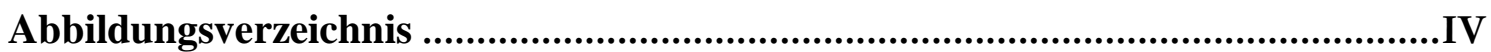

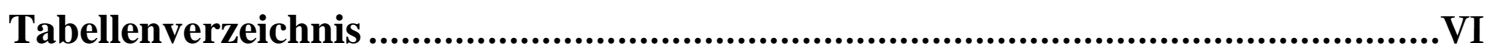

Abkürzungsverzeichnis ....................................................................................III

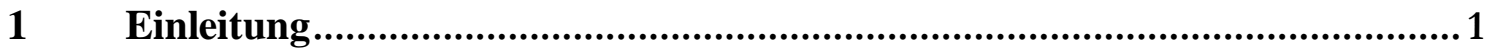

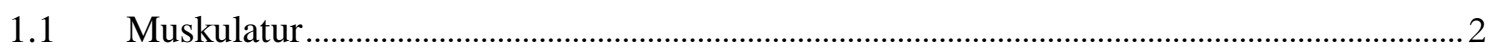

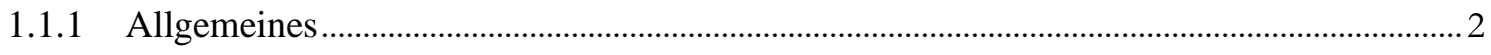

1.1.2 Aufbau der quergestreiften Skelettmuskulatur ...................................................................2

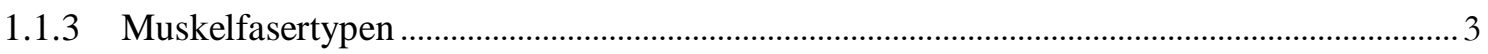

1.1.4 Regeneration der quergestreiften Skelettmuskulatur .........................................................

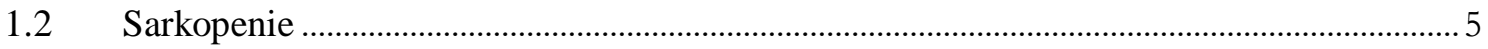

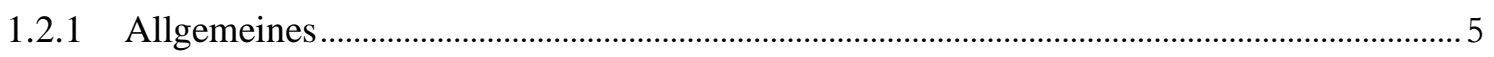

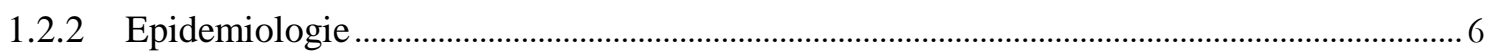

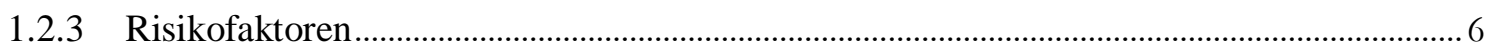

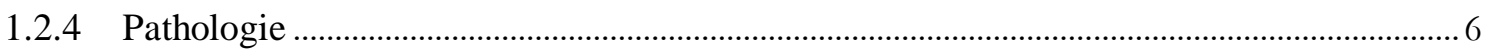

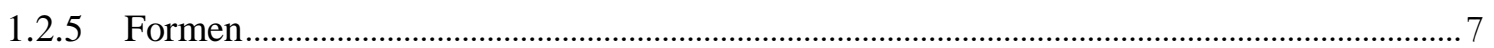

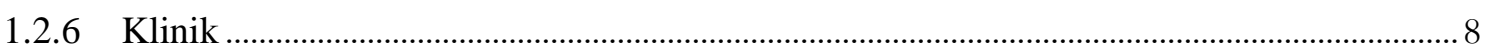

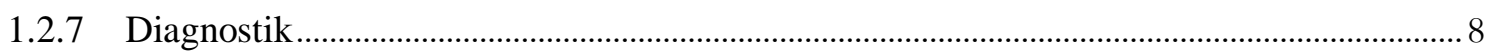

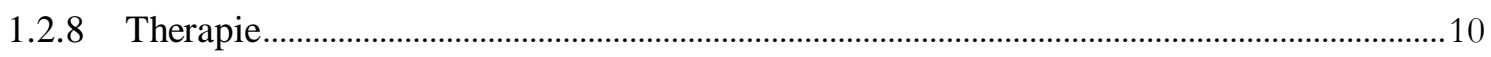

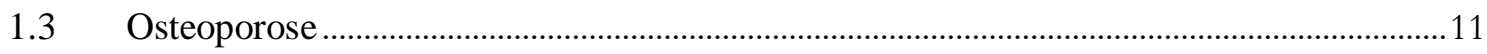

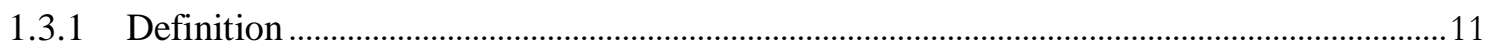

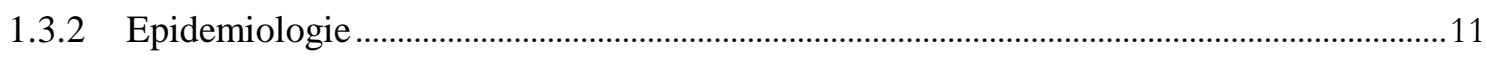

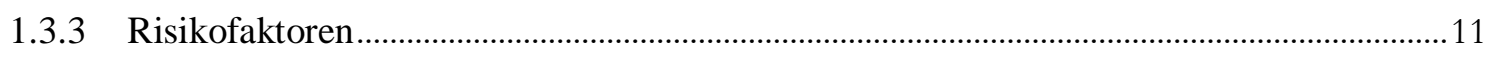

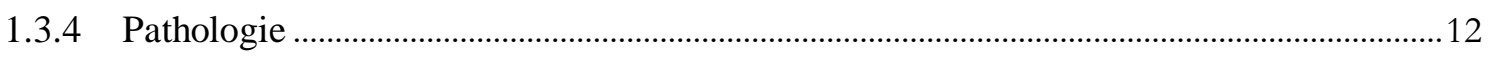

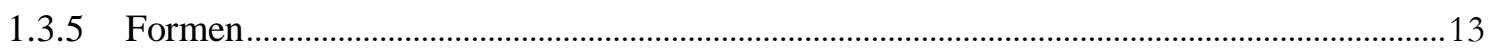

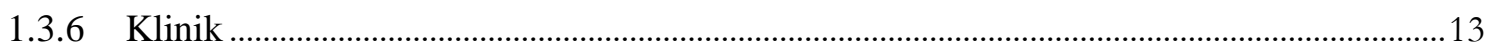

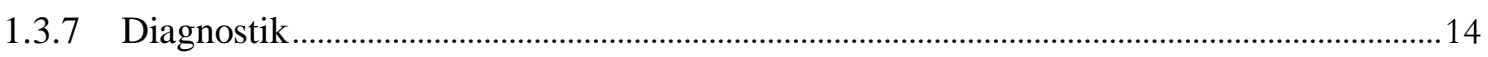

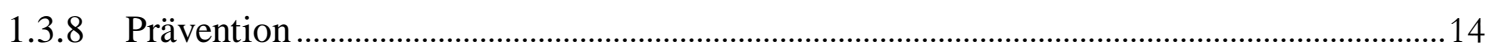

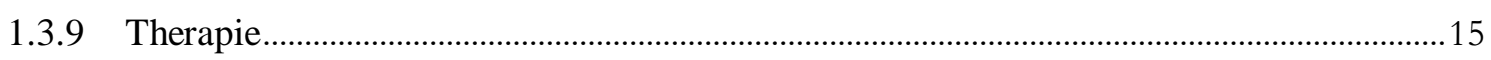

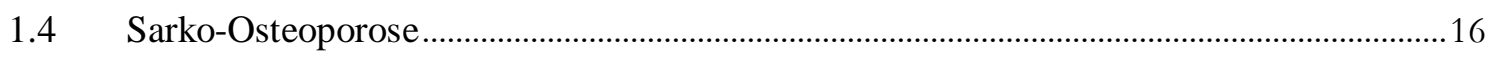

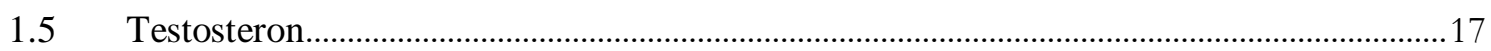

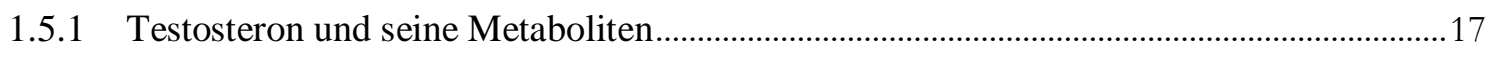

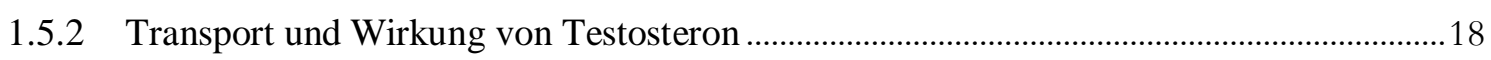

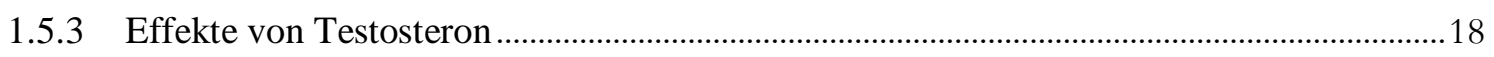

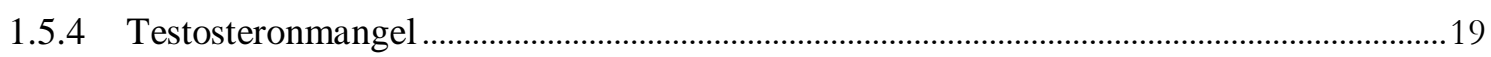

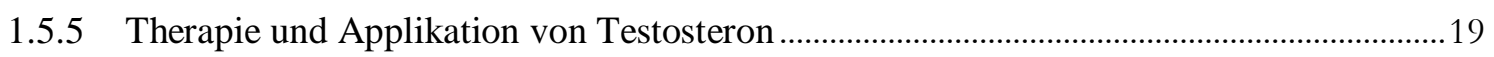

1.5.6 Nebenwirkungen der Testosterontherapie .......................................................................20

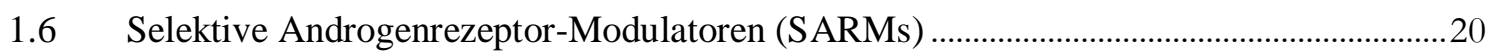

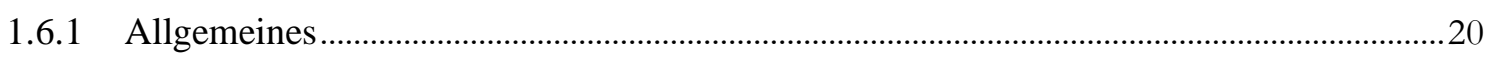




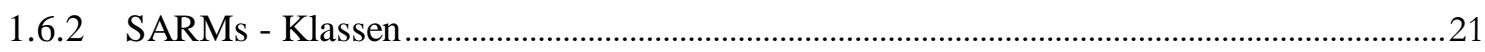

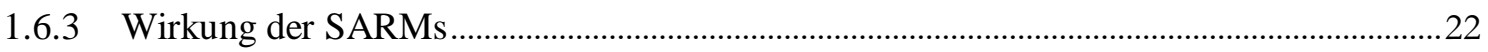

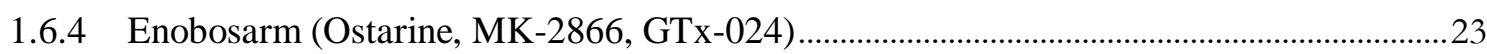

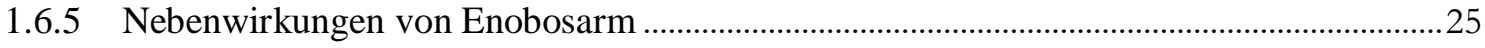

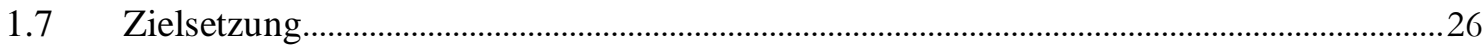

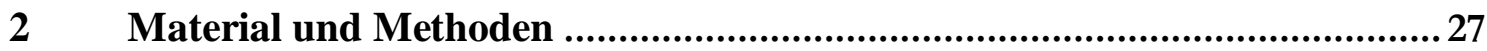

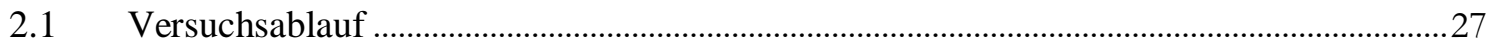

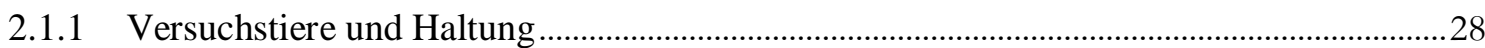

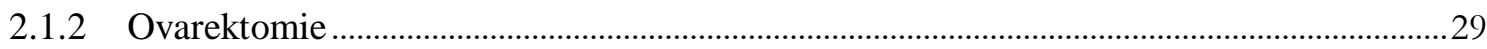

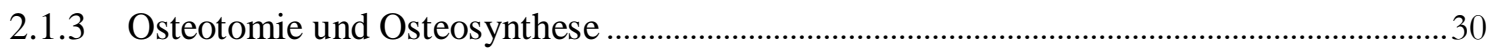

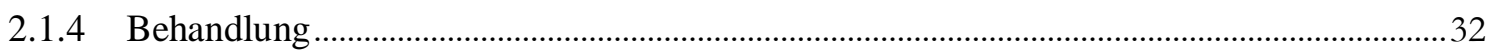

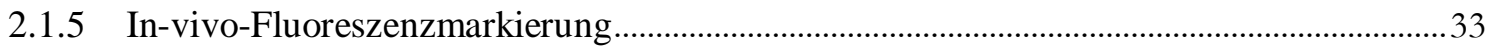

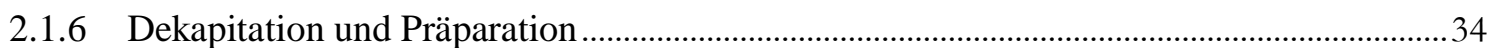

2.2 Dünnschnitte der quergestreiften Skelettmuskulatur .............................................................35

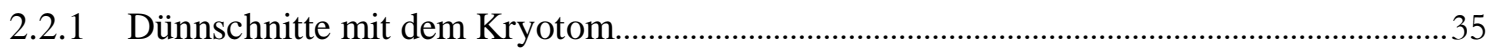

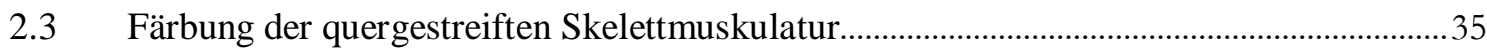

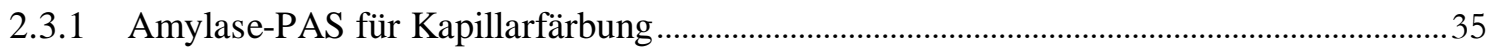

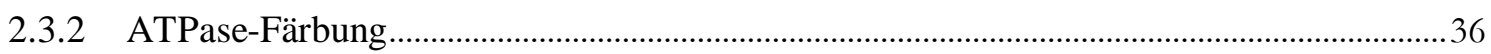

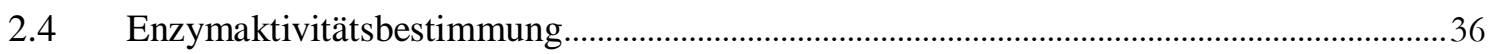

2.4.1 Enzymaktivitätsbestimmung der quergestreiften Skelettmuskulatur ................................36

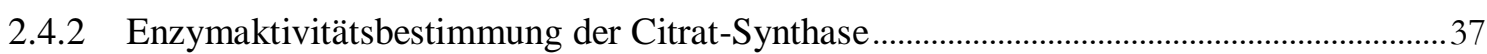

2.4.3 Enzymaktivitätsbestimmung der Laktatdehydrogenase ...................................................3 37

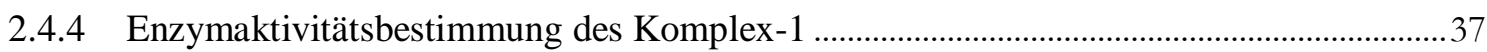

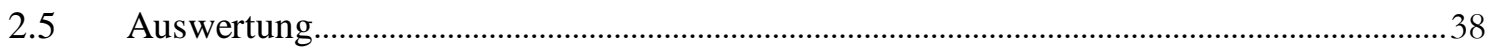

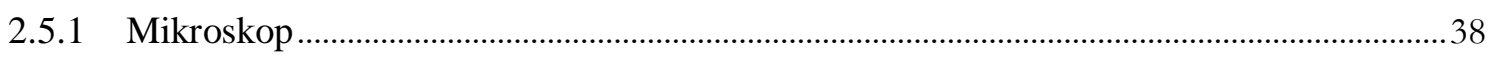

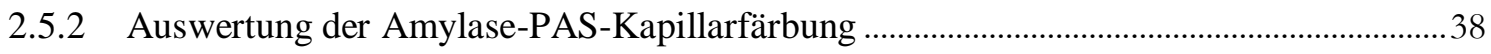

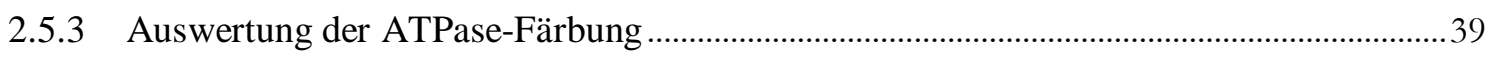

2.5.4 Auswertung der Enzymaktivitätsbestimmung der Citrat-Synthase ...................................4 41

2.5.5 Auswertung der Enzymaktivitätsbestimmung der Laktatdehydrogenase..........................4 41

2.5.6 Auswertung der Enzymaktivitätsbestimmung des Komplex-1 ...........................................42

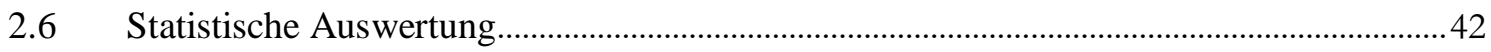

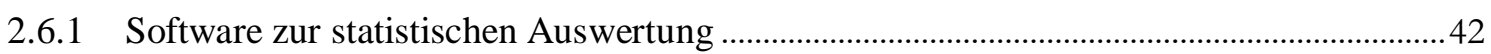

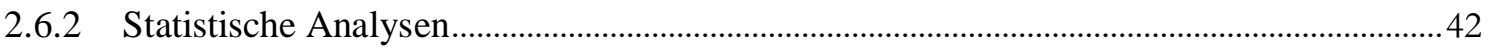

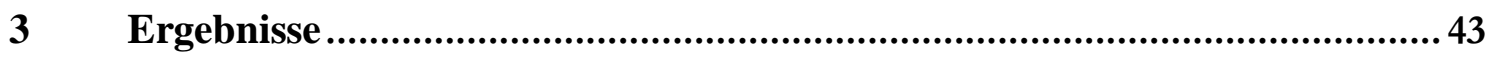

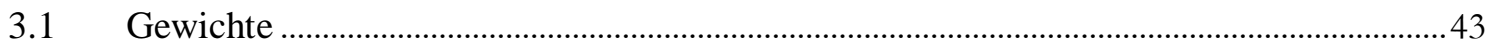

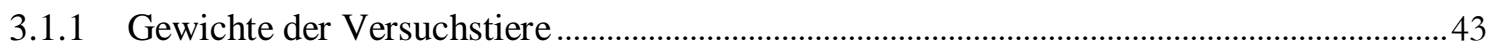

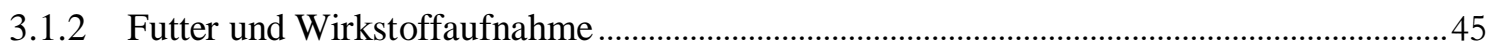

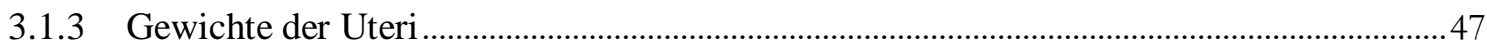

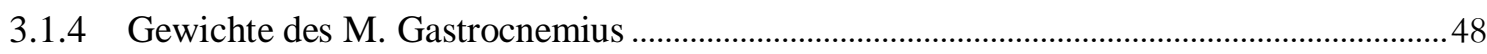

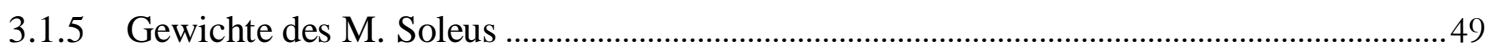




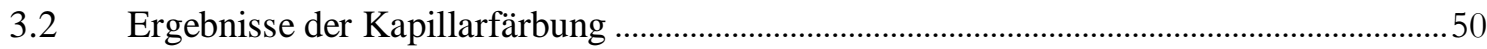

3.2.1 Ergebnisse der Kapillarfärbung des M. Gastrocnemius .....................................................50

3.2.2 Ergebnisse der Kapillarfärbung des M. Longissimus .......................................................... 51

3.2.3 Ergebnisse der Kapillarfärbung des M. Soleus ..................................................................53

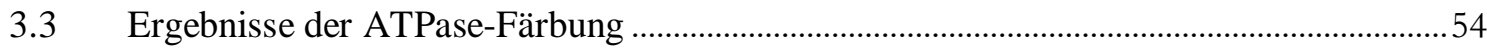

3.3.1 Ergebnisse der ATPase-Färbung des M. Gastrocnemius .....................................................5 54

3.3.2 Ergebnisse der ATPase-Färbung des M. Longissimus ......................................................5 57

3.3.3 Ergebnisse der ATPase-Färbung des M. Soleus ................................................................61

3.4 Ergebnisse der Enzymaktivitätsbestimmung ................................................................63

3.4.1 Ergebnisse der Enzymaktivitätsbestimmung der Citrat-Synthase......................................6.63

3.4.2 Ergebnisse der Enzymaktivitätsbestimmung der Laktatdehydrogenase ............................65

3.4.3 Ergebnisse der Enzymaktivitätsbestimmung des Komplex-1 ............................................67

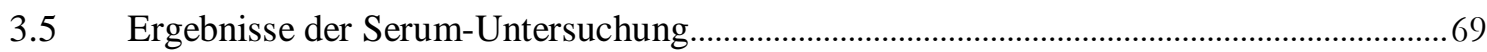

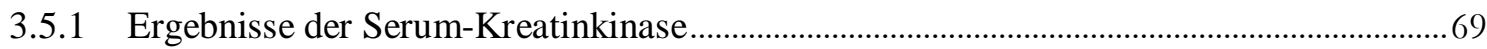

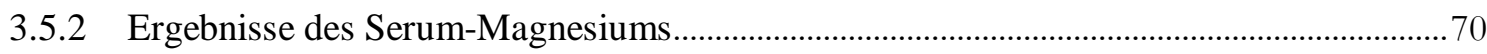

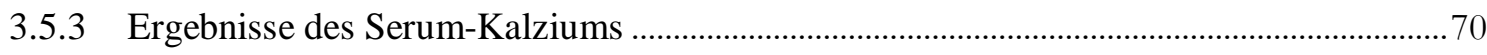

3.6 Zusammenfassung der signifikanten Ergebnisse ............................................................. 72

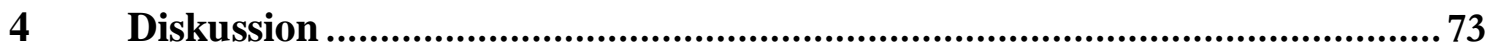

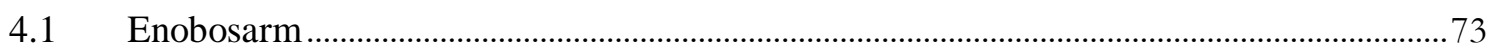

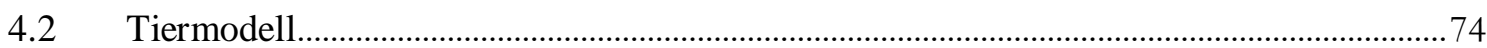

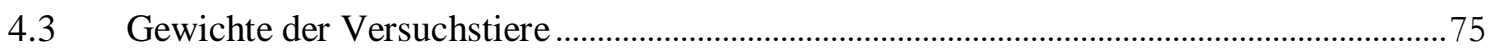

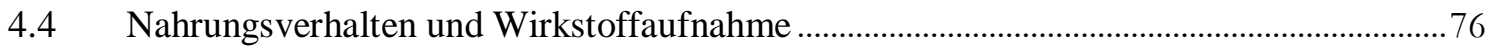

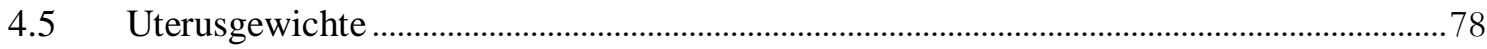

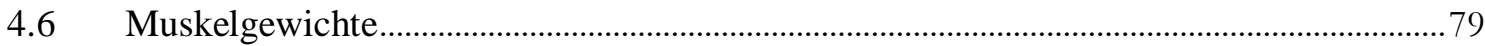

4.7 Verhältnis von Kapillaren zu Muskelzellen .....................................................................79

$4.8 \quad$ Verhältnis von glykolytischen zu nicht glykolytischen Zellen .........................................81

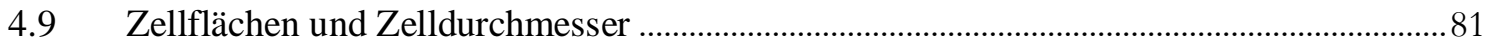

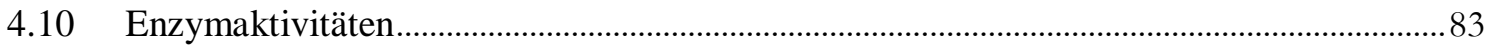

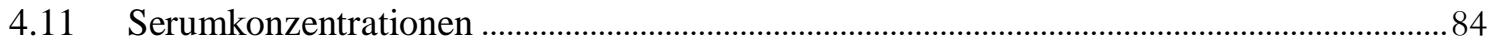

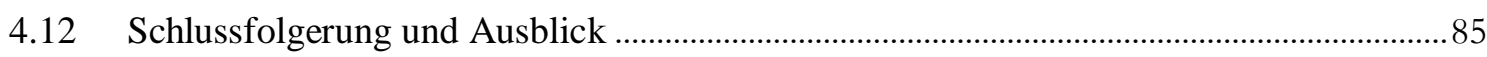

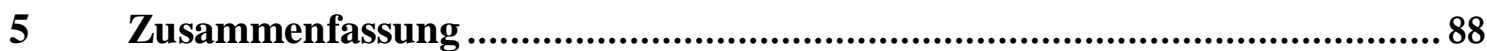

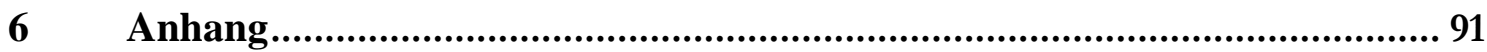

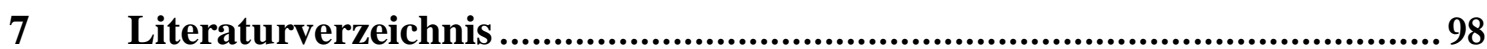




\section{Abbildungsverzeichnis}

Abbildung 1: Umwandlung von Testosteron in DHT und Estradiol ...............................................18

Abbildung 2: Klassen der selektiven Androgenrezeptor-Modulatoren............................................22

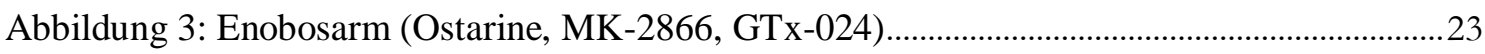

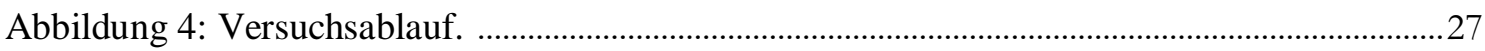

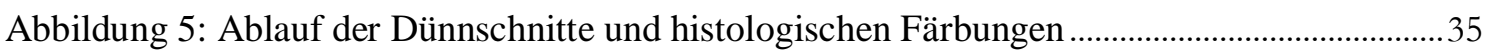

Abbildung 6: Ablauf der Enzymaktivitätsbestimmung …………………………………………....... 36

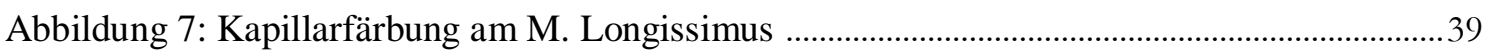

Abbildung 8: ATPase-Färbung am M. Gastrocnemius .................................................................. 40

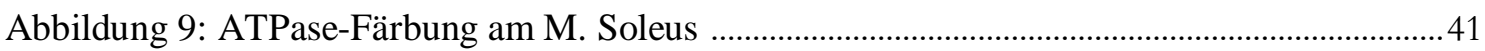

Abbildung 10: Körpergewichte bei Lieferung im Gruppenmittelwert …………………………...... 43

Abbildung 11: Körpergewichte über die gesamte Versuchsdauer. ...................................................... 44

Abbildung 12: Körpergewichte im Gruppenmittelwert am Ende des Versuches ..............................44

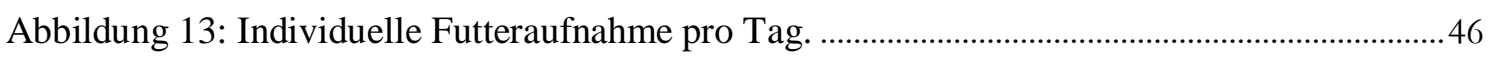

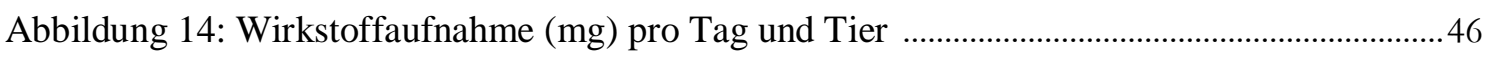

Abbildung 15: Uterusgewichte im Gruppenmittelwert....................................................................... 48

Abbildung 16: Gewichte des M. Gastrocnemius im Gruppenmittelwert............................................49

Abbildung 17: Gewichte des M. Soleus im Gruppenmittelwert ..........................................................50

Abbildung 18: Verhältnis von Kapillaren zu Muskelzellen in der Kapillarfärbung des M.

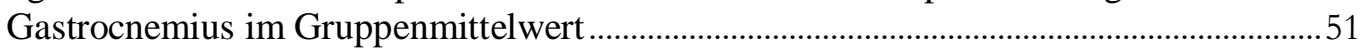

Abbildung 19: Verhältnis von Kapillaren zu Muskelzellen in der Kapillarfärbung des M. Longissimus im Gruppenmittelwert ......................................................................................52

Abbildung 20: Verhältnis von Kapillaren zu Muskelzellen in der Kapillarfärbung des M. Soleus im Gruppenmittelwert ............................................................................................53

Abbildung 21: Zellfläche der glykolytischen Zellen in der ATPase-Färbung des M. Gastrocnemius im Gruppenmittelwert

Abbildung 22: Zelldurchmesser der glykolytischen Zellen in der ATPase-Färbung des M.

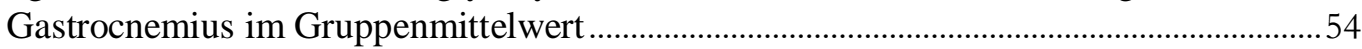

Abbildung 23: Zellfläche der nicht glykolytischen Zellen in der ATPase-Färbung des M. Gastrocnemius im Gruppenmittelwert ...................................................................................5

Abbildung 24: Zelldurchmesser der nicht glykolytischen Zellen in der ATPase-Färbung des

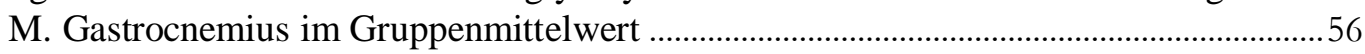

Abbildung 25: Zellfläche der glykolytischen Zellen in der ATPase-Färbung des M. Longissimus im Gruppenmittelwert

Abbildung 26: Zelldurchmesser der glykolytischen Zellen in der ATPase-Färbung des M. Longissimus im Gruppenmittelwert

Abbildung 27: Zellfläche der nicht glykolytischen Zellen in der ATPase-Färbung des M. Longissimus im Gruppenmittelwert

Abbildung 28: Zelldurchmesser der nicht glykolytischen Zellen in der ATPase-Färbung des M. Longissimus im Gruppenmittelwert...............................................................................59

Abbildung 29: Verhältnis von glykolytischen zu nicht glykolytischen Zellen in der ATPase-Färbung des M. Longissimus im Gruppenmittelwert

Abbildung 30: Zellfläche der glykolytischen Zellen in der ATPase-Färbung des M. Soleus im Gruppenmittelwert

Abbildung 31: Zelldurchmesser der glykolytischen Zellen in der ATPase-Färbung des M. Soleus im Gruppenmittelwert. 
Abbildung 32: Enzymaktivität der Citrat-Synthase des M. Gastrocnemius .63

Abbildung 33: Enzymaktivität der Citrat-Synthase des M. Longissimus. .64

Abbildung 34: Enzymaktivität der Citrat-Synthase des M. Soleus. . .64

Abbildung 35: Enzymaktivität der Laktatdehydrogenase des M. Gastrocnemius. .65

Abbildung 36: Enzymaktivität der Laktatdehydrogenase des M. Longissimus. . .66

Abbildung 37: Enzymaktivität der Laktatdehydrogenase des M. Soleus. .66

Abbildung 38: Enzymaktivität des Komplex-1 im M. Gastrocnemius . .67

Abbildung 39: Enzymaktivität des Komplex-1 im M. Longissimus. ..................................................68

Abbildung 40: Enzymaktivität des Komplex-1 im M. Soleus. ………………………........................68

Abbildung 41: Kreatinkinase (CK) aus dem Serum. ...................................................................69

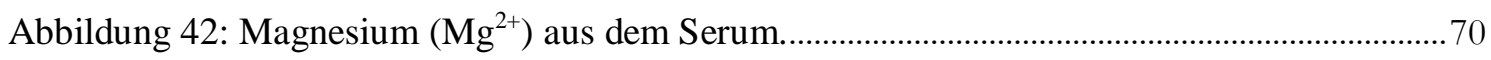

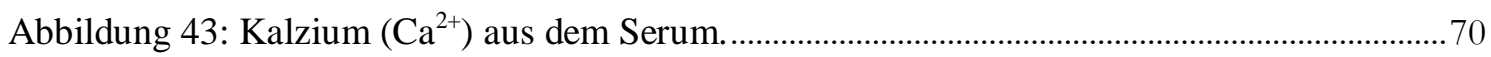




\section{Tabellenverzeichnis}

Tabelle 1: Folgen von Testosteronmangel und Wirkungen von Testosteron und Enobosarm. ....26

Tabelle 2: Übersicht der Gruppen, Behandlungsformen und Wirkstoffkonzentrationen................28

Tabelle 3: Anästhesie und Analgesie bei Ovarektomie ………………………………………….........

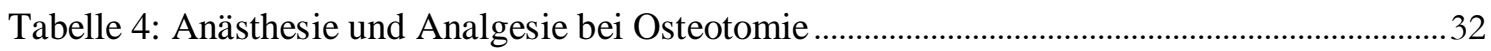

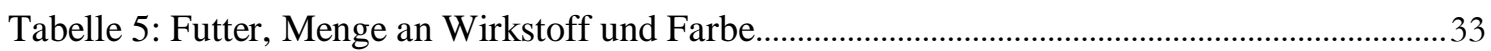

Tabelle 6: Farbstoffe, Dosierung und Zeitpunkte zur Fluoreszenzmarkierung ..................................33

Tabelle 7: Körpergewichte im Gruppenmittelwert am Versuchsbeginn und Versuchsende..........45

Tabelle 8: Futteraufnahme pro Tag und Tier im Gruppenmittelwert über die

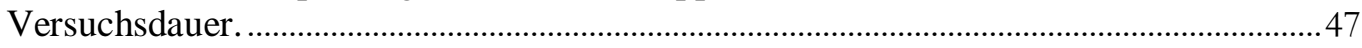

Tabelle 9: Wirkstoffaufnahme pro Tag und Tier im Gruppenmittelwert über die

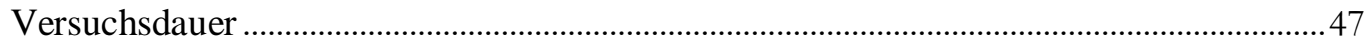

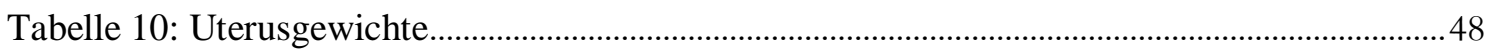

Tabelle 11: Gewichte des M. Gastrocnemius ……………………………...................................... 49

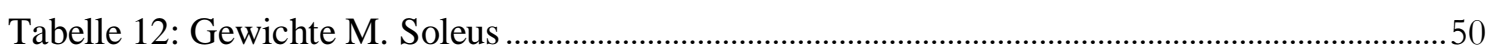

Tabelle 13: Verhältnis von Kapillaren zu Muskelzellen in der Kapillarfärbung beim

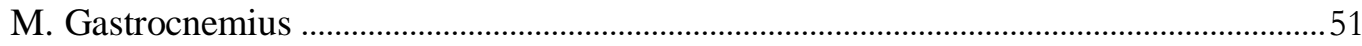

Tabelle 14: Verhältnis von Kapillaren zu Muskelzellen in der Kapillarfärbung beim M. Longissimus.

Tabelle 15: Verhältnis von Kapillaren zu Muskelzellen in der Kapillarfärbung beim

M. Soleus

Tabelle 16: Zellfläche und Zelldurchmesser der glykolytischen Zellen in der ATPase-

Färbung beim M. Gastrocnemius............................................................................................. 55

Tabelle 17: Zellfläche und Zelldurchmesser der nicht glykolytischen Zellen in der ATPase-

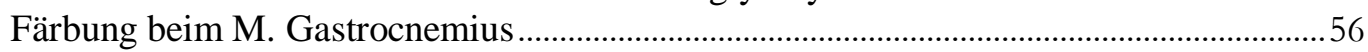

Tabelle 18: Zellfläche und Zelldurchmesser der glykolytischen Zellen in der ATPase-

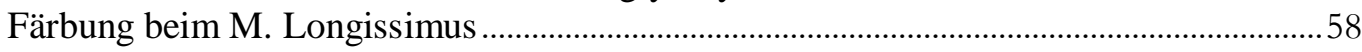

Tabelle 19: Zellfläche und Zelldurchmesser der nicht glykolytischen Zellen in der ATPase-

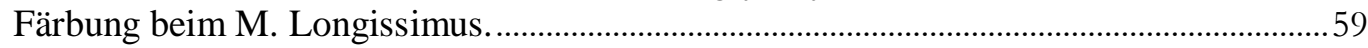

Tabelle 20: Verhältnis von glykolytischen zu nicht glykolytischen Zellen in der ATPaseFärbung beim M. Longissimus

Tabelle 21: Zellfläche und Zelldurchmesser der glykolytischen Zellen in der ATPase-

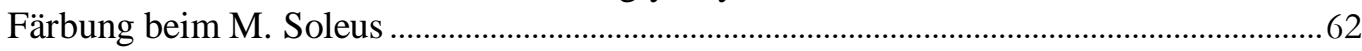

Tabelle 22: Enzymaktivität der Citrat-Synthase des M. Gastrocnemius, M. Longissimus und M. Soleus

Tabelle 23: Enzymaktivität der Laktatdehydrogenase des M. Gastrocnemius,

M. Longissimus und M. Soleus.

Tabelle 24: Enzymaktivität von Komplex-1 des M. Gastrocnemius, M. Longissimus und M. Soleus

Tabelle 25: Kreatinkinase (CK), Magnesium $\left(\mathrm{Mg}^{2+}\right)$ und Kalzium $\left(\mathrm{Ca}^{2+}\right)$ im Serum.....................71

Tabelle 26: Zusammenfassung der Signifikanten Ergebnisse............................................................. 72

Tabelle 27: Körpergewichte und geplante Wirkstoffaufnahme sowie erreichte Wirkstoffaufnahme über die Therapiedauer ..................................................................... 92

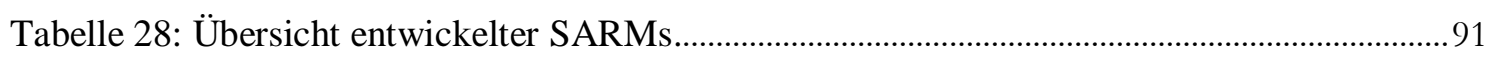

Tabelle 29: Protokoll der Amylase-PAS-Kapillarfärbung ...................................................................94

Tabelle 30: Rezepturen der Amylase-PAS-Kapillarfärbung ......................................................... 94 


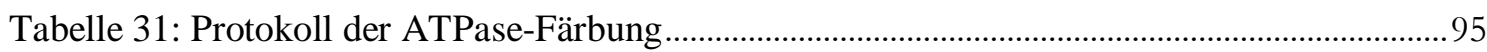

Tabelle 32: Rezeptur der ATPase-Färbung ................................................................................ 96

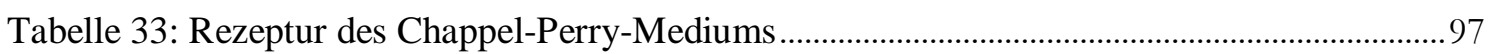

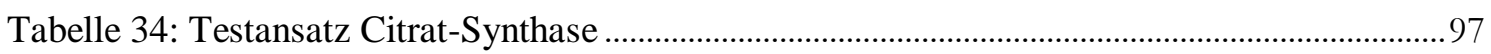

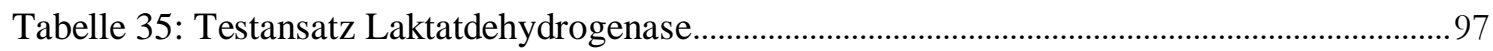

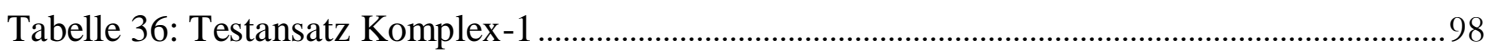




\section{Abkürzungsverzeichnis}

\begin{tabular}{|c|c|}
\hline A-Bande & Anisotrope-Bande \\
\hline ALT & Alanin-Aminotransferase \\
\hline $\mathrm{ADP}$ & Adenosindiphosphat \\
\hline $\mathrm{AK}$ & Alizarinkomplexon \\
\hline $\mathrm{AR}$ & Androgenrezeptor \\
\hline ATP & Adenosintriphosphat \\
\hline BIA & Bioimpedanzanalyse \\
\hline $\mathrm{Ca}^{2+}$ & Kalzium \\
\hline CG & Calceingrün \\
\hline CK & Kreatinkinase \\
\hline CLL & Chronisch Lymphatische Leukämie \\
\hline $\mathrm{CO}_{2}$ & Kohlenstoffdioxid \\
\hline $\mathrm{CS}$ & Citrat-Synthase \\
\hline $\mathrm{CT}$ & Computertomographie \\
\hline CYP & Cytochrom P 450 \\
\hline d & Schichtdicke \\
\hline DEXA & Dual Energy X-Ray Adsorptiometry \\
\hline DHT & 5- $\alpha$-Dihydrotestosteron \\
\hline DNA & Desoxyribonukleinsäure \\
\hline ER & Östrogenrezeptor \\
\hline FDA & Food and Drug Administration \\
\hline FFM & Fettfreie Körpermasse \\
\hline FG & Fast-twitch glykolytisch \\
\hline FOG & Fast-twitch oxidativ \\
\hline FSH & Follikelstimulierendes Hormon \\
\hline ggf. & gegebenenfalls \\
\hline GnRH & Gonadotropin-Releasing-Hormon, Gonadoliberin \\
\hline $\mathrm{g} / \mathrm{kg} / \mathrm{KG}$ & Gramm pro Kilogramm Körpergewicht \\
\hline H-Streifen & Hensen-Streifen \\
\hline $\mathrm{HDL}$ & High Density-Lipoprotein \\
\hline HRT & Hormon Replacement Therapy \\
\hline I-Bande & Isotrope-Bande \\
\hline
\end{tabular}




\begin{tabular}{|c|c|}
\hline IGF-1 & Insulin-like growth factor 1 \\
\hline IL-6 & Interleukin-6 \\
\hline IU & International Units (Enzymaktivität) \\
\hline i. $\mathrm{m}$. & Intramuskulär \\
\hline i. p. & Intraperitoneal \\
\hline i. v. & Intravenös \\
\hline $\mathrm{K}$ & Kreatin \\
\hline $\mathrm{KP}$ & Kreatinphosphat \\
\hline L-Tubuli & Longitudinal-Tubuli \\
\hline LDH & Laktatdehydrogenase \\
\hline LDL & Low Density-Lipoprotein \\
\hline LH & Luteinisierendes Hormon \\
\hline M & Mittelwert \\
\hline $\mathrm{Mg}^{2+}$ & Magnesium \\
\hline $\mathrm{mg} / \mathrm{kg} / \mathrm{KG}$ & Milligramm pro Kilogramm Körpergewicht \\
\hline MHC & Major Histocompatibility Complex \\
\hline $\mathrm{mM}$ & Millimolar \\
\hline MRT & Magnetresonanztomographie \\
\hline NADH & Nicotinamidadenindinukleotid \\
\hline $\mathrm{NF}-\kappa \mathrm{B}$ & Nuclear factor 'kappa-light-chain-enhancer of activated B-cells \\
\hline Non OVX & Nicht Ovarektomiert \\
\hline NSCLC & Non Small Cell Lung Cancer \\
\hline OVX & Ovarektomiert \\
\hline $\mathrm{P}$ & Phosphat \\
\hline PSA & Prostataspezifisches Antigen \\
\hline RANK & Receptor Activator of NF- $\mathrm{KB}$ \\
\hline RANKL & Receptor Activator of NF- $\mathrm{\kappa B}$ Ligand \\
\hline rpm & Rounds per minute \\
\hline SARMs & Selektive Androgenrezeptor-Modulatoren \\
\hline s. c. & Subkutan \\
\hline SD & Standardabweichung \\
\hline SERMs & Selektive Östrogenrezeptor-Modulatoren \\
\hline SHBG & Sexualhormon bindendes Globulin \\
\hline $\mathrm{SO}$ & Slow-twitch oxidativ \\
\hline
\end{tabular}


TC Tetrazyklin

T-Tubuli Transversal-Tubuli

TNF- $\alpha$ Tumornekrose-Faktor- $\alpha$

u. a. unter anderem

U/mg, U/g Enzymaktivität pro mg / g V Verdünnung des Homogenats

v. a. vor allem

VEGF Vascular Endothelial Growth Factor

WADA Welt-Anti-Doping-Agentur

WHO World Health Organisation

XO Xylenolorange

z. B. zum Beispiel

Z-Scheiben

Zwischen-Scheiben 


\section{$1 \quad$ Einleitung}

Osteoporose und Sarkopenie sind seit langem bekannte Gesundheitsbelastungen. Mit zunehmendem Alter kommt es zu einem progressiven Verlust sowohl von Knochen- als auch von Muskelmasse. Dieser verläuft über den Großteil der Zeit praktisch unbemerkt seitens der Betroffenen. Ab einem bestimmten Punkt kann sich dieser Verlust jedoch negativ auf die individuelle Gesundheit auswirken (Ferrucci et al. 2014).

Osteoporose betrifft derzeit zum überwiegenden Teil postmenopausale Frauen im Alter über 50 Jahren (Sirola und Kröger 2011). Durch die stetig zunehmende Lebenserwartung wird diese Erkrankung auch für Männer im höheren Lebensalter immer relevanter. Man geht davon aus, dass gesamtgesehen bereits ca. $25 \%$ der Männer von Osteoporose und mit Osteoporose assoziierten Frakturen betroffen sind, von einer Osteoporose sind ca. 6 \% aller Männer über 50 Jahre betroffen, Tendenz steigend (Bartl 2010, Hadji et al. 2013). Schon um das 30. Lebensjahr beginnt die Muskelmasse sowohl bei Männern als auch bei Frauen kontinuierlich abzunehmen. Der Muskel wird dann durch Binde- und Fettgewebe ersetzt (Lexell 1995). Das Resultat dieses Prozesses mit Abnahme der Muskelmasse, Muskelkraft und physischer Belastbarkeit bezeichnet man Sarkopenie.

Das kombinierte Auftreten von Sarkopenie und Osteoporose (Sarko-Osteoporose) wird bei Personen über 80 Jahren auf ca. $10 \%$ geschätzt, wobei die Prävalenz mit steigendem Alter stetig zunimmt (Buehring et al. 2013). Für beide Geschlechter konnte gezeigt werden, dass es einen Zusammenhang zwischen Muskelmasse und Knochenmineraldichte gibt, wobei mit abnehmender Muskelmasse das Risiko für die Entwicklung einer Osteoporose ansteigt (Kim et al. 2014). Beide Krankheitsbilder teilen sich viele gemeinsame Risikofaktoren und können im Verlauf zu den gleichen Folgen, wie beispielsweise Immobilisation, Stürzen, Frakturen, Einschränkungen im täglichen Leben und Reduktion der Lebensqualität führen (Ferrucci at al. 2014). Im Vergleich der SarkoOsteoporose mit einer isolierten Osteoporose bzw. Sarkopenie geht man von einer zusätzlichen Steigerung des Frakturrisikos aus (Walsh et al. 2006).

Postmenopausale Frauen haben im Vergleich zu Männern ein erhöhtes Risiko für Osteoporose und Sarkopenie. Bezüglich dieser Erkrankungen stellen sie somit eine wichtige Zielgruppe zur Prävention und Behandlung dar (Sirola und Kröger 2011). 
Bei ca. 3,2 Millionen neuen Krebserkrankungen weltweit pro Jahr gibt es eine Vielzahl an Patienten, die an tumorbedingter Kachexie oder Chemotherapie-assoziierter Osteoporose leiden (Ferlay et al. 2007, Pfeilschifter und Diel 2000). Auch diese Patienten könnten durch supportive Therapien deutlich an Lebensqualität gewinnen, wobei die ggf. ebenso anabolen Wirkungen auf evtl. verbliebene Tumorzellen beachtet und weiter untersucht werden sollten. Über den Einsatz ist dann im individuellen Fall zu entscheiden.

\subsection{Muskulatur}

\subsubsection{Allgemeines}

Muskelgewebe hat durch die Myofilamente Aktin und Myosin die Fähigkeit zur aktiven Kontraktion (Lüllmann-Rauch 2009). Dabei wird chemische Energie in mechanische Arbeit umgewandelt (Welsch und Deller 2010). Es lassen sich unterschiedliche Muskeltypen unterscheiden. Zum einen die glatte Muskulatur und zum anderen die quergestreifte Muskulatur, welche sich in Herzmuskel- und Skelettmuskelgewebe unterteilen lässt (Lüllmann-Rauch 2009).

\subsubsection{Aufbau der quergestreiften Skelettmuskulatur}

Jeder quergestreifte Muskel ist hierarchisch aufgebaut. Parallel verlaufende Muskelfasern bilden ein Primärbündel. Jede einzelne Muskelzelle wird dabei von dem sogenannten Endomysium umgeben, welches aus retikulären Fasern besteht. Das gesamte Primärbündel wiederum wird vom bindegewebigen Perimysium internum umgeben. Mehrere Primärbündel bilden das Sekundärbündel, welches vom Perimysium externum umhüllt ist. Von hier ausgehend ziehen Septen mit Blutgefäßen und Nerven in den Muskel, welche im Endomysium ein Netz aus Kapillaren bilden und der Versorgung dienen. Die Gesamtheit der Sekundärbündel bildet den Muskel, welcher von Epimysium umgeben ist (Welsch und Deller 2010). Das den Muskel umgebende Bindegewebe dient dazu, den Leitungsbahnen ihren Weg zu den Muskelzellen zu ermöglichen und bei Bewegungen entstehende Zugkräfte zu übertragen (Lüllmann-Rauch 2009).

Quergestreifte Muskelzellen sind lange, vielkernige Synzytien. Ihr Sarkoplasma (Zytoplasma) ist überwiegend durch Myofibrillen und Mitochondrien ausgefüllt. Den 
gruppiert in der Zellperipherie liegenden Zellkernen sind die Zellorganellen assoziiert. Da das Sarkolemm (Zellmembran) kontinuierlich mechanischem Stress ausgesetzt ist, wird es durch Proteine stabilisiert. Diese Stabilisierungen finden sich vor allem im Bereich der Zwischen-Scheiben (Z-Scheiben) und werden Costamere genannt. Das Sarkolemm bildet außerdem Einstülpungen in das Sarkoplasma, welche als TransversalTubuli (T-Tubuli) bezeichnet werden (Welsch und Deller 2010).

Die Myofibrillen der Skelettmuskelzelle zeigen eine sich wiederholende Querstreifung. Im Lichtmikroskop kann man unterschiedlich helle Banden unterscheiden. Die lichtmikroskopisch dunkle A-Bande ist anisotrop. Sie verhält sich im Polarisationsmikroskop doppelbrechend. In der A-Bande sind Myosin-Filamente lokalisiert. Die lichtmikroskopisch helle I-Bande ist dagegen isotrop. In dieser befinden sich die Aktin-Filamente. In der Mitte einer A-Bande ist der helle Hensen-Streifen (HStreifen), in dessen Mitte wiederum befindet sich die dunkle M-Linie. In dieser M-Linie werden die Myosin-Filamente über Proteine verankert und über das Titin in Position gehalten. In der Mitte der I-Bande befindet sich der Z-Streifen, welcher die AktinFilamente verankert. Zwei benachbarte Z-Streifen flankieren und bilden ein Sarkomer. Sarkomere wiederum sind die etwa 2,2 $\mu \mathrm{m}$ langen kontraktilen Einheiten einer Myofibrille. Durch die Kontraktion verkürzen sich die Sarkomere. Dabei verkürzen sich die I-Bande und der H-Streifen, wogegen sich die A-Bande nicht verändert (Welsch und Deller 2010, Lüllmann-Rauch 2009).

\subsubsection{Muskelfasertypen}

Die Einteilung der Muskelfasertypen beruht zum einen auf den individuellen morphologischen und physiologischen Eigenschaften und zum anderen auf verschiedenen Analysemethoden und den daraus resultierenden Beschreibungen. Dazu zählen histochemische Färbungen der Myosin-ATPase, biochemische Analysen metabolischer Enzyme und die Myosin-Isoform-Identifikationen (Scott et al. 2001). Prinzipiell kann man zwei große Gruppen von Muskelfasern unterscheiden, die Tonusfasern und Zuckungsfasern. Tonusfasern befinden sich in den Muskelspindeln und äußeren Augenmuskeln.

Zuckungsfasern können in weitere Fasertypen eingeteilt werden, welche von der innervierenden motorischen Einheit bestimmt werden (Lüllmann-Rauch 2009). Eine motorische Einheit besteht aus einem $\alpha$-Motoneuron und allen davon innervierten 
Muskelfasern (Scott et al. 2001). Sie arbeiten nach dem Alles-oder-Nichts-Prinzip (Lüllmann-Rauch 2009). Der Anteil der einzelnen Muskelfasertypen ist in jedem Muskel etwas unterschiedlich, zeigt sich jedoch über den individuellen Muskel homogen (Edgerton et al. 1975). Die Zusammensetzung der Fasern ist zum Teil dynamisch und kann sich an die aktuellen Bedürfnisse anpassen. Alle Muskelfasern eines Muskels zeigen diese Plastizität, wobei alle Fasern einer motorischen Einheit ihre Veränderung in die gleiche Richtung durchmachen.

Im Rahmen der Faserveränderungen kommt es zu einer angepassten Genexpression, welche man anhand der MHC-Isoform-Veränderung nachweisen kann. Diese können somit als „Marker“ dieser Veränderung und Zuteilung zu bestimmten Muskelfasertypen dienen (Pette und Staron 1997). Am häufigsten konnten Konversionen zwischen Typ-2aund Typ-2b- Fasern nachgewiesen werden (Scott et al. 2001).

Nach ihrer Myosin-ATPase (mATPase)-Aktivität können sieben Muskelfasertypen unterschieden werden. Es ergibt sich von langsam nach schnell folgende Reihenfolge: Typ1, -1C-, -2C-, -2AC-, -2A-, -2AB- und -2B Fasern. Über die biochemische Analyse der metabolischen Stoffwechselwege und der Kontraktionsgeschwindigkeit kann man die Muskelfasern in die Gruppen fast-twitch glykolytische (FG), fast-twitch oxidative (FOG) und slow-twitch oxidative (SO) Fasern aufteilen. Zusätzlich kann man den unterschiedlichen Muskelfasern bestimmte MHC-Isoformen zuordnen. In der Kombination aller Eigenschaften ergibt sich folgende Grundzuordnung: Typ1 (mATPase), SO, MHC1; Typ2a (mATPase), FOG, MHC2a; Typ2b (mATPase), FG, MHC2x/d(2b) (Scott et al. 2001).

\section{Typ-1-Fasern}

Die roten Typ-1-Fasern (SO, slow-twitch) haben die Hauptaufgabe Dauerleistungen zu erbringen. Sie ermüden nur langsam, haben viele Mitochondrien, sowie Myoglobin und einen relativ großen Energiespeicher in Form von Lipidtropfen. Die Gewinnung von Energie verläuft überwiegend oxidativ (Lüllmann-Rauch 2009). Die rote Farbe resultiert aus der erhöhten Konzentration an Myoglobin und besseren Kapillarisierung der Muskelfasern (McComas 1996). 
Typ-2-Fasern

Die weißen Typ-2-Fasern (FG, FOG, fast-twitch) haben die Aufgabe schnell Kraft zu entwickeln. Sie ermüden schneller im Vergleich zu Typ-1-Fasern, haben viel Glykogen und glykolytische Enzyme, dagegen aber relativ wenig Mitochondrien oder Myoglobin (Lüllmann-Rauch 2009). Man unterscheidet die Typ-2a-Fasern von den Typ-2b-Fasern. Im direkten Vergleich weisen die 2a-Fasern mehr Myoglobin und Mitochondrien auf als 2b-Fasern. Zusätzlich können sie sowohl glykolytischen als auch oxidativen Stoffwechsel ausüben, im Gegensatz zu 2b-Fasern, welche nur über den glykolytischen Stoffwechsel Energie gewinnen können (Behrends et al. 2012).

\subsubsection{Regeneration der quergestreiften Skelettmuskulatur}

Quergestreifte Skelettmuskulatur hat nur eine begrenzte Regenerationsfähigkeit. Diese setzt voraus, dass die Basallamina intakt ist und sowohl Nerven als auch Blutgefäße nicht beschädigt sind. Wenn diese Voraussetzungen erfüllt sind, gibt es grundsätzlich zwei Mechanismen der Regeneration. Sie kann von den Muskelzellen selbst oder von Satellitenzellen ausgehen (Welsch und Deller 2010). Die den Muskelfasern in der Basallamina direkt anliegenden Satellitenzellen sind ruhende Myoblasten mit Stammzellcharakter (Mauro 1961). Sie können bei Bedarf proliferieren und mit den Muskelfasern verschmelzen. Wenn jedoch die Basalmembran beschädigt ist, heilt der Defekt als bindegewebige Narbe aus (Lüllmann-Rauch 2009).

\subsection{Sarkopenie}

\subsubsection{Allgemeines}

Der Begriff der Sarkopenie wurde erstmals 1989 von Irwin H. Rosenberg eingeführt. Seinen Ursprung hat der Begriff im griechischen, wobei er sich aus den Wörtern „sarx“ (Fleisch) und „penia“ (Mangel) zusammensetzt (Rosenberg 1997). Dieses beschreibt den Verlust von Muskelmasse, Muskelfunktion und Muskelkraft im Alter (Studenski et al. 2014, Cruz-Jentoft et al. 2019). Nach heutigen Einschätzungen handelt es sich bei diesem Phänomen um einen primären Alterungsprozess (Morley et al. 2001). Seit 2016 hat die 
Sarkopenie mit der M62.50 einen eigenen ICD-10-Code (Goisser et al. 2019, Cruz-Jentoft et al. 2019).

\subsubsection{Epidemiologie}

Die Prävalenz der Sarkopenie steigt geschlechtsunabhängig mit zunehmendem Alter an und zeigt zusätzlich einen Zusammenhang mit zunehmender Adipositas (Baumgartner et al. 1998). Die Angaben Betroffener variieren erheblich, je nach Geschlecht, Methodik und Region der Datenerhebung (Schaap et al. 2018). Man geht davon aus, dass in der Altersgruppe der über 65-Jährigen zwischen $1 \%$ und $24 \%$, bei den über 80-Jährigen hingegen zwischen $17 \%$ und $50 \%$ betroffen sind (Baumgartner et al. 1998, Roubenoff 2000, Volpato et al. 2014).

\subsubsection{Risikofaktoren}

Allgemeine Risikofaktoren sind frühere und aktuelle körperliche Inaktivität, Fehl- bzw. Mangelernährung, Gewichtsverlust und vorhandene Komorbiditäten. Des Weiteren spielen hormonelle, neurodegenerative und inflammatorische Prozesse eine wichtige Rolle (Sayer et al. 2004, Bauer et al. 2008, Goisser et al. 2019, Cruz-Jentoft et al. 2019).

\subsubsection{Pathologie}

Bei der Entstehung von Sarkopenie handelt es sich um einen Prozess, der über Jahre verläuft, multifaktoriell bedingt ist und bisher noch nicht bis in das letzte Detail geklärt werden konnte (Evans 2010).

Es kommt zu einer Reduktion anaboler Stimuli, wie der abnehmenden Freisetzung von Östrogenen, Testosteron und Wachstumshormonen (Roubenoff 2000). Bei reduzierter Ausschüttung von Wachstumshormonen ist die Konzentration an Insulin-Like Growth Factor-1 (IGF-1) verringert (Roubenoff et al. 2003). IGF-1 ist ein wichtiger anaboler Faktor der Muskulatur zur Proliferation, Differenzierung, Regeneration und Hypertrophie (Philippou et al. 2007). Der Testosteronspiegel sinkt ab dem 50. Lebensjahr im Schnitt um ca. $1 \%$ pro Jahr. Das Resultat ist die Reduktion der fettfreien Körpermasse, Muskelmasse, Muskelkraft und Knochendichte. Es kommt zusätzlich zu einer Zunahme 
des viszeralen Fettgewebes (Morales et al. 2000). Durch einen zunehmenden Verlust von $\alpha$-Motoneuronen im Alter resultiert ein verringerter Signal-Input durch das zentrale Nervensystem (Brown 1972, Roubenoff 2000).

Ferner kommt es im Alter zum Anstieg von katabolen Stimuli mit vermehrt subklinischen Entzündungen (Roubenoff 2000). Diese Entzündungen führen, mit NF-אB als wichtigen Induktor (Chung et al. 2009), zu einem Anstieg von pro-inflammatorischen Zytokinen wie beispielsweise TNF- $\alpha$ und IL-6 (Roubenoff et al. 2003). Die im Alter zunehmenden Konzentrationen von TNF- $\alpha$ und IL-6 stehen im Zusammenhang mit der Abnahme von Muskelmasse und Muskelkraft. In Interaktion miteinander induziert TNF- $\alpha$ die Bildung von IL-6, wohingegen IL-6 die Expression von TNF- $\alpha$ in einen Feedback-Mechanismus hemmt (Schaap et al. 2009).

Die Zunahme freier Radikale im Alter ist ein weiterer Faktor für die Entwicklung der Sarkopenie. Die Reduktion von Antioxidantien wie Vitamin E steht demnach im Zusammenhang mit der sich entwickelnden Muskelatrophie (Khor et al. 2014). Auch die Abnahme von Vitamin D steht im Zusammenhang mit einer Abnahme von Muskelmasse und Muskelkraft, wobei nicht nur an Muskel- sondern auch an Knochenzellen VitaminD-Rezeptoren nachgewiesen werden konnten, was einen Einfluss auf beide Gewebe vermuten lässt (Janssen et al. 2002, Bischoff-Ferrari et al. 2004). Es resultieren Veränderungen und Umbauprozesse in der Skelettmuskulatur, was sich in einer Reduktion der Kapillardichte und dem Verlust an Muskelfasern zeigt. Hierbei sind in unterschiedlicher Ausprägung sowohl Typ 1- als auch Typ 2-Fasern betroffen, wobei v. a. die Typ 2-Fasern an Anzahl und Größe abnehmen (Lexell 1995, Frontera et al. 2000). Parallel kommt es zu einer Zunahme von Fett und Abnahme von Magnesium im Muskel (Forsberg et al. 1991).

\subsubsection{Formen}

Man kann die Sarkopenie in die primäre und sekundäre Form einteilen. Die primäre Form ist bedingt durch den natürlichen Alterungsprozess, wohingegen bei der sekundären Form zusätzliche Faktoren wie verminderte körperliche Aktivität, Mangel- oder Unterernährung und chronische Erkrankungen eine Rolle spielen. Die Ausprägung kann in Stadien eingeteilt werden. Eine isolierte Abnahme der Muskelmasse wird als Präsarkopenie bezeichnet. Wenn zusätzlich zu einer Verminderung der Muskelmasse 
auch die Muskelkraft und Muskelleistung reduziert ist, hat man das Vollbild einer Sarkopenie. Zusätzlich wird die akute von der chronischen Sarkopenie differenziert. (Cruz-Jentoft et al. 2010, Cruz-Jentoft et al. 2019).

\subsubsection{Klinik}

Durch die Abnahme der Muskelmasse und Muskelkraft kommt es zu Beeinträchtigungen der Alltagsfunktionen und Selbstständigkeit, einhergehend mit Bewegungseinschränkungen, verringerter Ausdauer, Belastbarkeit und herabgesetzter Lebensqualität. Im fortgeschrittenen Stadium kann es zu einem erhöhten Sturzrisiko mit der Gefahr von sturzassoziierten Frakturen kommen. Bei den Betroffenen ist das Sturzrisiko um den Faktor 3,2 erhöht (Landi et al. 2012). Zusätzlich zeigt sich eine erhöhte Mortalitätsrate (Maetzler et al. 2015).

\subsubsection{Diagnostik}

Um eine Sarkopenie zu diagnostizieren, wurde nach Empfehlung der European Working Group on Sarcopenia in Older People (EWGSOP2) ein aktualisierter 4-stufiger DiagnoseAlgorithmus erstellt. Dieser Umfasst zunächst einen fünf Fragen Umfassenden Screening-Fragebogen, den SARC-F (Malmstrom et al. 2016, Cruz-Jentoft et al. 2019). Anschließend soll dann, wenn dieser positiv ausfällt die Muskelkraft mittels Griffkraft oder Chair Stand Test ermittelt werden. Fällt hier eine reduzierte Muskelkraft auf, ist im klinischen Alltag die Empfehlung zur Messung mittels Dual Energy X-Ray Adsorptiometry (DEXA) oder Bioimpedanzanalyse (BIA) gegeben. Dieses dient der Bestätigung der klinischen Ergebnisse. Um letztendlich den Schweregrad der Sarkopenie zu einordnen zu können wird die physische Leistungsfähigkeit bestimmt. Hier ist die Ermittlung der Ganggeschwindigkeit, der 400-Meter-Gehtest oder der Time-Up-and-goTest geeignet (Cruz-Jentoft et al. 2019).

Das Mittel der Wahl zur Ermittlung der Muskelkraft ist die dynamometrische Handkraftmessung, z. B. mittels Jamar-Dynamometer nach dem Southhampton-Protokoll (Roberts et. al 2011, Ibrahim et al. 2016). Der Referenzwert bei Männern liegt bei $30 \mathrm{~kg}$, bei Frauen sind es $20 \mathrm{~kg}$ (Lauretani et al. 2003). Hierzu wird mittels hydraulischem HandDynamometer die erbrachte Griffkraft der rechten und linken Hand unabhängig 
voneinander gemessen (Dobs et al. 2013). Im Rahmen des Chair Stand Test wird die Zeit ermittelt, welche eine Person benötigt um fünfmal aus einer sitzenden Position ohne Hilfe aufzustehen. Diese ermittelt die Kraft der unteren Extremitäten (Jones et al. 1999, Beaudart et al. 2016, Cruz-Jentoft et al. 2019).

$\mathrm{Zu}$ den weiteren diagnostischen Möglichkeiten zur Ermittlung der Muskelmasse, vor allem im Rahmen der Forschung, zählen die Computertomographie (CT), Magnetresonanztomographie (MRT) und die Messung der Kreatininexkretion. Die Referenzwerte sind abhängig von der jeweiligen Messmethode. Diese werden nach EWGSOP2-Empfehlung ab - 2 SD (Standard-Abweichungen) von ihren jeweiligen Referenzgruppen angenommen. Unter speziellen Umständen kann diese auf - 2.5 SD erweitert werden (Cruz-Jentoft et al. 2010, Cruz-Jentoft et al. 2019). Die KreatininAusscheidung ist ein spezifischer Marker, welcher unter bestimmten Voraussetzungen, Rückschlüsse auf die totale Muskelmasse des Körpers zulässt. Zur Einschätzung der vorhandenen Muskelmasse, gibt es zusätzlich die Möglichkeit einen numerischen Wert zu errechnen (Newman et al. 2003, Clark et al. 2018).

Die körperliche Leistungsfähigkeit (Physical Performance) kann u. a. durch die Ganggeschwindigkeit, den Stair-Climb Test und die Short Physical Performance Battery (SPPB) ermittelt werden (Pahor et al. 2009, Cruz-Jentoft et al. 2019). Die Ermittlung der Ganggeschwindigkeit ist ein einfaches und probates Mittel im klinischen Alltag. Dabei wird die Zeit gestoppt, welche gebraucht wird um z. B. 4 Meter zu gehen. Der Referenzwert bei der Ermittlung der Ganggeschwindigkeit liegt bei 0,8 m/s (Lauretani et al. 2003, Maggio et al. 2016).

Die benötigte Zeit im Stair-Climb Test wird mittels elektronischen Trittflächen auf den Trittstufen (1, 4, 8 und 12) ermittelt. Die erbrachte Kraft wird mittels Folgender Formel errechnet: $\mathrm{P}($ Watt $)=(\mathrm{m} \times \mathrm{g} \times \mathrm{h}) / \mathrm{t}(\mathrm{m}=$ Patientengewicht in $\mathrm{Kg}, \mathrm{g}=$ Erdanziehungskraft, $\mathrm{h}=$ Stufenhöhe, $\mathrm{t}=$ benötigte Zeit in Sekunden) (Dobs et al. 2013).

Auch die Umfangsverringerung der Extremitäten-Muskulatur um > 2 SD vom Mittelwert verglichen mit einer jüngeren Referenzgruppe ist wegweisend (Baumgartner et al 1998). In der täglichen Routine bietet sich die Messung des Unterschenkelumfanges an, wobei ein Umfang von weniger als $31 \mathrm{~cm}$ auf eine Sarkopenie hinweist (Bauer et al. 2008). 


\subsubsection{Therapie}

Die Therapie der Sarkopenie besteht aus den Säulen des körperlichen Trainings, Ernährung und ggf. medikamentöser Therapie. Es wird eine Kombination aus Kraft-, Ausdauer- und Balancetraining zum Aufbau der Muskelkraft, -masse und -leistung empfohlen. Eine ergänzende Ernährung mit essentiellen Aminosäuren, Kreatin und Vitamin D kann diesen Trainingseffekt noch zusätzlich verbessern (Morley 2016).

Welche genaue Trainingsform hierbei den größten Effekt zur Verbesserung der Muskelmasse hat, konnte bisher noch nicht eindeutig geklärt werden. Empfohlen wird zwei bis dreimal wöchentlich, Trainingseinheiten mit einem Umfang von mindestens 30 Minuten durchzuführen (Goisser et al. 2015, Ziaaldini et al. 2017, Marzetti et al. 2017, Goisser et al. 2019).

Die angepasste Energie- und Nährstoffzufuhr mit dem Fokus auf Aminosäuren und Eiweißen hat einen positiven Effekt auf die Muskulatur (Bauer et al. 2008, Deutz et al. 2014). Durch diese angepasste Ernährung soll eine katabole Stoffwechsellage vermieden, sowie Mangelernährung und Gewichtsverlust verhindert werden (Volkert 2009, Bauer 2011, Goisser et al. 2019).

Dazu wird eine tägliche Proteinzufuhr von 1,0 - 1,2 g/kg/KG pro Tag, bei zusätzlicher Erkrankung 1,2 - 1,5 g/kg/KG pro Tag angestrebt (Bauer et al. 2013, Deutz et al. 2014, DGE 2016, Goisser et al. 2019). Verzweigtkettige Aminosäuren sind essentiell für die Proteinbiosynthse der Muskulatur. Es wird eine Zufuhr von mindestens 2,5 bis $3 \mathrm{~g}$ Leucin pro Mahlzeit empfohlen um die postprandiale Muskelproteinsynthese zu stimulieren (Maetzler et al. 2015, Kiesswetter 2015).

Die Einnahme von Vitamin D wird in der Literatur kontrovers diskutiert. Wenn es substituiert wird, ist die empfohlene Dosis 800 - 1000 IU Vitamin D pro Tag. Dieses sollte jedoch nur bei einem Vitamin D Defizit erfolgen (Rizzoli et al. 2013, Goisser et al. 2019).

Dazu kann die Einnahme von Vitamin E einen zusätzlichen protektiven Effekt auf die Muskelatrophie haben und die Muskelregeneration verbessern (Khor et al. 2014).

Als medikamentöse Ergänzung kann die Einnahme von Testosteron zu einer Zunahme von Muskelmasse und Muskelkraft führen, zeigt jedoch vielfältige Nebenwirkungen (siehe Kapitel: 1.5.3 und 1.5.6). 


\subsection{Osteoporose}

\subsubsection{Definition}

Osteoporose ist eine Erkrankung des Skelettsystems, welche zum einen durch die Abnahme der Knochenfestigkeit und zum anderen durch ein gesteigertes Frakturrisiko charakterisiert ist (Kanis 2007, Leitlinie Osteoporose 2017). Die Knochenfestigkeit wird durch die Faktoren Knochendichte und Knochenqualität bestimmt (NIH 2001). Nach Definition der WHO aus dem Jahr 1994 sind die Kriterien einer Osteoporose erfüllt, wenn die Knochenmineraldichte an der Lendenwirbelsäule und/oder am proximalen Femur im T-Wert um -2,5 SD von gesunden prämenopausalen 20 bis 29 jährigen Frauen im Mittel in der DXA-Knochendichtemessung abweicht. Bei Männern bezieht sich diese Definition auf ein männliches Patientenkollektiv (Leslie et al. 2006).

\subsubsection{Epidemiologie}

Osteoporose ist die häufigste Skeletterkrankung in Europa. Etwa jede dritte Frau und jeder fünfte Mann zählen zu den betroffenen (Wülker et al. 2015). Es zeigt sich eine zunehmende Prävalenz mit steigendem Alter, wobei Frauen gesamt gesehen ein höheres Risiko aufweisen als Männer (Häussler et al. 2007). Vor allem die Postmenopause stellt bei Frauen einen kritischen Entwicklungspunkt dar (Khosla und Riggs 2005). Die EPOS Studie zeigte eine Prävalenz von $15 \%$ bei postmenopausalen Frauen im Alter von 50 60 Jahren, welche auf $45 \%$ im Alter über 70 Jahren anstieg (Scheidt-Nave et al. 1997).

\subsubsection{Risikofaktoren}

Es werden allgemeine, spezielle, beeinflussbare und nicht beeinflussbare Risikofaktoren unterschieden. $\mathrm{Zu}$ den allgemeinen Risikofaktoren zählen Lebensalter, das weibliche Geschlecht, Anzahl und Schwere von stattgehabten Wirbelkörperfrakturen, nichtvertebrale Frakturen, proximale Femurfrakturen bei den Eltern, multiple Stürze, Immobilität (Gehstrecke unter $100 \mathrm{~m}$ ), verminderte Handgriffstärke, Rauchen und COPD, Untergewicht, Vitamin-D- und Kalziummangel (Serum 25-Hydroxy-Vitamin D3 $<20 \mathrm{ng} / \mathrm{ml}$, Kalziumzufuhr $<500 \mathrm{mg} / \mathrm{Tag})$, Homozysteinmangel, Folsäuremangel, Vitamin B-12 Mangel, Hyponatriämie, erhöhte Kadmiumzufuhr und -ausscheidung, Alkohol und hochsensitives-CRP. Spezielle Risikofaktoren sind u. a. Erkrankungen wie 
das Cushing-Syndrom, primärer Hyperparathyreodismus, Wachstumshormonmangel, Diabetes Mellitus 1 und 2, rheumatoloische Erkrankungen, neurologische Erkrankungen u. v. m. (Leitlinie Osteoporose 2017).

Hierbei kann man die beeinflussbaren und nicht beeinflussbaren Risikofaktoren für die Entwicklung einer Osteoporose unterscheiden. Zu den beeinflussbaren Faktoren zählen unter anderem geringe körperliche Aktivität, Mangelernährung und Untergewicht, Rauchen, Alkohol, COPD, Dauermedikation mit Glukokortikoiden, Vitamin D-, Kalzium-, Folsäure- und Vitamin B12 Mangel, sowie eine Hyponatriämie (Kinsella et al. 2010, Schauder und Ollenschläger 2006, Jakob et al. 2014). Körperliche Inaktivität beschleunigt den Knochenabbau zusätzlich. Bettlägerige Menschen verlieren im Vergleich zu aktiven Personen innerhalb einer Woche etwa so viel Knochenmasse, wie sie es sonst innerhalb eines Jahres bei normaler Aktivität tun würden (Kanis et al. 2013). Innerhalb weniger Monate können Betroffene somit bis zu 30 \% ihrer Knochenmasse verlieren. Insbesondere bei längerer Bettruhe nach Frakturen stellt dieses schnelle Fortschreiten für Osteoporose-Patienten ein Problem dar (Bartl 2010).

Nicht beeinflussbare Faktoren sind für beide Geschlechter das zunehmende Lebensalter, eine positive Familienanamnese (genetische Determination), das weibliche Geschlecht, späte Menarche und frühe Menopause (Schauder und Ollenschläger 2006). Die Inzidenz für Knochenbrüche, u. a. gezeigt an Hüft- und Wirbelkörperfrakturen, steigt mit jeder Lebensdekade um das ca. zwei- bis vierfache an (van der Klift et al. 2004, Pfeilschifter et al. 2012, Jakob et al. 2015, Leitlinie Osteoporose 2017).

\subsubsection{Pathologie}

Im Alter von 18 bis 25 Jahren ist das Entwicklungsmaximum der Knochenmasse erreicht. Dieses wird durch genetische Faktoren, Ernährung, den endokrinen Status und physische Aktivität bestimmt (Khosla und Riggs 2005).

$\mathrm{Ab}$ etwa dem 30. Lebensjahr übersteigt dann der Knochenabbau den Knochenaufbau (Wülker et al. 2015). Der Verlust an Knochenmasse bei Frauen und Männern ist zu einem nicht unerheblichen Teil durch die Veränderungen der Sexualhormone und einem sekundären Hyperparathyreoidismus bedingt. Zusätzlich gibt es noch weitere Faktoren, welche Einflüsse auf die Knochenmasse haben, wie z. B. ein generell geringes Maximum der Knochenmasse, Vitamin-D-Mangel, Defekte der Osteoblastenfunktion, Sarkopenie 
und die beeinträchtigte Regulation von Wachstumshormonen. Der Verlust an Knochenmasse führt in der Folge zu einem steigenden Frakturrisiko (Khosla und Riggs 2005).

Der postmenopausale Abfall von Östrogen führt $\mathrm{zu}$ einer erhöhten Osteoklastenaktivierung und einer gesteigerten Sensitivität des Knochens für das katabol wirkende Parathormon. Dieses führt zusätzlich zu einem vermehrten Knochenabbau (Wülker et al. 2015). Durch die verminderte Aktivität der Osteoblasten zeigt sich in der Folge eine histologisch nachweisbare Verschmälerungen der Knochenbälkchen (Roessner et al. 2008).

\subsubsection{Formen}

Man kann die Osteoporose in eine primäre (95\%) und sekundäre (5\%) Form einteilen (Bartl 2010). Bei der primären Osteoporose findet sich keine ursächliche Grunderkrankung. Unterschieden wird die postmenopausale- (Typ 1) von der senilen Form (Typ 2). Die sekundäre Osteoporose ist i. d. R. mit einer Grunderkrankung assoziiert. Diese können z. B. Hyperthyreose, Hyperparathyreoidismus, Morbus Cushing, Diabetes Mellitus, Hypogonadismus, nephrologische-, rheumatologische-, kardiologische- und hämatologische Erkrankungen sein (Schauder und Ollenschläger 2006, Bartl 2010).

\subsubsection{Klinik}

Osteoporose ist zu Beginn häufig symptomlos. Eines der ersten Symptome kann oftmals chronischer, jedoch nicht frakturbedingter Schmerz sein. Manifest wird die Erkrankung oft erst durch assoziierte Frakturen und deren Folgen (Allolio und Schulte 2010, Wilson et al. 2012). Die Schmerzen finden sich häufig im Bereich der Wirbelsäule, welche latent bei z. B. alltäglichen Belastungen oder akut bei Wirbelkörpereinbrüchen auftreten. In Folge kann es zu einer Formveränderung der Wirbelsäule kommen, wodurch es typischerweise zu einer progredienten Kyphose der Brust- und Hyperlordose der Lendenund Halswirbelsäule kommt (Wülker et al. 2015). 


\subsubsection{Diagnostik}

Die Diagnostik setzt sich aus den Säulen Anamnese, klinischer Untersuchung, Basislabor, Urinuntersuchung und bildgebender Diagnostik zusammen (Leitlinie Osteoporose 2017). Im Rahmen der Anamnese und klinischen Untersuchung erfasst man die Risikofaktoren, bestehende Einschränkungen, vorhandene Schmerzen und vorherige Frakturen. Mittels z. B. Timed-up an go oder Chair Stand Test werden Einschränkung von Muskelkraft und Koordination ermittelt (Jakob et al. 2016). Durch das Basislabor schließt man die sekundären Ursachen einer Osteoporose aus. Die Urinuntersuchung gibt u. a. Aufschluss über die Höhe des Knochenumbaus (Allolio und Schulte 2010). Mittels Röntgen, der am häufigsten betroffenen Regionen, können Frakturen ausgeschlossen und der aktuelle Knochenzustand beurteilt werden.

Die Bestimmung des Schweregrades erfolgt durch die Dual-Energy-X-rayAbsorptiometry (DEXA). Die DEXA misst den Knochenmineralgehalt pro Fläche in $\mathrm{g} / \mathrm{cm}^{2}$ (Wülker et al. 2015). Als normal wird eine T-Wert Veränderung bis zu -1 SD vom gesunden Vergleichskollektiv angesehen. Bei einer Osteopenie liegt diese Abweichung zwischen -1 SD und -2,5 SD. Eine Abweichung von mehr als -2,5 SD bezeichnet man als Osteoporose, wobei zusätzliche Frakturen zu der Definition einer schwerwiegenden Osteoporose führen (Kanis et al. 1994, Leitlinie Osteoporose 2017).

\subsubsection{Prävention}

Zur Prävention der Osteoporose gibt es unterschiedliche Ansatzpunkte. Es wird ausreichende körperliche Bewegung empfohlen. Zusätzlich eine ausgeglichene Ernährung mit genügend Zufuhr von Kalzium (1000 mg / Tag) und Vitamin D (800 bis 1000 IE / Tag) (Schauder und Ollenschläger 2006, Leitlinie Osteoporose 2017). Des Weiteren sollte auf Nikotin- und Alkoholkonsum verzichtet werden (Kanis et al. 2013). Ergänzend soll regemäßig die individuelle Medikation hinsichtlich Sturz-begünstigender Medikamente überprüft werden. Das Tragen von Hüftprotektoren kann das Risiko für Hüftnahe Frakturen bei Stürzen reduzieren (Gillespie et al. 2010, Santesso et al. 2014). 


\subsubsection{Therapie}

Die Therapie der Osteoporose setzt sich aus der Basis- und medikamentösen Therapie zusammen. Die Basistherapie besteht aus sportlicher Aktivität, Ernährungsanpassung und Modifikation von Umwelt und Lebensstilfaktoren zur Frakturprophylaxe. Die Effekte können je nach individuellen Voraussetzungen in unterschiedlichem Maße von Nutzen sein (Michael et al. 2010). Körperliche Bewegung und Sport stellen einen wichtigen Bestandteil der Therapie dar, so auch die Anpassung der Ernährung (Bonaiuti et al. 2002). Dabei sollte vor allem auf die Zufuhr von Proteinen, Kalzium und Vitamin D geachtet werden (Rizzoli 2008). Die Reduktion von Risikofaktoren für Stürze kann durch Optimierung des häuslichen Umfeldes und der individuellen Gesundheitsfaktoren erfolgen. Dazu gehören unter anderem die optimale Einstellung der Sehkraft und Kontrolle bestehender Medikationen (Michael et al. 2010).

Bei den Medikamenten gibt es unterschiedliche Wirkstoffe, welche Vor- und Nachteile mit sich bringen. Sie sind in unterschiedlichem Ausmaß in der Lage den Verlust an Knochenmasse vorzubeugen oder das Risiko für Wirbelkörper- und andere Frakturen zu reduzieren (Kanis et al. 2013).

Bisphosphonate wie z. B. Alendronat und Risedronat, sind Therapeutika erster Wahl und schützen durch Hemmung der Aktivität und Induktion der Apoptose von Osteoklasten vor Knochenabbau (Stevenson et al. 2005, Kanis et al. 2013). Als Nebenwirkungen wurden unter anderem gastrointestinale Störungen, Schmerzen des muskuloskelettalen Apparates, Akut-Phase-Reaktionen, Vorhofflimmern, atypische subtrochantäre Frakturen sowie verzögerte Frakturheilung und Osteonekrosen des Kieferknochens beschrieben (Rizzoli et al. 2008, Rizzoli et al. 2011).

Eine Hormonersatztherapie (Hormon Replacement Therapy, HRT) durch Östrogene oder Progesteron reduziert den postmenopausalen Knochenumbau und schützt vor Knochenverlust (Torgerson und Bell-Syer 2001, Kanis et al. 2013). Als problematisch anzusehen ist das erhöhte Risiko für das Auftreten von z. B. koronarer Herzerkrankung, Brustkrebs und Schlaganfällen (Rossouw et al. 2002).

Selektive Östrogenrezeptor-Modulatoren (SERMs) wie z. B. Raloxifen, werden als Ersatz zur HRT zur Prävention und Behandlung der postmenopausalen Osteoporose eingesetzt. Sie wirken je nach Zielgewebe als Agonist oder Antagonist am Östrogenrezeptor. Als Nebenwirkungen wurden unter anderem Hitzewallungen, grippeähnliche Symptome, periphere Ödeme sowie ein erhöhtes Risiko tiefer Beinvenenthrombosen und 
Lungenembolien beschrieben. Ein positiver Nebeneffekt ist ein signifikant geringeres Auftreten von Brustkrebs (Ettinger et al. 1999, Kanis et al. 2013).

Parathormon und Teriparatide führen durch Aktivierung und Erhöhung der Osteoblastenzahl zu einer Zunahme der Knochenmasse. Als Nebenwirkungen wurden beispielsweise Nausea, Kopfschmerzen, Schwindel und eine Erhöhung des Serumkalziums beschrieben (Shrader und Ragucci 2005, Kanis et al. 2013).

Strontium-Ranelat wird ebenfalls zur Therapie der postmenopausalen Osteoporose eingesetzt, wobei der genaue Wirkmechanismus bisher nicht vollständig geklärt ist (Reginster et al. 2005, Kanis et al. 2013). Nebenwirkungen sind unter anderem Nausea, Durchfall und ein erhöhtes Risiko für tiefe Beinvenenthrombosen (European Medicines Agency 2009, Rizzoli et al. 2011).

$\mathrm{Zu}$ den vergleichsweise neueren, teilweise noch präklinischen Therapieoptionen gehören Denusomab, Odanacatib und Sclerostin-Inhibitoren. Denusomab ist ein humaner monoklonaler RANKL-Antikörper, der nach Bindung an RANKL die Interaktion mit RANK verhindert und die Aktivierung der Osteoklasten blockiert (Cummings et al. 2009). Odanacatib blockiert das Enzym Cathepsin K, wodurch der Knochenabbau gehemmt wird (Komrakova et al. 2016). Vor kurzem wurde der Sclerostin-Inhibitor Romosozumab durch die FDA bei Osteoporose mit hohem Frakturrisiko zugelassen. Durch die Bindung an Sclerostin, resultiert eine Blockade der Bindung an LRP 5/6. Der Wnt-Signalweg wird nicht gehemmt und folgend die Knochenresorption blockiert (Cheng et al. 2019).

\subsection{Sarko-Osteoporose}

Das muskuloskelettale System ist als eine biomechanische Einheit zu sehen, welche sich u. a. Abhängig der mechanischen Last anpassen kann. Eine abnehmende Muskelmasse resultiert demnach zumindest zum Teil in einer abnehmenden Knochenmasse (Brotto und Bonewald 2015, Li et al. 2019). Die Interaktion geht jedoch weit über die rein mechanische hinaus. Es konnten niedermolekulare Faktoren nachgewiesen werden, welche durch Muskelzellen ausgeschüttet werden und Osteozyten vor Glucocorticoidinduzierter Apoptose schützen (Jähn et al. 2012).

Sowohl die Sarkopenie, als auch die Osteoporose werden bisher oft noch isoliert voneinander betrachtet. Es zeigt sich aber, dass die Sarkopenie bei mindestens 62,7 \% der 
80-jährigen Menschen komorbide mit Osteoporose auftritt (Huo et al. 2015). Die kombinierte Sarkopenie und Osteoporose (Sarko-Osteoporose) mit den resultierenden altersentsprechenden Veränderungen, welche zu einer kombinierten muskuloskelettalen Atrophie führen, können dann in einem erhöhten Sturzrisiko, Frakturrisiko und gesteigerter Mortalität enden (Girgis 2015, Li et al. 2019). Neuere Betrachtungsweisen beschreiben beide Krankheitsbilder als eine gemeinsame Erkrankung mit Manifestation in unterschiedlichen physiologischen Systemen. Das diagnostische Hauptaugenmerk liegt oft auf der Osteoporose und weniger auf der oft noch wenig prominenten und oft unterdiagnostizierten Sarkopenie. Da die Ursachen in einem hohen Anteil der Fälle auf den Alterungsprozess und eine damit verbundene reduzierte Mobilität zurückzuführen sind, wird in diesen Fällen auch der Begriff des dysmobility syndrome vorgeschlagen (Binkley et al. 2013). Ein zukünftiges Ziel könnte es sein, dass durch neue Wirkstoffe wie z. B. selektive Androgenrezeptor-Modulatoren (SARMs) gleichzeitig sowohl das Defizit im muskulären als auch skelettalen System zu verbessern. SARMs zeigen einen anabolen Effekt auf das gesamte muskuloskelettale System, wodurch sie potentiell in der Lage sind, den katabolen Alterseffekten entgegen zu wirken (Girgis 2015).

\subsection{Testosteron}

\subsubsection{Testosteron und seine Metaboliten}

Testosteron wird in seine aktiven Metaboliten 5- $\alpha$-Dihydrotestosteron (DHT) und Estradiol umgewandelt (Abbildung 1) (Mooradian et al. 1987). Das Enzym 5- $\alpha$ Reduktase wandelt dabei Testosteron in DHT um. Die Typ-1 5- $\alpha$-Reduktase befindet sich v. a. in der Haut und Leber, die Typ-2 5- $\alpha$-Reduktase v. a. in der Prostata und urogenitalen Geweben. Ihre Wirkung entfalten sowohl Testosteron als auch DHT über den Androgenrezeptor (AR), wobei DHT im Vergleich eine höhere Bindungsaffinität aufweist (Srinivas-Shankar und Wu 2006). Estradiol wird durch das Enzym Aromatase aus Testosteron gebildet. Die Aromatase befindet sich v. a. in Knochen, Fettgewebe und dem zentralen Nervensystem (Clarke und Khosla 2009). Seine Wirkung entfaltet Estradiol dann über Östrogenrezeptoren (ER) an seinen Zielstrukturen (Mooradian et al. 1987). 


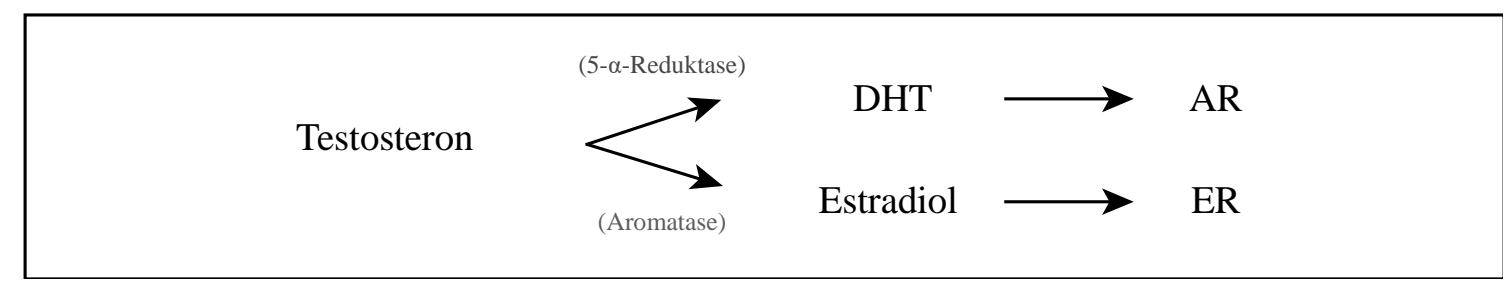

Abbildung 1: Umwandlung von Testosteron in DHT und Estradiol (Mooradian et al. 1987, Mooradian et al. 1987, Srinivas-Shankar und Wu 2006).

\subsubsection{Transport und Wirkung von Testosteron}

Im Blut werden ca. $65 \%$ des Testosterons an das Sexualhormon-bindende-Globulin (SHBG) gebunden transportiert. Ein weiterer Teil findet sich in einer losen Albuminbindung. Nur circa $1-2 \%$ liegen frei vor und können direkt am Zielgewebe wirken. Dafür diffundiert es passiv in das Zytoplasma der Zellen und bindet dort die Androgenrezeptoren. Dieser Hormon-Rezeptor-Komplex bindet dann die DNA und beeinflusst die Transkription androgenabhängiger Gene (Srinivas-Shankar und $\mathrm{Wu}$ 2006).

\subsubsection{Effekte von Testosteron}

Bei Männern, die an Hypogonadismus leiden, konnte gezeigt werden, dass die Supplementierung von Testosteron zu einer Zunahme der fettfreien Körpermasse (FFM = Körpergewicht - Körperfettanteil) und Kraft führt (Bhasin et al. 1997). Gleichzeitig kommt es zu einer Abnahme des Fettgewebes (Tabelle 1) (Katznelson et al. 1996). Im Knochengewebe schützt Testosteron vor Knochensubstanzverlust (Leifke et al. 1998) und bewirkt, beispielhaft gezeigt an Wirbelkörper und Femur, eine Zunahme der Knochendichte bei Männern (Tabelle 1) (Katznelson et al. 1996).

Für die androgene Wirkung werden unterschiedliche Mechanismen diskutiert. Zum einen wird Estradiol durch eine lokale Aromatase in spongiösen Knochen aus Testosteron gebildet (Vanderschueren et al. 2004). Zum anderen konnte eine direkte Wirkung von DHT auf den Knochen nachgewiesen werden (Wakley et al. 1991). DHT hat dabei eine apoptotische Wirkung auf Osteoklasten und eine abschwächend apoptotische Wirkung auf Osteoblasten (Kousteni et al. 2002). An mesenchymal pluripotenten Stammzellen bewirken Testosteron und DHT die Differenzierung in Richtung der myogenen Zelllinie. 
Auf der anderen Seite verhindern sie die Differenzierung in Richtung der adipogenen Linie (Singh et al. 2003).

Im Muskelgewebe kommt es, abhängig von der totalen und freien Testosteronmenge, zu einer Hypertrophie der Typ 1 - und Typ 2 Muskelfasern, einer nachweislichen Vermehrung von Zellkernen (Sinha-Hikim et al. 2002) und einer Zunahme der Satellitenzellen (Chen et al. 2005). Durch die lokale Umwandlung von Testosteron in DHT wie z. B. in der Prostata und anderen Geweben, sowie Drüsen des Sexualtraktes kommt es lokal zu einer zusätzlich verstärkt androgenen Wirkung (Chen et al. 2005).

Supraphysiologische Konzentrationen von Testosteron, welche möglicherweise unter Therapie auftreten, können einen supprimierenden Effekt sowohl auf die GnRHLH/FSH-Achse als auch auf die Spermatogenese haben (Gao und Dalton 2007).

\subsubsection{Testosteronmangel}

Mit dem Alter kommt es zur Abnahme von Testosteron. Damit assoziiert sind auch körperliche Veränderungen wie die Zunahme des viszeralen Fettgewebes (Seidell et al. 1990) sowie die Abnahme von Muskelmasse, Muskelkraft und der Knochenmasse (Tenover 1997). Dieses konnte auch bei jüngeren Männern nach Orchiektomie gezeigt werden. Es kam zu einem Verlust an Knochenmenge und -dichte. Diese Situation ist vergleichbar mit der einer postmenopausalen Östrogendefizienz bei Frauen (Stepan et al. 1989). Dadurch steigt auch das Risiko von Frakturen. Dies konnte im Rahmen einer Untersuchung an älteren Männern mit minimal-Trauma-Hüftfrakturen und verringerter Testosteronkonzentrationen gezeigt werden (Stanley et al. 1991).

\subsubsection{Therapie und Applikation von Testosteron}

Die ersten Therapien mit Testosteron begannen schon circa in den 1940er Jahren. Seitdem wurden verschiedene Möglichkeiten der Applikation entwickelt, welche sich u. a. in ihrer Bioverfügbarkeit, Pharmakokinetik und Halbwertszeit unterscheiden. Dazu gehören beispielsweise Implantate, Kapseln, Pflaster, Gele und intramuskuläre Injektionen (Srinivas-Shankar und Wu 2006). 


\subsubsection{Nebenwirkungen der Testosterontherapie}

Es ist bekannt, dass der Einsatz von Testosteron neben den gewünschten, auch weniger gewünschte Effekte hervorruft. Die Applikation mittels Injektion zeigt Konzentrationsschwankungen, welche sich zwischen supraphysiologischen bis subnormalen Konzentrationen bewegen können. Dies begünstigt zusätzlich das Auftreten von Nebenwirkungen. Die transdermale Applikation kann zu Hautirritationen führen, wobei die benötigte tägliche Applikation die Therapieakzeptanz mindert. Die orale Applikation hat u. a. den Nachteil der erhöhten Lebertoxizität (Negro-Vilar 1999).

Unabhängig von der Applikationsform, kam es unter anderem zum vermehrten Auftreten von Akne, Hirsutismus und Hepatotoxizität (Clarke und Khosla 2009). Des Weiteren kann es zu einer Zunahme kardiovaskulärer Erkrankungen, dem Anstieg des Hämatokrits, PSA Erhöhung, einer gesteigerten Zahl von Prostatabiopsien und Prostata Karzinomen kommen (Bhasin et al. 2005, Basaria et al. 2010). Außerdem wurde ein gehäuftes Auftreten peripherer Ödeme, vermehrte Exazerbationen bei bestehender Schlafapnoe, Polyzythämie und Gynäkomastie beobachtet (Tenover 1997).

\subsection{Selektive Androgenrezeptor-Modulatoren (SARMs)}

\subsubsection{Allgemeines}

Die selektiven Androgenrezeptor-Modulatoren (SARMs) stellen eine Wirkstoffklasse dar, welche die positiven Eigenschaften einer Therapie mit Testosteron zeigt ohne die entsprechend ausgeprägten Nebenwirkungen (z. B. auf Prostata oder das kardiovaskuläre System) zu haben (Chen et al. 2005, Bhasin und Jasuja 2009). Ihre besondere Eigenschaft im Vergleich zu der klassischen Therapie mit Testosteron ist ihre variable Androgenrezeptorspezifität (Chen et al. 2005). SARMs sind somit potentielle Kandidaten für die Therapie von Männern und Frauen bei einer Vielzahl von Krankheitsbildern, wie beispielsweise Osteoporose, Sarkopenie, Tumorkachexie, Hypogonadismus, benigne Prostata-Hyperplasie, Anämie, der hormonellen Kontrazeption bei Männern, Stressharninkontinenz, Brustkrebs und Duchenne-Muskeldystrophie (Chen et al. 2005, Clarke und Khosla 2009, Dalton et al. 2018). Sie können oral eingenommen werden, was die Akzeptanz der Anwender und Patienten im Vergleich zu anderen Applikationsformen erhöht (Gao und Dalton 2007). 


\subsubsection{SARMs - Klassen}

In der heterogenen Gruppe der selektiven Androgenrezeptor-Modulatoren gibt es unterschiedliche Wirkstoffklassen und Gruppen. Sie können in die Klassen steroidal und nicht-steroidal eingeteilt werden. Die ersten Entwicklungen steroidaler SARMs gehen bis in die 1940er Jahre zurück. Sie basieren auf strukturellen Modifikationen des Testosteronmoleküls (Bhasin und Jasuja 2009).

Die nicht-steroidalen SARMs können nach ihrer chemischen Struktur in verschiedene Gruppen eingeteilt werden (Abbildung 2): Den Anfang machten die ArylpropionamidAnaloga (GTX Inc. ${ }^{\circledR}$, z. B. Enobosarm, Andarine), Chinolinon-Analoga (Ligand Parmaceuticals $®)$, Bizyklische-Hydantoin-Analoga $(\mathrm{BMS} \circledast)$ und TetrahydrochinolinAnaloga (Kaken Pharmaceuticals Inc. $\left.{ }^{\circledR}\right)$ (Gao und Dalton 2007). Durch strukturelle Veränderungen wurden die Potenz, Bindungsfähigkeit und pharmakologische Aktivität der Moleküle verändert (Chen et al. 2005). Die ersten Arylpropionamide wurden erstmalig 1988 beschrieben (Tucker at al. 1988). Die Modifikation der anti-androgenen Arylpropionamid-Analoga, Bicalutamide und Hydroxyflutamide führte im Jahre $1998 \mathrm{zu}$ der ersten Generation von selektiven Androgenrezeptor-Modulatoren (Bhasin et al. 2005). Yin et al. konnten 2003 die gewebespezifische Selektivität der SARMs nachweisen. Im Laufe der Zeit sind weitere Gruppen, wie die Azasteroide (Merck ${ }^{\circledR}$ ), Aniline und Benzoxazepinone (GSK®) entwickelt worden (Tabelle 28) (Narayanan et al. 2008). Viele Pharmafirmen begannen mit der Entwicklung von SARMs. Hier zeigten viele präklinische Studien eine potentielle anabole Aktivität und spezifische Gewebeselektivität. Bei den meisten Substanzen folgten jedoch z. B. aufgrund mangelnder Wirksamkeit oder zu hoher Toxizität keine weiterführenden klinischen Studien (Dalton et al. 2018). 


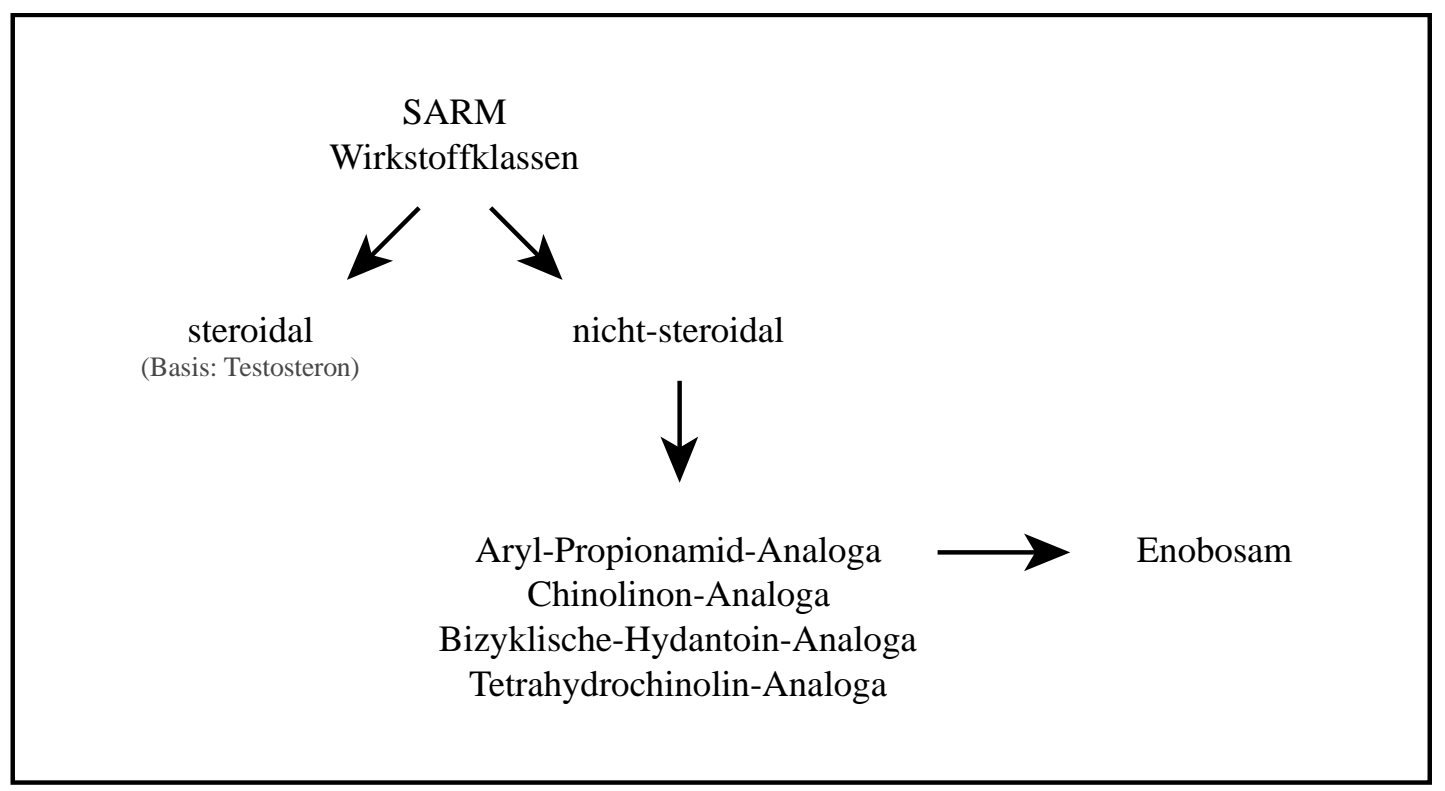

Abbildung 2: Klassen der selektiven Androgenrezeptor-Modulatoren (Bhasin und Jasuja 2009, Gao und Dalton 2007).

\subsubsection{Wirkung der SARMs}

Die SARMs haben eine differenzierte Wirkung in verschiedenen Geweben. In Knochenund Muskelgewebe wirken sie myo- und osteoanabol (Cilotti und Falchetti 2009) (Tabelle 1). In androgenen Geweben, wie z. B. der Prostata wirken sie als partielle Agonisten hingegen weniger stark (Clarke und Khosla 2009).

Zur Erklärung der spezifischen Wirkung gibt es verschiedene Ansätze. SARMs können im Gegensatz zu Testosteron weder durch die 5- $\alpha$-Reduktase noch durch die Aromatase als Substrat genutzt werden (Bhasin et al. 2006). Es zeigt sich somit keine gewebespezifische Aktivierung (Cilotti und Falchetti 2009). Die Co-AktivatorHypothese geht davon aus, dass bei der Androgen-Rezeptor-Bindung mit SARMs andere co-regulierende Proteine assoziiert sind als bei Testosteron, was in einer veränderten Genexpression resultiert (Bhasin und Jasuja 2009). Die Konformationshypothese besagt, dass unterschiedliche Liganden zu einer jeweils anderen Konformation der Rezeptoren führen. Folglich kommt es zu einer veränderten Interaktion mit Proteinen und CoRegulatoren unter Zell-Rezeptor-Kontakt mit den SARMs, was ebenso in einer veränderten Genexpression resultiert (Bhasin und Jasuja 2009). 


\subsubsection{Enobosarm (Ostarine, MK-2866, GTx-024)}

Enobosarm hat die Strukturformel (2S)-3-(4-cyanophenoxy)-N-[4-cyano-3(trifluoromethyl)-phenyl]-2-hydroxy-2-methylpropanamide) (Abbildung 3). Es ist ein nicht steroidaler Androgenrezeptor Modulator (SARM), der Firma GTx Inc. $®$ (Memphis, TN, USA) welcher hauptsächlich hepatisch über das CYP3A4 System metabolisiert wird (Srinath und Dobs 2014). Daten weisen außerdem darauf hin, dass eine inhibierende Interaktion mit CYP2C9 besteht (Coss et al. 2016). Entsprechend sollten bei CoMedikation mögliche Arzneimittelinteraktionen beachtet werden. Die Halbwertszeit beträgt zwischen 14 und 21 Stunden (Srinath und Dobs 2014). Enobosarm hat gewebespezifische anabole Effekte v. a. auf die Skelettmuskulatur und den Knochen (Tabelle 1). Unter Therapie kommt es zu einer Zunahme der fettfreien Körpermasse, einer physischen Leistungsverbesserung (u. a. gezeigt im Step-Climb Test) und Abnahme der totalen Fettmasse (Tabelle 1). Es konnte eine gute Verträglichkeit sowohl bei älteren Männern als auch postmenopausalen Frauen gezeigt werden (Dalton et al. 2011).

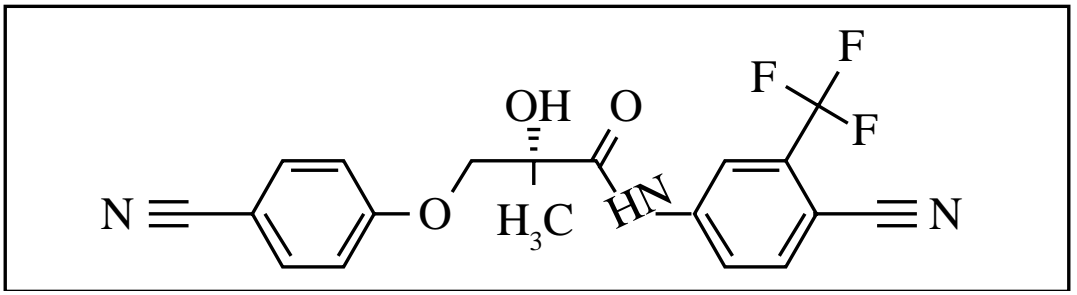

Abbildung 3: Enobosarm, Ostarine, MK-2866, GTx-024 (Ponnusamy et al. 2017).

Enobosarm wurde trotz nachgewiesener guter Wirkung mit wenigen Nebenwirkungen aufgrund der strengen Zulassungsbeschränkungen bisher nicht zur Therapie einer Sarkopenie zugelassen und dieses trotz sehr vielversprechenden Ergebnissen bis zu einer Phase 2 Studie an einem Patientenkollektiv mit Sarkopenie (Garber und Arbor 2016). In dieser doppelblinden, randomisierten, Placebo kontrollierten Phase 2 Studie, welche an gesunden Männern über 60 Jahre und postmenopausalen Frauen durchgeführt wurde konnte unter Enobosarm eine signifikante Zunahme der fettfreien Körpermasse und Steigerung der physischen Funktion (gemessen im Stair-Climb Test) gezeigt werden. Zusätzlich wurde eine signifikante Abnahme der Insulinresistenz nachgewiesen, ohne das schwerwiegende Nebenwirkungen auftraten (Dalton et al. 2011).

Die US-Amerikanische Food and Drug Administration (FDA) forderte von der Firma GTx Inc. ${ }^{\circledR}$ eine ergänzende kardiovaskuläre-Sicherheitsstudie, welche zusätzlich ca. 500 Millionen US Dollar gekostet hätte um eine Zulassung zur Therapie bei Sarkopenie bei 
Männern und Frauen mit Altersgebrechlichkeit (Frailty) zu bekommen. Eine geplante Phase 3 Studie mit diesem Therapieschwerpunkt (Sarkopenie) wurde verworfen und mit dem Aspekt der schnelleren Zulassung u. a. auf die Therapie von TumorassoziierterKachexie umgelagert. Man hofft in diesem Kontext keine ergänzende kardiovaskuläreSicherheitsstudie nachweisen zu müssen (Garber und Arbor 2016).

In zwei Phase 3 Studien an Patienten mit Tumor-Kachexie konnte mit Enobosarm eine Zunahme der fettfreien Körpermasse gezeigt werden. Nur in einer der beiden Studien war es jedoch möglich eine Leistungssteigerung im Stair-Climb Test nachzuwiesen (Garber und Arbor 2016, Dalton et al. 2018). Eine nachgewiesene Leistungssteigerung ist jedoch ein wichtiges Kriterium zur Zulassung durch die FDA (Garber und Arbor 2016).

In dieser doppelblinden, randomisierten, Placebo kontrollierten, multizentrischen Phase 3 Studie an postmenopausalen Frauen und Männern über 45 Jahren mit NSCLC (Stadium 3 oder 4) unter Chemotherapie, wurde sowohl der präventive als auch therapeutische Einsatz von Enobosarm getestet. Hierfür wurden alle Patienten, auch ohne die Voraussetzung einer Kachexie oder eines Minimums an Gewichtsverlust in die Studie einbezogen (Crawford et al. 2016). Es zeigte sich eine Steigerung der Muskelmasse, jedoch nur eine geringfügige Verbesserung der physischen Funktion (Dalton et al. 2018). Es scheint jedoch alles andere als einfach zu sein, bei diesem Patientenkollektiv mit einer Vielzahl an Komorbiditäten, in hohem Alter, geringer körperlicher Aktivität, Appetitverlust, multiplen chronischen Erkrankungen, ggf. chronischen Schmerzen und unter laufender Chemotherapie, die Wirkung von Enobosarm signifikant nachzuweisen (Dalton 2017).

Derzeit erfolgen außerdem Studien zur Erforschung weiterer Einsatzgebiete von SARMs wie Enobosarm. Hierunter zählen der Einsatz bei Stressharninkontinenz, Androgenrezeptor-positivem Brustkrebs, sowie trippel-negativem Brustkrebs und Duchenne-Muskeldystrophie (Dalton 2017, Dalton et al. 2018).

In einer weiteren doppelblinden, randomisierten, Placebo kontrollierten Phase 2 Studie bei Tumorpatienten mit Kachexie (NSCLC, Kolorektal Karzinom, Non-Hodgkin Lymphom, CLL, Brustkrebs) konnte auch eine signifikante Zunahme der fettfreien Körpermasse und Zunahme der Muskelkraft (gemessen im Stair-Climb Test) gezeigt werden. Hier zeigte sich weder ein Anstieg von PSA bei Männern, noch eine Virilisierung bei Frauen, welches üblicherweise aus der Therapie mit Testosteron bekannt ist (Dobs et al. 2013). 
Enobosarm wird bereits seit längerem im Kraftsport, zur Unterstützung der schnelleren Zunahme von Muskelmasse und -kraft eingesetzt. Hier gilt es als günstige, sichere und nebenwirkungsarme Steroid-Alternative (Androgem Ingredients: Bulk MK 2866). Jedoch ist seit dem 01.01.2008 die Einnahme von Substanzen der Wirkstoffgruppe SARMs zur Leistungssteigerung von der Welt-Anti-Doping-Agentur (WADA) verboten worden (WADA: SARM).

\subsubsection{Nebenwirkungen von Enobosarm}

Die häufigsten Nebenwirkungen der Therapie mit Enobosarm sind Kopfschmerzen, Rückenschmerzen (Dalton et al. 2011), Fatigue, Nausea, Diarrhoe und grippeähnliche Symptome (Srinath und Dobs 2014).

Laborchemisch zeigte sich eine Abnahme der Blutglukose und eine abnehmende InsulinResistenz. Dieses ist vergleichbar mit den Effekten von oralen Antidiabetika wie z. B. Metformin. Beobachtet wurde ebenfalls die Reduktion des totalen Cholesterins, des HDL und der Triglyzeride. Der LDL/HDL-Quotient verblieb hierbei im Bereich des niedrigen kardiovaskulären Risikos. Des Weiteren kam es zu einer leichten Zunahme des Hämoglobins und Hämatokrits. Auch eine zeitweise Erhöhung der Leberenzyme (ALT) konnte festgestellt werden. Bei den behandelten Männern konnte eine Abnahme der SHBG-Konzentration und des totalen Serum-Testosterons nachgewiesen werden. Bei den behandelten Frauen konnte eine Abnahme der LH- und FSH-Konzentration ohne klinische Signifikanz, sowie eine Reduktion des SHBG gezeigt werden. Es kam im Gegensatz zur Therapie mit Testosteron jedoch nicht zu einer erhöhten Talkproduktion oder vermehrtem Haarwachstum (Dalton et al. 2011). 
Tabelle 1: Folgen von Testosteronmangel und Wirkungen von Testosteron und Enobosarm (Ergebnisse aus klinischen Studien, *: Studien am Modellorganismus).

\begin{tabular}{|l|l|l|l|l|}
\hline & Muskel & Knochen & Fett & Frakturen \\
\hline Testosteronmangel & $\downarrow^{1}$ & $\downarrow^{1}$ & $\uparrow^{1}$ & $\uparrow^{2}$ \\
\hline HRT: Testosteron & $\uparrow^{3}$ & $\uparrow^{4}$ & $\downarrow^{4}$ & \\
\hline SARM: Enobosarm & $\uparrow^{5}$ & $\uparrow^{4} 5$ & $\downarrow^{5}$ & \\
\hline
\end{tabular}

$\downarrow$ : Reduktion, verringert $\uparrow:$ Zunahme, gesteigert. (1: Tenover 1997, 2: Stanley et al. 1991, 3: Bhasin et al. 1997 , 4: Katznelson et al. 1996 5: Dalton et al. 2011)

\subsection{Zielsetzung}

Ziel dieser Arbeit ist es, die Effekte der Therapie mit dem selektiven AndrogenrezeptorModulator Enobosarm am Krankheitsmodell für Osteoporose zur Prävention einer komorbide auftretenden Sarkopenie festzustellen. Diese wurden am Modellorganismus der ovarektomierten Ratte untersucht. Der Schwerpunkt der Analyse lag dabei auf dem Nachweis histologischer und enzymatischer Veränderungen der quergestreiften Skelettmuskulatur.

Es ist seit langem bekannt, dass nicht nur der Mangel an Östrogen, sondern auch eine Androgendefizienz zu einem zunehmenden Verlust von Muskel- und Knochensubstanz, nicht nur bei Männern, sondern auch bei Frauen führt (Abu et al. 1997). In der Menopause kommt es zu einer kombinierten Reduktion der Östrogen- und Androgenproduktion. Studiendaten zeigen, dass eine additive Therapie mit Androgenen, zusätzlich zur Östrogentherapie, den Therapieeffekt verbessert (Dobs et al. 2002). Dieses kann durch Androgenrezeptoren im Knochengewebe von Frauen, vergleichbar zu Männern erklärt werden (Abu et al. 1997). Damit ist der Einsatz von selektiven Androgenrezeptor Modulatoren nicht nur bei Männern, sondern ebenso bei Frauen als möglicher Therapieansatz denkbar. Aus diesem Grund diente in diesem Versuch die weibliche Ratte als Modellorganismus. 


\section{Material und Methoden}

\subsection{Versuchsablauf}

Die Versuchstiere wurden zufällig in fünf Gruppen eingeteilt (Tabelle 2). Gruppe eins (Non OVX) diente als gesunde, Gruppe zwei (OVX) als erkrankte, nicht behandelte Kontrollgruppe. Die Gruppen drei (low-dose, SARM 1), vier (medium-dose, SARM 2) und fünf (high-dose, SARM 3) dienten als Behandlungsgruppen und bekamen eine medikamentöse Therapie in jeweils unterschiedlicher Wirkstoffkonzentration. In einer ersten Operation wurden die Ratten der Gruppen zwei bis fünf ovarektomiert. Diese ovarektomierten Tiere sollten danach die Eigenschaften einer Osteoporose entwickeln. Die Ratten der Gruppe Non OVX wurden nicht ovarektomiert und sollten dieses entsprechend nicht ausbilden. In einer zweiten Operation wurden die Tibiae der Ratten aller Gruppen bilateral osteotomiert. Die Fraktur wurde anschließend osteosynthetisch versorgt. Nach dieser Operation wurden die Versuchstiere der Gruppen SARM 1, SARM 2 und SARM 3 dann fünf Wochen mit dem Wirkstoff Enobosarm aus der Gruppe der selektiven Androgenrezeptor Modulatoren behandelt. Zur anschließenden mikroskopischen Dokumentation der Frakturheilung erhielten die Ratten an definierten Zeitpunkten im Behandlungsintervall unterschiedlich fluoreszierende Farbstoffe. Nach 35-tägiger Behandlung wurden die Ratten mittels Dekapitation getötet. Zur weiteren Analyse wurden Muskeln, Knochen und Blut gewonnen (Abbildung 4).

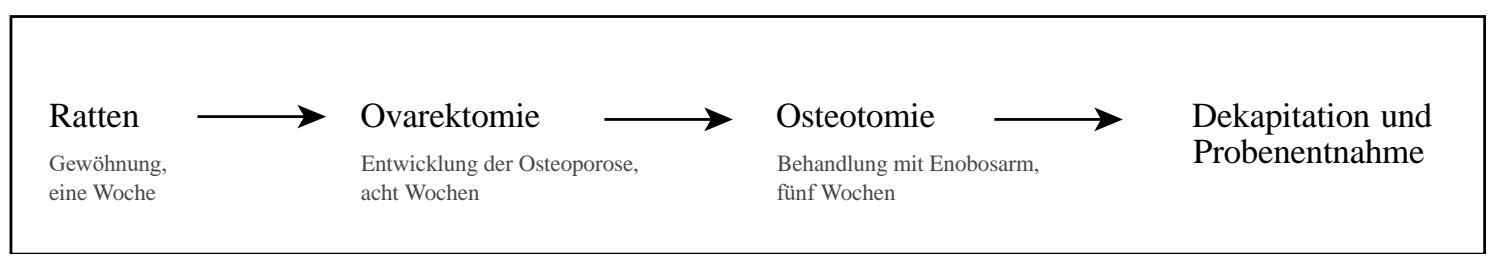

Abbildung 4: Versuchsablauf.

Im Rahmen dieser Arbeit werden als Schwerpunkte die Ergebnisse der histologischen Untersuchungen am quergestreiften Skelettmuskel und die Enzymaktivitätsuntersuchungen dargestellt. Die histologischen Dünnschnitte, Färbungen und Auswertungen, sowie die enzymatischen Analysen und die statistische Auswertung wurden eigenständig durchgeführt.

Die Untersuchungen der Knochen erfolgten durch andere Doktoranden. Die Betreuung der Versuchstiere, sowie die Operationen und Probenentnahmen wurden durch alle am Versuch beteiligten Personen durchgeführt. 
Tabelle 2: Übersicht der Gruppen, Behandlungsformen und Wirkstoffkonzentrationen.

\begin{tabular}{|l|l|l|l|}
\hline Gruppe & Bezeichnung & Behandlung & Medikation \\
\hline 1 & Non OVX & $\begin{array}{l}\text { Keine Ovarektomie, } \\
\text { Osteotomie }\end{array}$ & \\
\hline 2 & OVX & $\begin{array}{l}\text { Ovarektomie, } \\
\text { Osteotomie }\end{array}$ & $\begin{array}{l}\text { Enobosarm, } 0,04 \\
\mathrm{mg} / \mathrm{kg} / \mathrm{KG}\end{array}$ \\
\hline 3 & SARM 1 & $\begin{array}{l}\text { Ovarektomie, } \\
\text { Osteotomie }\end{array}$ & Enobosarm, $0,4 \mathrm{mg} / \mathrm{kg} / \mathrm{KG}$ \\
\hline 4 & SARM 2 & $\begin{array}{l}\text { Ovarektomie, } \\
\text { Osteotomie }\end{array}$ & Enobosarm, $4,0 \mathrm{mg} / \mathrm{kg} / \mathrm{KG}$ \\
\hline 5 & SARM 3 & $\begin{array}{l}\text { Ovarektomie, } \\
\text { Osteotomie }\end{array}$ \\
\hline
\end{tabular}

\subsubsection{Versuchstiere und Haltung}

Als Modellorganismen wurden weibliche Sprague-Dawley-Ratten (Harlan Winkelmann $\mathrm{GmbH}{ }^{\circledR}$, Borchen, Deutschland) im Alter von drei Monaten verwendet. Die 63 Ratten wurden in fünf Gruppen zu je 12 bis 13 Tieren eingeteilt. Jeder Ratte wurde zur Identifikation im Rahmen der ersten Operation ein elektronischer Transponder in das subkutane Fettgewebe im Bereich des Nackens implantiert. Die Tiere sind über den Zeitraum des Versuches in Käfigen (Makrolon Typ IV, zentrale tierexperimentelle Einrichtung, Göttingen, Deutschland) $\mathrm{zu}$ je drei bis vier Tieren, bei $22{ }^{\circ} \mathrm{C}$ Raumtemperatur und $55 \%$ Luftfeuchtigkeit gehalten worden. Die Käfige wurden alle drei Tage gewechselt und gereinigt. Alle 12 Stunden wurde ein Tag-Nacht-Rhythmus durch Helligkeitswechsel simuliert. Die Ratten hatten freien Zugang zu Wasser und sojafreiem Futter (Ssniff Spezial Diät $\mathrm{GmbH}{ }^{\circledR}$, Soest, Deutschland). Die jeweiligen Behandlungsgruppen erhielten den Wirkstoff Enobosarm, nach Ovarektomie über das Futter. Unter der Annahme, jede Ratte nehme ca. $20 \mathrm{~g}$ bis $25 \mathrm{~g}$ Futter täglich zu sich, erhielt die Gruppe SARM 1 0,04 mg/kg/KG, SARM 2 0,4 mg/kg/KG und SARM 3 4,0 $\mathrm{mg} / \mathrm{kg} / \mathrm{KG}$ des Wirkstoffes, dem sojafreien Futter beigemischt (Enobosarm: Reinheit > 
$98 \%$, Biochempartner Co. Ltd. ${ }^{\circledR}$, ShangHai, Futter: Ssniff Spezial Diät GmbH®, Soest, Deutschland). Die niedrigste Dosis der Gruppe SARM 1 wurde von Dalton et al. 2011 übernommen. Die Gruppen SARM 2 und SARM 3 erhielten die 10-fache bzw. 100-fache Menge, um einen dosisabhängigen Effekt zu Untersuchen (Hoffmann et al. 2018). Sowohl das Körpergewicht der Tiere als auch das Restgewicht des Futters wurde wöchentlich ermittelt und dokumentiert. Über den gesamten Versuch verstarben insgesamt fünf Versuchstiere aufgrund narkosebedingter Nebenwirkungen bei Ovarektomie und Osteotomie.

\subsubsection{Ovarektomie}

Nach einer Eingewöhnungszeit von sieben Tagen wurden die Versuchstiere der Gruppen zwei bis fünf (Tabelle 2) zur Induktion der Osteoporose ovarektomiert. Alle Gruppen wurden mit $\mathrm{CO}_{2}$ narkotisiert. Peri- und postoperativ bekamen die Versuchstiere der Gruppen zwei bis fünf zur Narkose und Analgesie Rimadyl (Pfizer®, Karlsruhe, Deutschland), Ketamin (Medistar ${ }^{\circledR}$, Holzwickede, Deutschland), Xylazin (Riemser ${ }^{\circ}$, Greifswald-Insel Riems, Deutschland) und zur Infektionsprophylaxe eine single-shotAntibiose mit Dihydrostreptomycin (Zur Verfügung gestellt durch die Tierärzte der Zentralen Tierexperimentellen Einrichtung, ZTE, Göttingen, Deutschland) (Tabelle 3).

\section{Ablauf der Ovarektomie}

Nach Narkoseeinleitung erfolgte die Haarentfernung der Lumbalregion beidseits mit einem elektrischen Rasierer. Anschließend wurde das Operationsgebiet desinfiziert (Braunovidon Lösung ${ }^{\circledR}$, Bayer, Deutschland) und es folgte ein circa 1,5 cm langer Hautschnitt in der Medianen über dem Lendenwirbelbereich lateral zwischen Rippenbogen und Hinterläufen. Dann wurde im subkutanen Gewebe stumpf bis auf die Bauchmuskulatur präpariert. Diese wurde ebenfalls stumpf, paramedian auf circa einem cm Länge durchtrennt und das Peritoneum dargestellt. Das Peritoneum wurde eröffnet. Die Ovarien wurden freigelegt und dargestellt. Diese wurden durch eine resorbierbare Vicryl Ligatur (Johnson \& Johnson ${ }^{\circledR}$, Norderstedt, Deutschland) von den Tuben getrennt, abgesetzt und entfernt. Die Uterushörner wurden zurückverlagert, das Peritoneum und die Bauchmuskulatur mittels Vicryl-Faden verschlossen. Die Hautschnitte wurden jeweils mit zwei bis drei Hautklammern $\left(7,5\right.$ x 1,75 mm, Michel ${ }^{\circledR}$, Heiland, Stuttgart) 
versorgt. Postoperativ erhielt jede Ratte ein Flüssigkeitsdepot (s. c.) von drei ml $\mathrm{NaCl}$ 0,9 $\%$ und wurde in auf $37{ }^{\circ} \mathrm{C}$ vorgewärmte Käfige gelegt. Diese standen dazu auf regulierbaren Wärmeplatten. Bis zum Erwachen wurden alle Versuchstiere durchgehend überwacht (siehe auch: Doell 2011).

Tabelle 3: Anästhesie und Analgesie bei Ovarektomie.

\begin{tabular}{|l|l|l|l|}
\hline Medikament & Dosis & OP Tag & Erste Tag post-OP \\
\hline $\mathrm{CO}_{2}$ & Inhalativ & X & \\
\hline Rimadyl & $5 \mathrm{mg} / \mathrm{kg} / \mathrm{KG}$, s. c. & $X$ & $X$ \\
\hline Ketamin & $100 \mathrm{mg} / \mathrm{kg} / \mathrm{KG}$, i. p. & X & \\
\hline Xylazin & $7 \mathrm{mg} / \mathrm{kg} / \mathrm{KG}, \mathrm{i} . \mathrm{p}$. & $X$ & \\
\hline Antibiotikum & $0,1 \mathrm{ml} / 100 \mathrm{~g} / \mathrm{kg} / \mathrm{KG}$ & $X$ & \\
\hline
\end{tabular}

\subsubsection{Osteotomie und Osteosynthese}

Acht Wochen nach Ovarektomie wurden alle Gruppen osteotomiert (siehe auch: Stuermer et al. 2010). Die Narkose, Analgesie und Antibiose am Tag der Osteotomie war bis auf die additive Gabe von Dezentan (Merck ${ }^{\circledR}$, Darmstadt, Deutschland) und Buprenorphin (Reckitt Benckiser Healthcare ${ }^{\circledR}$, Berkshire, England) identisch mit dem Schema bei Ovarektomie. Am Abend nach Operation wurde nochmals Buprenorphin verabreicht. Am ersten postoperativem Tag erhielten die Versuchstiere nochmals Rimadyl und Buprenorphin, nachfolgend erhielten sie täglich von Tag zwei bis vier Rimadyl (Tabelle 4).

\section{Ablauf der proximalen Tibiaosteotomie}

Die Behaarung der Hinterbeine wurde mit einem elektrischen Rasierer entfernt und das Operationsgebiet anschließend desinfiziert. Unterhalb des Kniegelenkes wurde dann parapatellar, medio-ventral über der Tibia ein Hautschnitt von circa drei $\mathrm{cm}$ Länge durchgeführt. Anschließend wurde die körpernahe Tibia, unter Schonung der Muskulatur, 
präpariert. Mittels Schablone wurde die Osteotomielinie ca. fünf bis sieben mm distal der Epiphysenfuge mit einem Skalpell markiert. Dann wurde eine T-Form, 5-LochTitanplatte (XS-Titanfixationsplatte, Stryker Trauma ${ }^{\circledR}$, Selzach, Schweiz) mit zwei proximalen und zwei distalen Schrauben vorfixiert. Danach wurde die Platte entfernt und die Osteotomie mittels gepulstem Ultraschall (OT 7 Piezosurgery, Mectron Medical Technology ${ }^{\circledR}$, Carasco, Italien) durchgeführt. Folgend wurde das Osteosynthesematerial wieder in die vorher bestimmte Position eingebracht. Das Operationsgebiet wurde dann mit $\mathrm{NaCl}$ 0,9 \% und Braunovidon Lösung® (Bayer, Deutschland) gespült und die Muskulatur mit resorbierbaren Vicryl-Nähten (Johnson \& Johnson ${ }^{\circledR}$, Norderstedt, Deutschland) readaptiert. Die Hautschnitte wurden jeweils mit zwei bis drei Hautklammern (7,5 x 1,75 mm, Michel ${ }^{\circledR}$, Heiland, Stuttgart) versorgt. Postoperativ erhielt jede Ratte ein Flüssigkeitsdepot (s. c.) von drei $\mathrm{ml} \mathrm{NaCl}$ 0,9\% und wurde bis zum Erwachen beaufsichtigt. Hierzu wurden die Ratten, wie auch nach der Ovarektomie, in vorgewärmte Käfige $\left(37^{\circ} \mathrm{C}\right)$ gelegt, welche auf Wärmeplatten standen (siehe auch: Brandsch 2011). 
Tabelle 4: Anästhesie und Analgesie bei Osteotomie.

\begin{tabular}{|l|l|l|l|l|l|}
\hline Medikament & Dosis & $\begin{array}{l}\text { OP } \\
\text { Tag }\end{array}$ & $\begin{array}{l}\text { OP } \\
\text { Abend }\end{array}$ & $\begin{array}{l}\text { Erster } \\
\text { post-OP- } \\
\text { Tag }\end{array}$ & $\begin{array}{l}\mathbf{2} \text { - } \\
\text { post-OP- } \\
\text { Tag }\end{array}$ \\
\hline $\mathrm{CO}_{2}$ & Inhalativ & $X$ & & & \\
\hline Rimadyl & $5 \mathrm{mg} / \mathrm{kg} / \mathrm{KG}$, s. c. & $X$ & & $X$ & $X$ \\
\hline Ketamin & $100 \mathrm{mg} / \mathrm{kg} / \mathrm{KG}, \mathrm{i} . \mathrm{p}$. & $X$ & & & \\
\hline Xylazin & $7 \mathrm{mg} / \mathrm{kg} / \mathrm{KG}, \mathrm{i} . \mathrm{p}$. & $X$ & & & \\
\hline Dezentan & $4 \mathrm{mg} / \mathrm{kg} / \mathrm{KG}, \mathrm{s.c}$. & $\mathrm{X}$ & & & \\
\hline Buprenorphin & $0,1 \mathrm{mg} / \mathrm{kg} / \mathrm{KG}, \mathrm{s} . \mathrm{c}$. & $\mathrm{X}$ & $\mathrm{X}$ & $\mathrm{X}$ & \\
\hline Antibiotikum & $0,1 \mathrm{ml} / 100 \mathrm{~g} / \mathrm{kg} / \mathrm{KG}$ & $\mathrm{X}$ & & & \\
\hline
\end{tabular}

\subsubsection{Behandlung}

Die Therapie startete sofort nach Osteotomie und erfolgte über einen Zeitraum von fünf Wochen. Dazu erhielten alle Ratten sojafreies Futter (Ssniff spezial Diät GmbH®, Soest, Deutschland). Die Gruppen Non OVX und OVX bekamen Futter ohne weitere Zusätze. Die Behandlungsgruppen hingegen erhielten die Substanz dem Futter beigemischt. Zur besseren Identifikation unterschied sich sowohl die Wirkstoffkonzentration (2.1.1), als auch die Farbe des Futters (Ssniff spezial Diät GmbH®, Soest, Deutschland) der einzelnen Behandlungsgruppen (Tabelle 5). 
Tabelle 5: Futter, Menge an Wirkstoff und Farbe.

\begin{tabular}{|l|l|l|}
\hline Gruppe & Dosis & Farbe \\
\hline Non OVX & - & - \\
\hline OVX & - & - \\
\hline SARM 1 & $0,04 \mathrm{mg} / \mathrm{kg} / \mathrm{KG}$ & Violett \\
\hline SARM 2 & $0,4 \mathrm{mg} / \mathrm{kg} / \mathrm{KG}$ & Blau \\
\hline SARM 3 & $4 \mathrm{mg} / \mathrm{kg} / \mathrm{KG}$ & Rot \\
\hline
\end{tabular}

\subsubsection{In-vivo-Fluoreszenzmarkierung}

Den Ratten wurden an definierten Zeitpunkten nach Osteotomie unterschiedliche Fluorochrome subkutan appliziert (nach Rahn 1976, modifiziert von Stürmer et al. 2010) (Tabelle 6). Dazu gehörten Xylenolorange (Farbe: orange, Merck Chemicals GmbH®, Schwalbach, Deutschland), Calceingrün (Farbe: grün, Chroma/Waldeck GmbH®, Münster, Deutschland), Alizarincomplexon (Farbe: rot, Merck Chemicals GmbH®, Schwalbach, Deutschland) und Tetrazyklin (Farbe: gelb, Roth ${ }$, Karlsruhe, Deutschland). Diese Farbstoffe lagerten sich im Rahmen der Frakturheilung in den neu gebildeten Knochen ein (siehe auch: Brandsch 2011).

Tabelle 6: Farbstoffe, Dosierung und Zeitpunkte zur Fluoreszenzmarkierung.

\begin{tabular}{|l|l|l|}
\hline Farbstoff & Dosierung & Zeitpunkt \\
\hline Xylenolorange (XO) & $90 \mathrm{mg} / \mathrm{kg} / \mathrm{KG}$ & 13. Tag \\
\hline Calceingrün (CG) & $10 \mathrm{mg} / \mathrm{kg} / \mathrm{KG}$ & $20 . \mathrm{Tag}$ \\
\hline Alizarinkomplexon (AK) & $30 \mathrm{mg} / \mathrm{kg} / \mathrm{KG}$ & 28.Tag \\
\hline Tetrazyklin (TC) & $30 \mathrm{mg} / \mathrm{kg} / \mathrm{KG}$ & 36.Tag (eine Stunde vor Dekapitation) \\
\hline
\end{tabular}




\subsubsection{Dekapitation und Präparation}

Am 35. Tag nach der Osteotomie endete der Versuch. Alle Ratten wurden unter $\mathrm{CO}_{2-}$ Narkose dekapitiert. Daraufhin wurden unterschiedliche Proben für weiterführende Untersuchungen entnommen. Die Blutproben wurden nach Entnahme von ca. acht bis zehn $\mathrm{ml}$ bei $-20{ }^{\circ} \mathrm{C}$ zur weiteren Analyse gelagert. Diese fand in der Abteilung Klinische Chemie der Universitätsmedizin Göttingen statt. Es wurden die Konzentrationen der Kreatinkinase $(\mathrm{CK})$, Magnesium $\left(\mathrm{Mg}^{2+}\right)$, Kalzium $\left(\mathrm{Ca}^{2+}\right)$ und Phosphat $(\mathrm{P})$ bestimmt (Architect c16000, Abbott ${ }^{\circledR}$, Wiesbaden, Deutschland). Der Uterus wurde zur Gewichtsanalyse entfernt und gewogen.

Den Ratten wurden bilateral der M. Gastrocnemius, M. Soleus und M. Longissimus entnommen. Nach einem Hautschnitt im Bereich der Tibia mittels Skalpell, wurde der M. Gastrocnemius mit Hilfe einer Schere freipräpariert. Mit einem Skalpell wurde dann die distale Sehne durchtrennt und der M. Soleus vom M. Gastrocnemius abpräpariert. Beide Muskeln wurden mittels Skalpell an ihren proximalen Sehnen durchtrennt, gewogen und das Gewicht dokumentiert. Der M. Gastrocnemius wurde quer zum Faserverlauf in der Mitte des Muskelbauches halbiert. Es folgte ein Hautschnitt entlang der Processi Spinosi, vom Os Sacrum bis Höhe der Scapulae. Der M. Longissimus wurde oberhalb des Os Sacrum mittels Skalpell durchtrennt. Folgend wurde mit Pinzette und Schere ein circa drei bis vier cm langer Muskelabschnitt entnommen (siehe auch: Kling 2015).

Die Muskeln wurden randomisiert den Analysegruppen zugeteilt. Zur histologischen Untersuchung wurden sie mit Talkum bedeckt (Moline und Glenner 1964) und in flüssigem Stickstoff vorgefroren. Anschließend sind sie mit Alufolie umwickelt, beschriftet und bei $-80{ }^{\circ} \mathrm{C}$ gelagert worden. Zur enzymatischen Untersuchung wurden die Muskeln direkt in flüssigem Stickstoff vorgefroren, anschließend in Proberöhrchen ( $5 \mathrm{ml}$, Sarstedt ${ }^{\circledR}$, Nümbrecht, Deutschland) gepackt und bei $-80{ }^{\circ} \mathrm{C}$ gelagert. Nach diesem Arbeitsschritt wurden histologische- und Enzymaktivitätsanalysen durchgeführt.

Die weitere Entnahme, Untersuchung und Analyse der Knochen (Tibiae, Femora und Wirbelkörper) sind nicht Gegenstand dieser Arbeit und werden im Rahmen weiterer Dissertationen und Publikationen behandelt. 


\subsection{Dünnschnitte der quergestreiften Skelettmuskulatur}

\subsubsection{Dünnschnitte mit dem Kryotom}

Nach Randomisierung wurden jeweils von einem M. Gastrocnemius, M. Soleus und M. Longissimus mittels Kryotoms (Leica CM1900, Leica Instruments GmbH® , Nussloch, Deutschland) $12 \mu \mathrm{m}$ Dünnschnitte angefertigt. Die Schnitte verliefen quer zum ursprünglichen Muskelfaserverlauf. Die Umgebungstemperatur in der Kammer betrug $-20{ }^{\circ} \mathrm{C}$. Die Objektträgertemperatur, auf welcher die Muskelproben mittels Eis temporär fixiert wurden, betrug $-18{ }^{\circ} \mathrm{C}$. Mindestens sechs Querschnitte wurden auf zwei Objektträger (Superfrost Plus, Gerhard Menzel GmbH®, Braunschweig, Deutschland) aufgebracht und nach einer Trocknungszeit von circa einer Stunde bei $-20{ }^{\circ} \mathrm{C}$ gelagert (Abbildung 5).

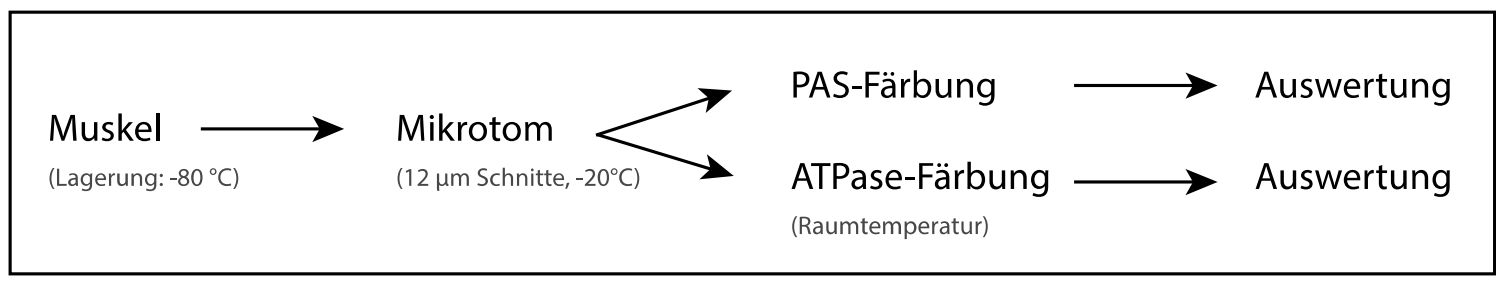

Abbildung 5: Ablauf der Dünnschnitte und histologischen Färbungen.

\subsection{Färbung der quergestreiften Skelettmuskulatur}

\subsubsection{Amylase-PAS für Kapillarfärbung}

An jeweils einem Objektträger jedes Muskels mit Muskelquerschnitten wurde eine Kapillarfärbung durchgeführt (nach Horak, 1983). Nach Lagerung der Proben bei $-20{ }^{\circ} \mathrm{C}$ wurden sie zum Antauen bei Raumtemperatur gelagert. Im Anschluss wurde die Kapillarfärbung nach Amylase-PAS Protokoll durchgeführt (Tabelle 29). Die Lösungen (Andersen 1975) wurden am Tag der Färbung frisch hergestellt (Tabelle 30). Die angegebenen Mengenverhältnisse entsprachen dabei einer Küvette in der ca. 14 Objektträger gefärbt wurden. 


\subsubsection{ATPase-Färbung}

An dem zweiten Objektträger jedes Muskels mit Muskelquerschnitten wurde nach vorheriger Fixierung eine ATPase-Färbung, kombiniert mit Diaphorase gemacht (Meijer et al. 1970, Komrakova et al. 2009). Nach Lagerung der Proben bei $-20{ }^{\circ} \mathrm{C}$ wurden sie zum Antauen bei Raumtemperatur gelagert und die Färbung nach ATPase-Protokoll durchgeführt (Tabelle 31). Die Lösungen wurden am Tag der Färbung frisch hergestellt (Tabelle 32). Die angegebenen Mengenverhältnisse entsprachen dabei einer Küvette in der ca. 14 Objektträger gefärbt wurden.

\subsection{Enzymaktivitätsbestimmung}

\subsubsection{Enzymaktivitätsbestimmung der quergestreiften Skelettmuskulatur}

Zur Bestimmung enzymatischer Aktivitäten in den Muskeln, wurden diese nach Lagerung bei $-80{ }^{\circ} \mathrm{C}$ in Teflongefäßen mit einer Metallkugel bei $2500 \mathrm{rpm}$ für 30 Sekunden homogenisiert (Mikro-Dismembrator S, Satorius ${ }^{\circledR}$, Göttingen, Deutschland). Anschließend wurde der homogenisierte Muskel im Chappel-Perry-Medium (Tabelle 32) gelöst (Verhältnis: CS 1:3, LDH 1:100, Komplex-1 1:1). Danach wurde die Aktivität der Citrat-Synthase (CS), Laktatdehydrogenase (LDH) und NADH-Ubiquinon Oxidoreduktase (Komplex-1) innerhalb von zwei Stunden nach Homogenisierung gemessen. Die Enzymaktivität wurde anhand der Extinktionsänderung $(\Delta \mathrm{E})$ in photometrischer Messung (Libra, Biochrom ${ }^{\circledR}$, Cambridge, England) bestimmt.

Die Analyse jeder Probe wurde für jedes Tier in Doppelbestimmung mit paralleler Leerwertbestimmung durchgeführt. Die Aktivität der CS wurde in U/mg, die der LDH und Komplex-1 in U/g angegeben (Abbildung 6).

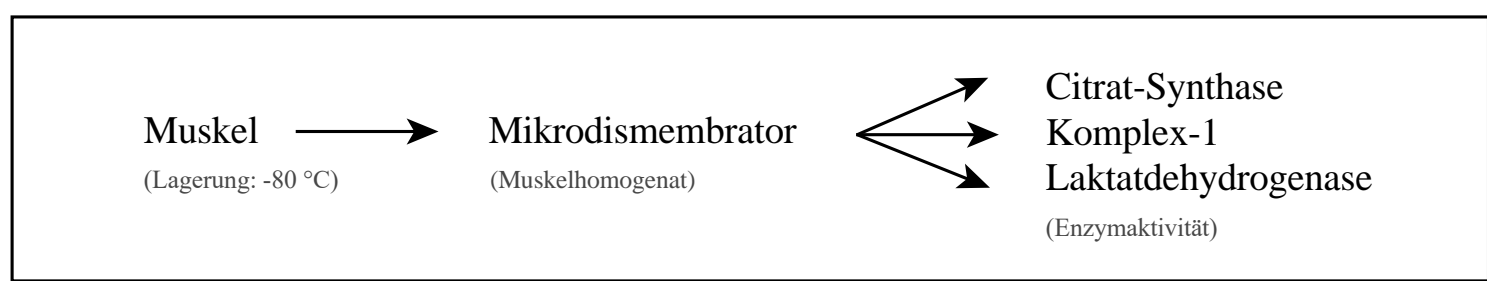

Abbildung 6: Ablauf der Enzymaktivitätsbestimmung. 


\subsubsection{Enzymaktivitätsbestimmung der Citrat-Synthase}

Zur Bestimmung der Aktivität der Citrat-Synthase wurde das Gemisch aus Muskelhomogenat und Chappel-Perry-Medium in den dazugehörigen Testansatz (nach Schwerzmann et al. 1989) gegeben (Tabelle 33, Tabelle 34).

Nach Zugabe der Probe fand eine Vorinkubation von zehn Minuten bei $30{ }^{\circ} \mathrm{C}$ in einer Küvette statt. Der Reaktionsstart erfolgte durch Hinzufügen von $50 \mu 1 \quad 10 \mathrm{mM}$ Oxalessigsäure. Am Zeitpunkt Null (direkt nach Zugabe von Oxalessigsäure) und nach fünf Minuten folgte dann die Extinktionsmessung bei $412 \mathrm{~nm}$. Die Enzymaktivität wurde dann unter Berücksichtigung des Proteingehaltes in U/mg umgerechnet (Formel siehe Kapitel 2.5.4).

\subsubsection{Enzymaktivitätsbestimmung der Laktatdehydrogenase}

Im Falle der Aktivitätsbestimmung der Laktatdehydrogenase wurde das Gemisch aus Muskelhomogenat und Chappel-Perry-Medium in den dazugehörigen Testansatz gegeben (Tabelle 33, Tabelle 35).

Eine Vorinkubation von zehn Minuten fand nach Probenzugabe bei $30{ }^{\circ} \mathrm{C}$ in einer Küvette statt. Der Reaktionsstart erfolgte durch Hinzufügen von $30 \mu 140$ mM Pyruvat. Am Zeitpunkt Null (direkt nach Zugabe von Pyruvat) und nach fünf Minuten folgte eine Extinktionsmessung bei $340 \mathrm{~nm}$. Die Enzymaktivität wurde dann unter Berücksichtigung des Proteingehaltes in U/g umgerechnet (Formel siehe Kapitel 2.5.5).

\subsubsection{Enzymaktivitätsbestimmung des Komplex-1}

Zur Komplex-1 Aktivitätsbestimmung wurde das Gemisch aus Muskelhomogenat und Chappel-Perry-Medium in den dazugehörigen Testansatz (nach Hatefi und Rieske 1967) gegeben (Tabelle 33, Tabelle 36).

Nach Zugabe der Probe fand eine Vorinkubation von zehn Minuten bei $30{ }^{\circ} \mathrm{C}$ in einer Küvette statt. Der Reaktionsstart erfolgte durch Hinzufügen von $20 \mu 16 \mathrm{mM}$ CoenzymQ und 10 mM NADH. Am Zeitpunkt Null (direkt nach Zugabe von CoenzymQ und NADH) und nach zehn Minuten folgte dann die Extinktionsmessung bei $340 \mathrm{~nm}$. Anschließend wurden $20 \mu 1$ 0,5 mM Rotenon hinzugegeben. Die Extinktion wurde ebenso am Zeitpunkt 
Null und nach zehn Minuten bei 340 nm gemessen. Die Enzymaktivität wurde dann unter Berücksichtigung des Proteingehaltes in U/g umgerechnet (Formel siehe Kapitel 2.5.6).

\subsection{Auswertung}

\subsubsection{Mikroskop}

Die Auswertung der Muskelquerschnitte erfolgte am Mikroskop (Nikon®, Eclipse E600, Kamera: Nikon ${ }^{\circledR}$, DS-Fi2) in zehnfacher Vergrößerung. Die Aufnahmen wurden digital am Computer dargestellt, bearbeitet und gespeichert. Dazu wurde das Programm NISElements verwendet $\left(\right.$ Nikon ${ }^{\circledR}$, Version: 4.00.08, Copyright 1991-2012, Laboratory Imaging).

\subsubsection{Auswertung der Amylase-PAS-Kapillarfärbung}

Es wurden zwei zufällig ausgewählte Bereiche innerhalb eines Muskelquerschnittes mit einer Gesamtgröße von $0,5 \mathrm{~mm}^{2}$ ausgewertet. Hierfür wurden um die jeweiligen Ausschnitte ein Rahmen mit einer Seitenlänge von 500 x $500 \mu$ m festgelegt. Innerhalb dieser Fläche wurde die Anzahl von Kapillaren und Zellen ausgezählt (Abbildung 7). Im Anschluss wurde das Verhältnis von Kapillaren zu Zellen berechnet. Hierzu wurde folgende Formel verwendet:

Anzahl Kapillaren pro Zellen $(\mathrm{n})=\frac{\text { Anzahl Kapillaren }(\mathrm{nK})}{\text { Anzahl Zellen }(\mathrm{nZ})}$ 


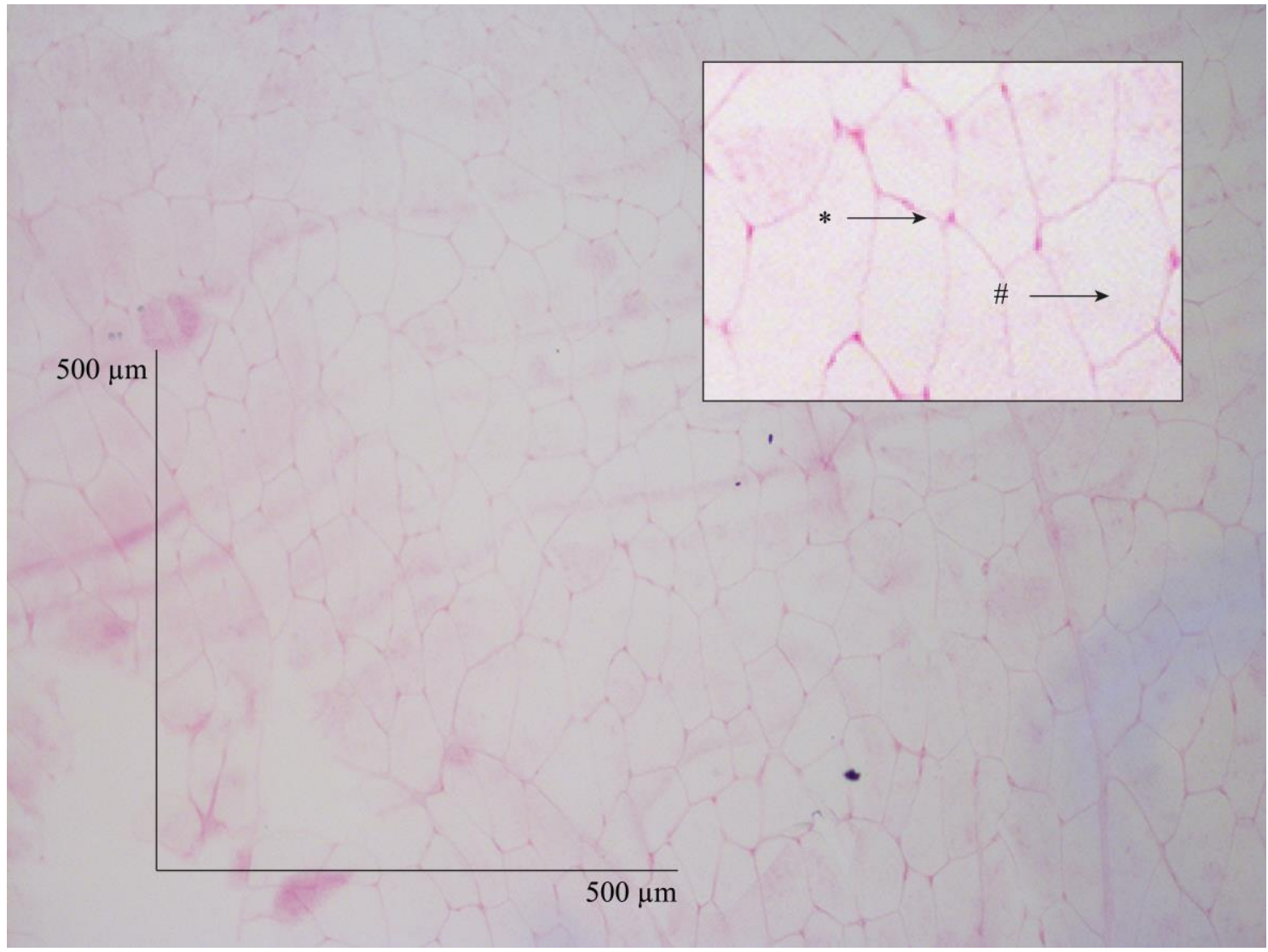

Abbildung 7: Kapillarfärbung am M. Longissimus (*: Kapillare, \#: Zelle).

\subsubsection{Auswertung der ATPase-Färbung}

Es wurde sowohl die Fläche $\left(\mu \mathrm{m}^{2}\right)$ als auch der äquivalente Zelldurchmesser $(\mu \mathrm{m})$ bestimmt. Die jeweilige Auswertung unterschied sich leicht zwischen den einzelnen Muskeln. Im Falle des M. Longissimus und M. Gastrocnemius wurden die Zellen zur Auswertung in die Kategorien: glykolytische (hell: FG Fasern) und nicht glykolytische (dunkel: FOG Fasern, SO Fasern) Muskelzellen eingeteilt (Abbildung 8). Es wurden jeweils drei zufällig gewählte Bildausschnitte mit je 30 Zellen jeder Gruppe ausgemessen. Es sind insgesamt 90 glykolytische und 90 nicht-glykolytische Zellen pro Muskel gemessen und ausgewertet worden. Die Messungen erfolgten durch manuelles Umkreisen der einzelnen Muskelzellen im Querschnitt. Im Anschluss wurde der Mittelwert aus den 90 Einzelwerten gebildet. Im Falle des M. Longissimus wurde zusätzlich das Verhältnis von glykolytischen zu nicht glykolytischen Zellen auf einer Fläche von $1 \mathrm{~mm}^{2}$ bestimmt. 


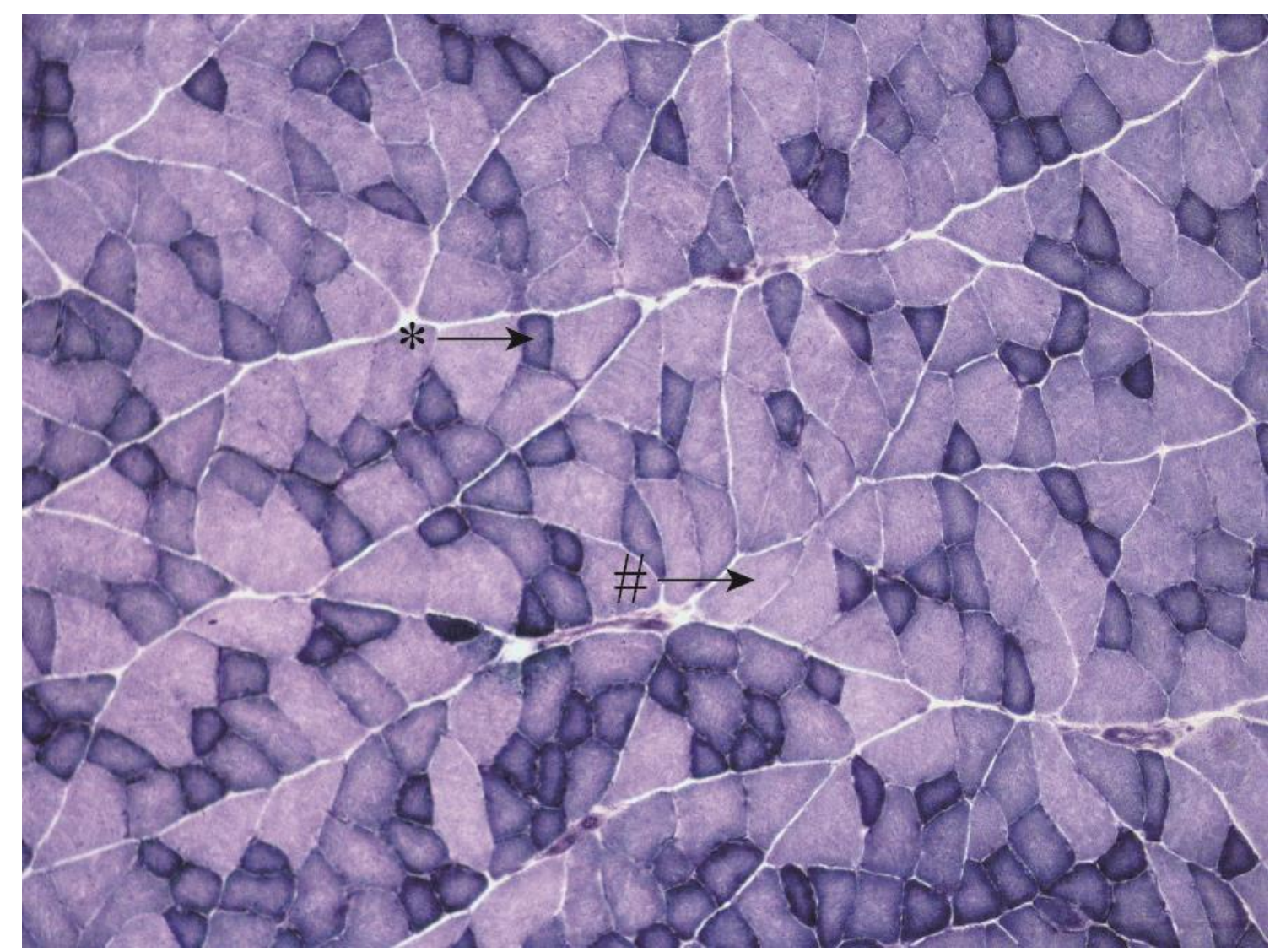

Abbildung 8: ATPase-Färbung am M. Gastrocnemius (*: dunkle Zellen = nicht glykolytisch, \#: helle Zellen = glykolytisch).

Da sich im M. Soleus ausschließlich nicht glykolytische Muskelzellen finden lassen, wurden hier insgesamt 90 Muskelzellen pro Muskelschnitt ausgewertet (Abbildung 9). 


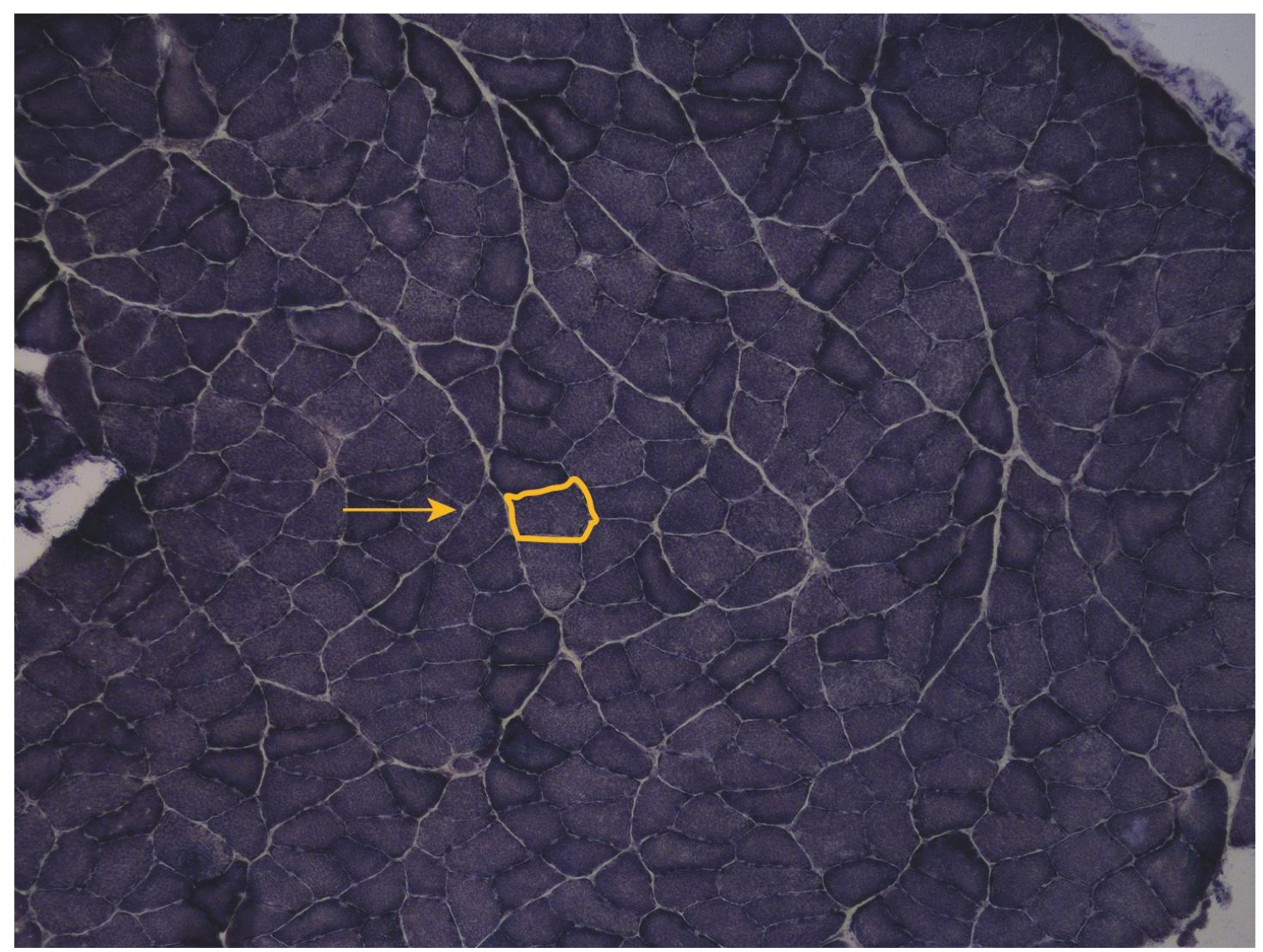

Abbildung 9: ATPase-Färbung am M. Soleus (Pfeil: Beispielhafte Bestimmung der Fläche und des äquivalenten Durchmessers einer nicht-glykolytischen Zelle).

\subsubsection{Auswertung der Enzymaktivitätsbestimmung der Citrat-Synthase}

Die Aktivität der Citrat-Synthase wurde nach folgender Formel bestimmt:

Aktivität $=\frac{(\Delta \mathrm{E}-\Delta \mathrm{E} \text { Leerwert }) \cdot 1000 \mu \mathrm{l} \cdot \mathrm{V}}{\mathrm{d} \cdot \mathrm{E} \cdot 5 \text { Minuten } \cdot 20 \mu \mathrm{l}}$

$\mathrm{V}=$ Verdünnung des Homogenats, $\mathrm{d}=$ Schichtdicke, $\mathrm{E}=13.6 \mathrm{mM}-1 \cdot \mathrm{cm}-1, \Delta \mathrm{E}=$ Veränderung der Extinktion, 5 Minuten = Inkubationszeit, $20 \mu \mathrm{l}=$ Homogenatvolumen

\subsubsection{Auswertung der Enzymaktivitätsbestimmung der Laktatdehydrogenase}

Die Aktivität der Laktatdehydrogenase wurde nach folgender Formel bestimmt:

Aktivität $=\frac{(\Delta \mathrm{E}-\Delta \mathrm{E} \text { Leerwert }) \cdot 1000 \mu \mathrm{l} \cdot \mathrm{V}}{\mathrm{d} \cdot \mathrm{E} \cdot 5 \text { Minuten } \cdot 20 \mu \mathrm{l}}$

$\mathrm{V}=$ Verdünnung des Homogenats, $\mathrm{d}=$ Schichtdicke, $\mathrm{E}=6.2 \mathrm{mM}-1 \cdot \mathrm{cm}-1, \Delta \mathrm{E}=$ Veränderung der

Extinktion, 5 Minuten = Inkubationszeit, $20 \mu \mathrm{l}=$ Homogenatvolumen 


\subsubsection{Auswertung der Enzymaktivitätsbestimmung des Komplex-1}

Die Komplex-1 Aktivität wurde nach folgender Formel bestimmt:

Aktivität $=\frac{(\Delta \mathrm{E} \text { ohne Rotenon }-\Delta \mathrm{E} \text { mit Rotenon }) \cdot 1000 \mu \mathrm{l} \cdot \mathrm{V}}{\mathrm{d} \cdot \mathrm{E} \cdot 10 \text { Minuten } \cdot 20 \mu \mathrm{l}}$

$\mathrm{V}=$ Verdünnung des Homogenats, $\mathrm{d}=$ Schichtdicke, $\mathrm{E}=6.2 \mathrm{mM}-1 \cdot \mathrm{cm}-1, \Delta \mathrm{E}=$ Veränderung der Extinktion, 10 Minuten = Inkubationszeit, $20 \mu \mathrm{l}=$ Homogenatvolumen, $\mathrm{R}=$ Rotenon

\subsection{Statistische Auswertung}

\subsubsection{Software zur statistischen Auswertung}

Die statistische Auswertung und graphische Darstellung wurde mit dem Softwareprogramm GraphPad Prism (Version 5.0a, 1992 - 2008, GraphPad, San Diego, USA) durchgeführt.

\subsubsection{Statistische Analysen}

Zur Datenanalyse wurden die Mittelwerte (M), Standardabweichungen (SD), Mediane, Standardfehler, Minimum, Maximum und eine parametrische one-way ANOVA mit anschließendem Tukey`s Comparison post-hoc Test durchgeführt. Das Signifikanzniveau wurde auf ein $\mathrm{p}$ - Wert $<0,05$ festgesetzt. Die graphischen Darstellungen der Ergebnisse erfolgen als Mittelwerte und Standardabweichungen. 


\section{Ergebnisse}

\subsection{Gewichte}

\subsubsection{Gewichte der Versuchstiere}

Bei Lieferung betrug das Gewicht aller Ratten im Mittelwert 243,6 g ( \pm 7,8 g). Nach randomisierter Zuteilung der Versuchstiere zu ihren Gruppen ergaben sich im Vergleich bei einem Signifikanzniveau von $\mathrm{p}<0,05$ keine signifikanten Gewichtsunterschiede (Abbildung 10, Tabelle 7). Im Versuchsverlauf zeigte sich im jeweiligen Gruppenmittelwert eine stetige Körpergewichtszunahme der Versuchstiere. Ab der zweiten Woche fällt die Gewichtszunahme der Gruppe Non OVX im Vergleich zu den ovarektomierten Gruppen leicht zurück. In der neunten Woche nach Osteotomie fand sich eine gruppenübergreifende Gewichtsabnahme (Abbildung 11). Am Tag der Dekapitation zeigte sich ein signifikanter Gewichtsunterschied $(\mathrm{p}<0,001)$ im Vergleich der Kontrollgruppe Non OVX zu den Gruppen OVX, SARM 1, SARM 2 sowie SARM 3 (Abbildung 12, Tabelle 7). Zwischen den anderen Gruppen gab es keine signifikanten Gewichtsunterschiede.

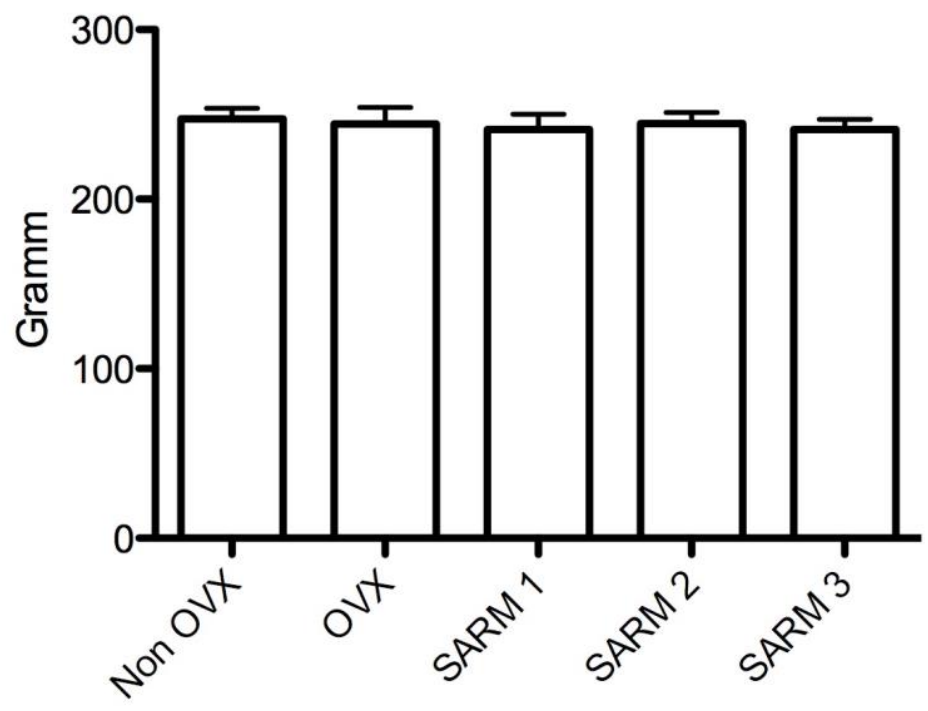

Abbildung 10: Körpergewichte bei Lieferung im Gruppenmittelwert (nach Zuteilung in die Versuchsgruppen). 


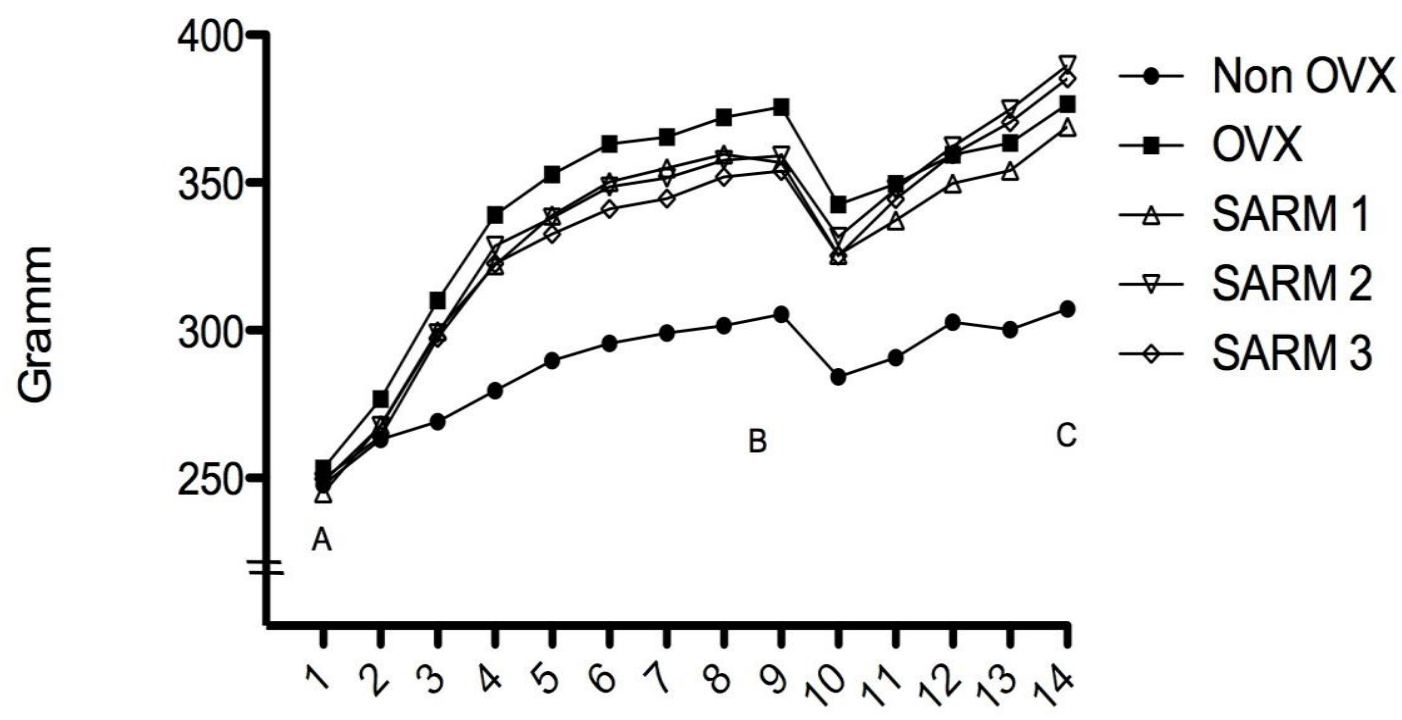

Woche
A: Ovarektomie (Woche 1)
B: Osteotomie (Woche 9)
C: Dekapitation (Woche 14)

Abbildung 11: Körpergewichte über die gesamte Versuchsdauer.

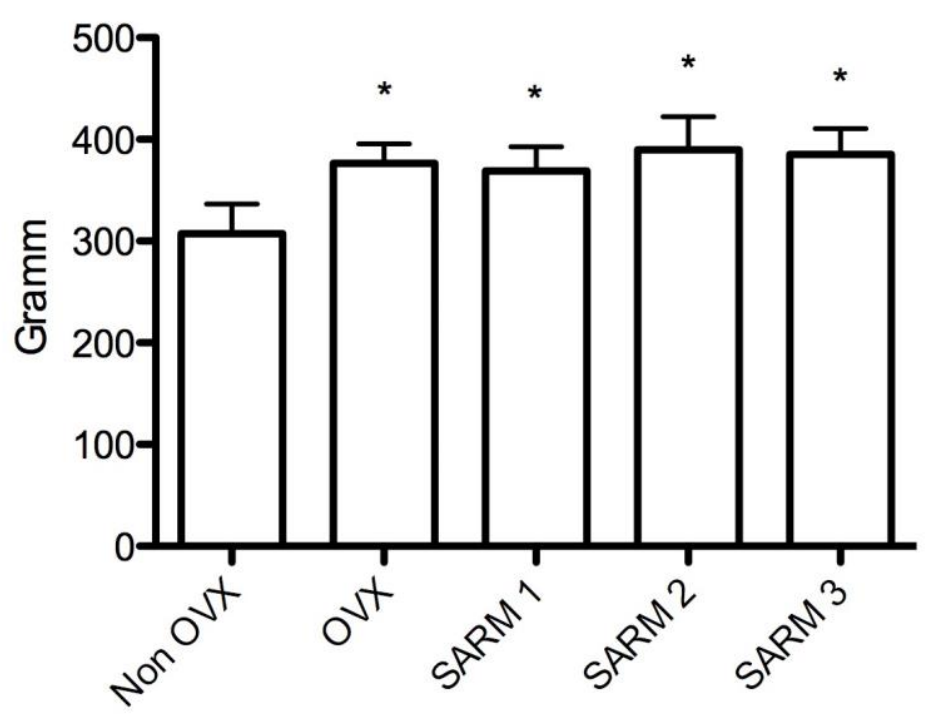

Abbildung 12: Körpergewichte im Gruppenmittelwert am Ende des Versuches (* vs. Non OVX, p <0,05, Tukey-Test). 
Tabelle 7: Körpergewichte im Gruppenmittelwert am Versuchsbeginn und Versuchsende.

\begin{tabular}{|l|l|l|l|l|l|l|}
\hline & & Non OVX & OVX & SARM 1 & SARM 2 & SARM 3 \\
\hline Beginn & M & 247,4 & 244,3 & 241,1 & 244,5 & 241,2 \\
\hline & \pm SD & 6,10 & 9,77 & 8,98 & 6,55 & 6,08 \\
\hline Ende & M & 307,2 & 376,6 & 369,9 & 389,7 & 385,3 \\
\hline & \pm SD & 29,12 & 19,18 & 25,62 & 32,43 & 25,14 \\
\hline
\end{tabular}

\subsubsection{Futter und Wirkstoffaufnahme}

Im Vergleich der Gruppen ergaben sich bei einem Signifikanzniveau von $\mathrm{p}<0,05$ keine signifikanten Unterschiede bezüglich der Futteraufnahme zwischen den einzelnen Gruppen. Non OVX lag im Vergleich zu den übrigen Gruppen in der durchschnittlichen Futteraufnahme leicht zurück (Tabelle 8). In der neunten Woche, nach Osteotomie fand sich eine gruppenübergreifende Abnahme der Futteraufnahme. Diese stieg in den folgenden Wochen bis zur Probenentnahme auf das Niveau vor Osteotomie an (Abbildung 13). Die Menge des aufgenommenen Wirkstoffes pro Ratte erhöhte sich mit der aufgenommenen Futtermenge. Die im Mittelwert aufgenommene Dosis über die fünf Therapiewochen betrug in der Gruppe SARM 1 0,010 mg, SARM 2 0,11 mg und SARM 3 1,07 mg pro Tag (Abbildung 14, Tabelle 9). 


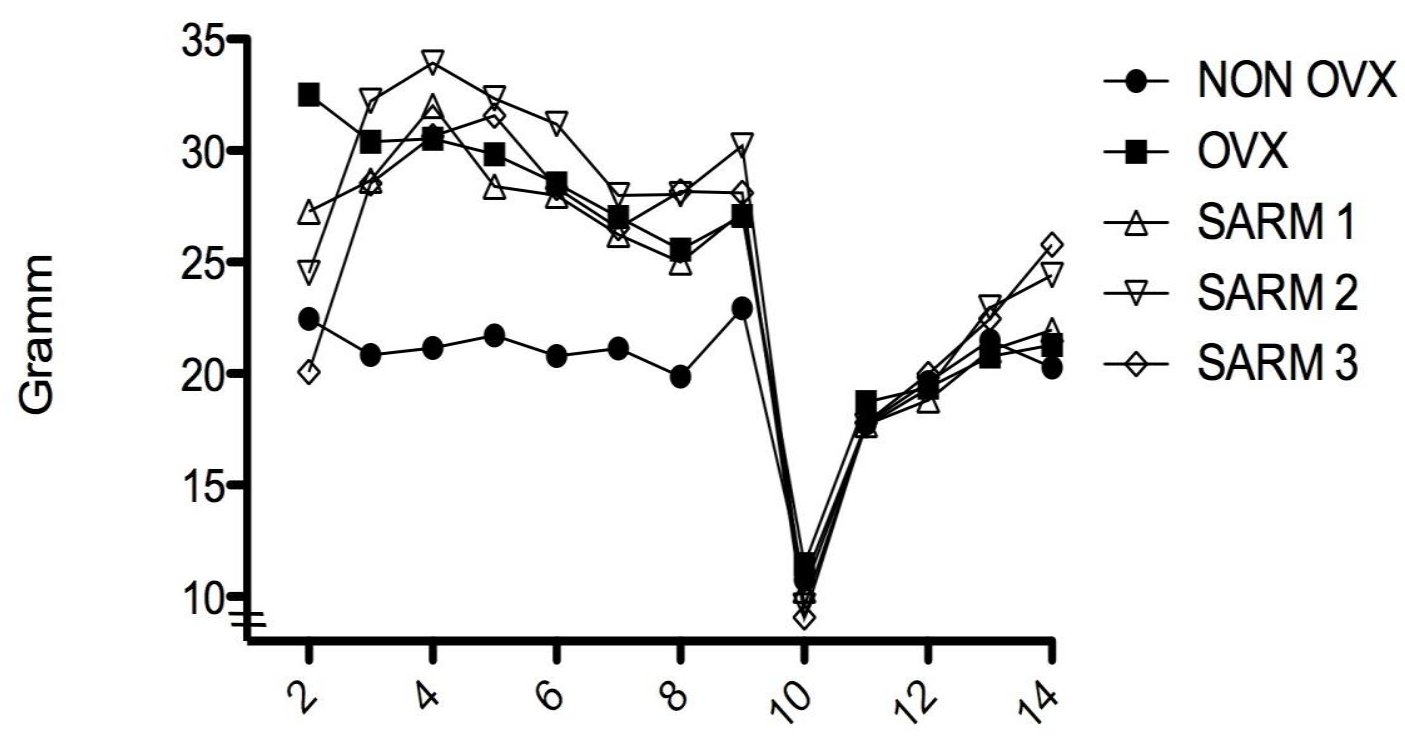

Woche

Abbildung 13: Individuelle Futteraufnahme pro Tag.

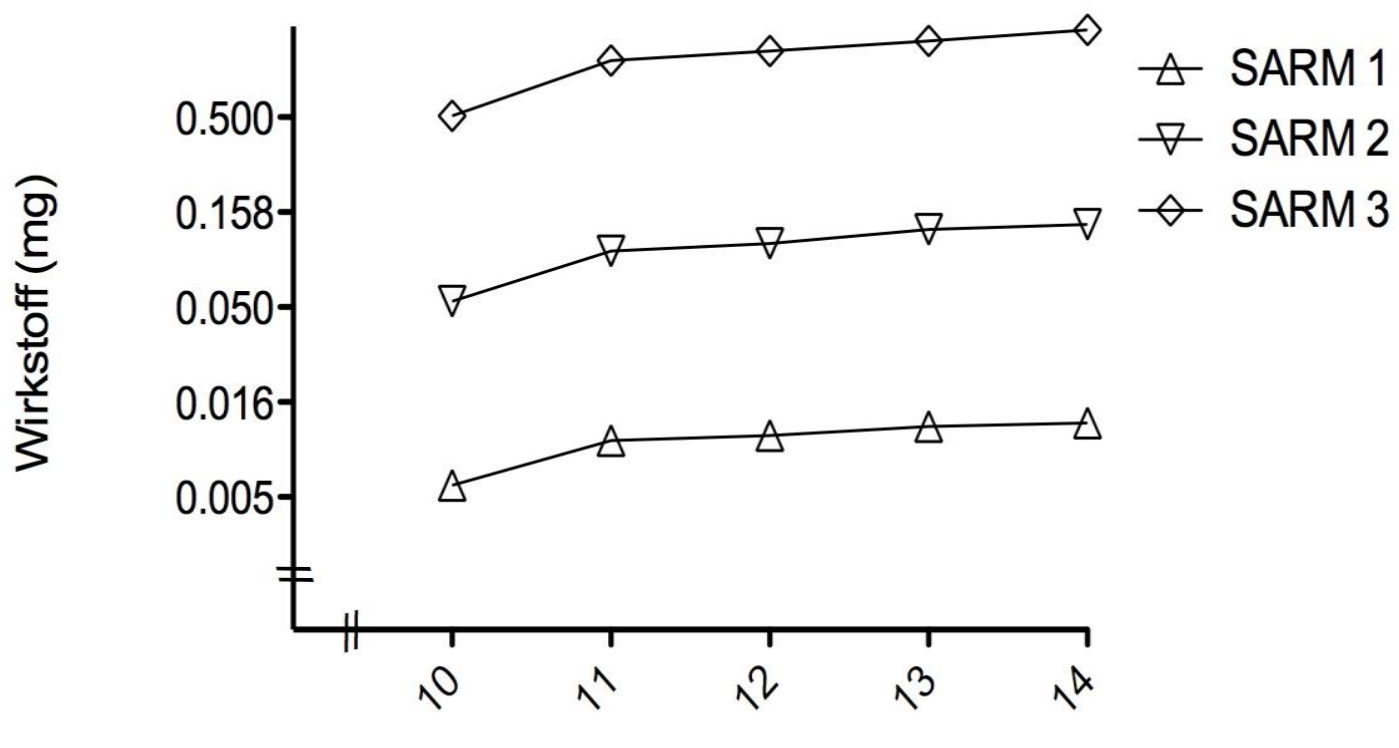

Woche

Abbildung 14: Wirkstoffaufnahme (mg) pro Tag und Tier. 
Tabelle 8: Futteraufnahme pro Tag und Tier im Gruppenmittelwert über die Versuchsdauer (in g).

\begin{tabular}{|l|l|l|l|l|l|l|}
\hline & & Non OVX & OVX & SARM 1 & SARM 2 & SARM 3 \\
\hline Futter (g) & M & 141,1 & 162,6 & 157,7 & 157,7 & 161,1 \\
\hline & $\pm \mathrm{SD}$ & 24,82 & 36,18 & 35,60 & 37,51 & 42,66 \\
\hline
\end{tabular}

Tabelle 9: Wirkstoffaufnahme pro Tag und Tier im Gruppenmittelwert über die Versuchsdauer (in mg, $\mathrm{W}=$ Woche. MAD = Mittlere aufgenommene Dosis der Woche 1 bis 5, Therapiewochen $10-14)$.

\begin{tabular}{|l|l|l|l|l|l|l|l|}
\hline & & & $\begin{array}{l}\text { Non } \\
\text { OVX }\end{array}$ & OVX & SARM 1 & SARM 2 & SARM 3 \\
\hline Wirkstoff (mg) & W 1 & M & - & - & 0,006 & 0,054 & 0,51 \\
\hline & & \pm SD & - & - & 0,0012 & 0,002 & 0,06 \\
\hline & W 2 & M & - & - & 0,01 & 0,099 & 1 \\
\hline & & \pm SD & - & - & 0,0005 & 0,002 & 0,02 \\
\hline & W 3 & M & - & - & 0,011 & 0,11 & 1,12 \\
\hline & W 4 & M SD & - & - & 0,0005 & 0,003 & 0,1 \\
\hline & & \pm SD & - & - & 0,0007 & 0,001 & 0,03 \\
\hline & W 5 & M & - & - & 0,012 & 0,14 & 1,44 \\
\hline & & \pm SD & - & - & 0,0006 & 0,003 & 0,14 \\
\hline MAD (mg) & W. 1 - 5 & M & - & - & 0,010 & 0,11 & 1,07 \\
\hline & & \pm SD & - & - & 0,002 & 0,03 & 0,31 \\
\hline
\end{tabular}

\subsubsection{Gewichte der Uteri}

Im jeweiligen Gruppenvergleich zwischen Non OVX mit OVX, SARM 1, SARM 2 und SARM 3 zeigte sich ein signifikanter Gewichtsunterschied $(\mathrm{p}<0,001)$ bezüglich der Uterus-Gewichte. Der Vergleich der Gruppe OVX mit SARM 2 sowie SARM 3 zeigte 
ebenfalls einen signifikanten Unterschied ( $\mathrm{p}<0,001)$. Auch die Bedingung SARM 1 unterschied sich im Vergleich mit SARM 2 und SARM 3 mit einem p-Wert $<0,001$ signifikant (Abbildung 15, Tabelle 10).

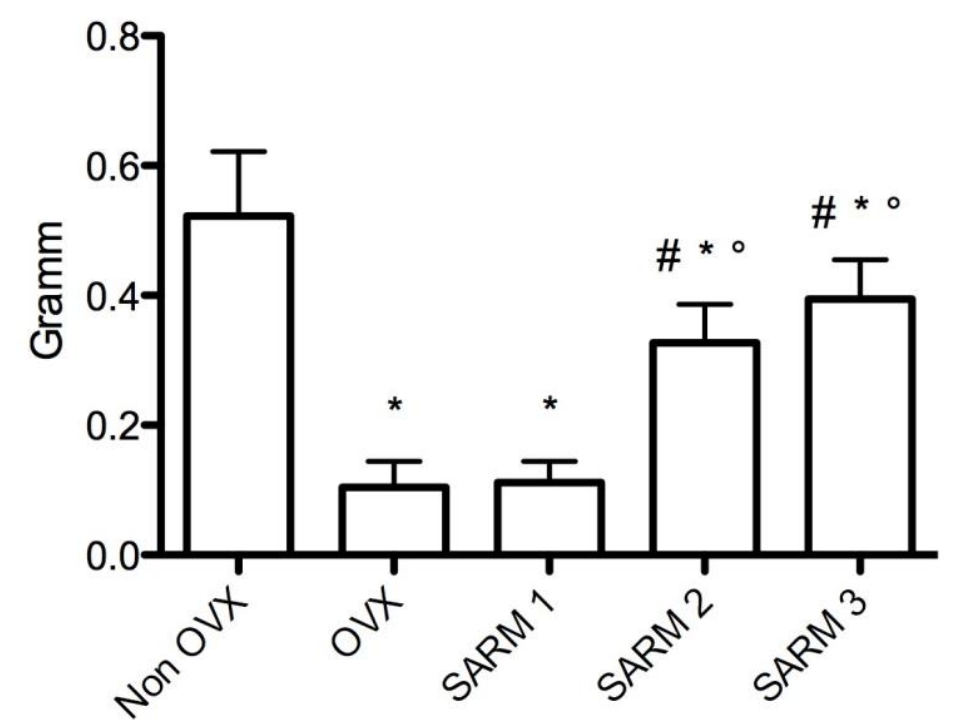

Abbildung 15: Uterusgewichte im Gruppenmittelwert (* vs. Non OVX, \# vs. OVX, ${ }^{\circ}$ vs. SARM 1, P $<0,05$, Tukey-Test).

Tabelle 10: Uterusgewichte (Gruppenmittelwert).

\begin{tabular}{|l|l|l|l|l|l|l|}
\hline & & Non OVX & OVX & SARM 1 & SARM 2 & SARM 3 \\
\hline Gewicht $(\mathrm{g})$ & $\mathrm{M}$ & 0,52 & 0,10 & 0,11 & 0,33 & 0,40 \\
\hline & $\pm \mathrm{SD}$ & 0,10 & 0,04 & 0,03 & 0,06 & 0,06 \\
\hline
\end{tabular}

\subsubsection{Gewichte des M. Gastrocnemius}

Im Gruppenvergleich Non OVX mit den Gruppen SARM 1, SARM 2 sowie SARM 3 zeigten sich signifikante Unterschiede $(\mathrm{p}<0,05)$ bezogen auf das Muskelgewicht des M. Gastrocnemius. Im Vergleich der anderen Gruppen fanden sich keine signifikanten Gewichtsunterschiede (Abbildung 16, Tabelle 11). 


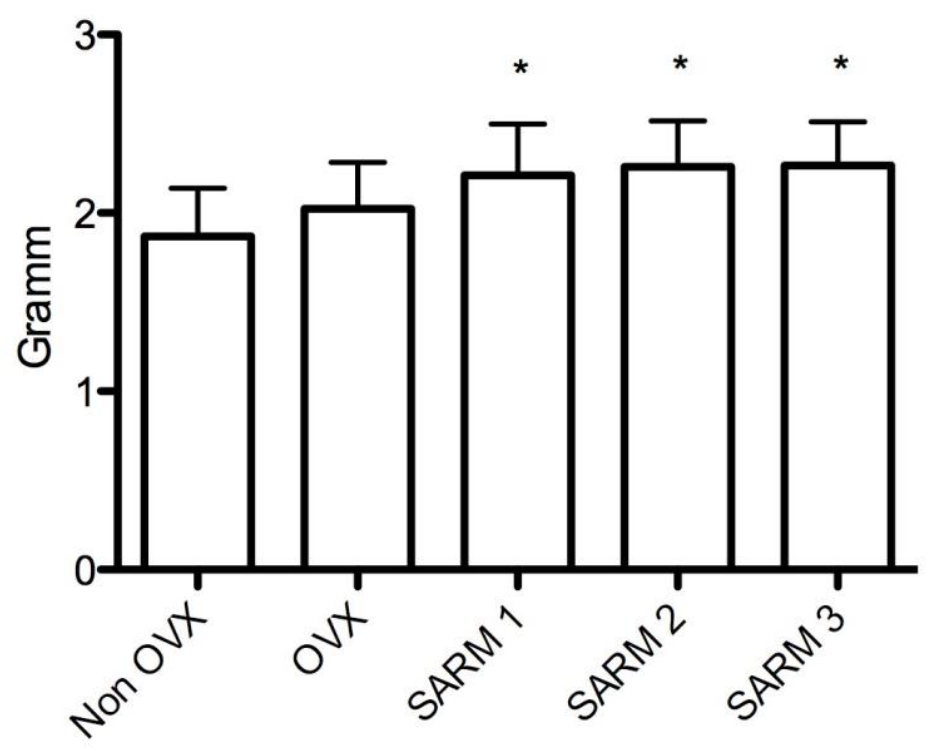

Abbildung 16: Gewichte des M. Gastrocnemius im Gruppenmittelwert (* vs. Non OVX, $\mathrm{P}<0,05$, Tukey-Test).

Tabelle 11: Gewichte des M. Gastrocnemius (im Gruppenmittelwert).

\begin{tabular}{|l|l|l|l|l|l|l|}
\hline & & Non OVX & OVX & SARM 1 & SARM 2 & SARM 3 \\
\hline Gewicht (g) & M & 1,87 & 2,02 & 2,21 & 2,26 & 2,27 \\
\hline & \pm SD & 0,27 & 0,26 & 0,29 & 0,26 & 0,24 \\
\hline
\end{tabular}

\subsubsection{Gewichte des M. Soleus}

Beim M. Soleus ergaben sich keine signifikanten Unterschiede im Gewichtsvergleich zwischen den einzelnen Gruppen. Es zeigte sich eine Tendenz in der Gewichtszunahme der Gruppen SARM 1, SARM 2 und SARM 3 im Vergleich zu Non OVX und OVX (Abbildung 17, Tabelle 12). 


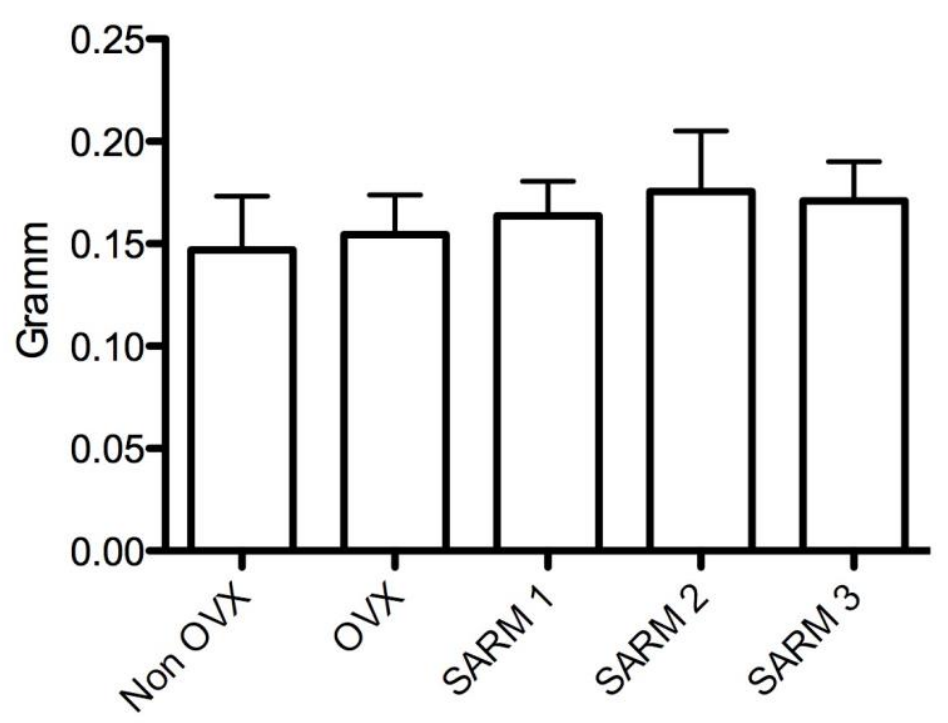

Abbildung 17: Gewichte des M. Soleus im Gruppenmittelwert.

Tabelle 12: Gewichte M. Soleus (im Gruppenmittelwert).

\begin{tabular}{|l|l|l|l|l|l|l|}
\hline & & Non OVX & OVX & SARM 1 & SARM 2 & SARM 3 \\
\hline Gewicht $(\mathrm{g})$ & M & 0,15 & 0,15 & 0,16 & 0,18 & 0,17 \\
\hline & $\pm \mathrm{SD}$ & 0,03 & 0,02 & 0,02 & 0,03 & 0,02 \\
\hline
\end{tabular}

\subsection{Ergebnisse der Kapillarfärbung}

\subsubsection{Ergebnisse der Kapillarfärbung des M. Gastrocnemius}

Im Verhältnis von Kapillaren zu Muskelzellen bezüglich der gemessenen Muskelfläche zeigten sich signifikante Unterschiede im jeweiligen Gruppenvergleich zwischen den Gruppen Non OVX zu SARM 1 ( $\mathrm{p}<0,001)$, SARM 2 sowie SARM 3 ( $\mathrm{p}<0,01)$.

Des Weiteren fanden sich im Vergleich der Gruppe OVX zu SARM 1 (p < 0,01) und SARM $3(\mathrm{p}<0,05)$ signifikante Unterschiede (Abbildung 18, Tabelle 13). 


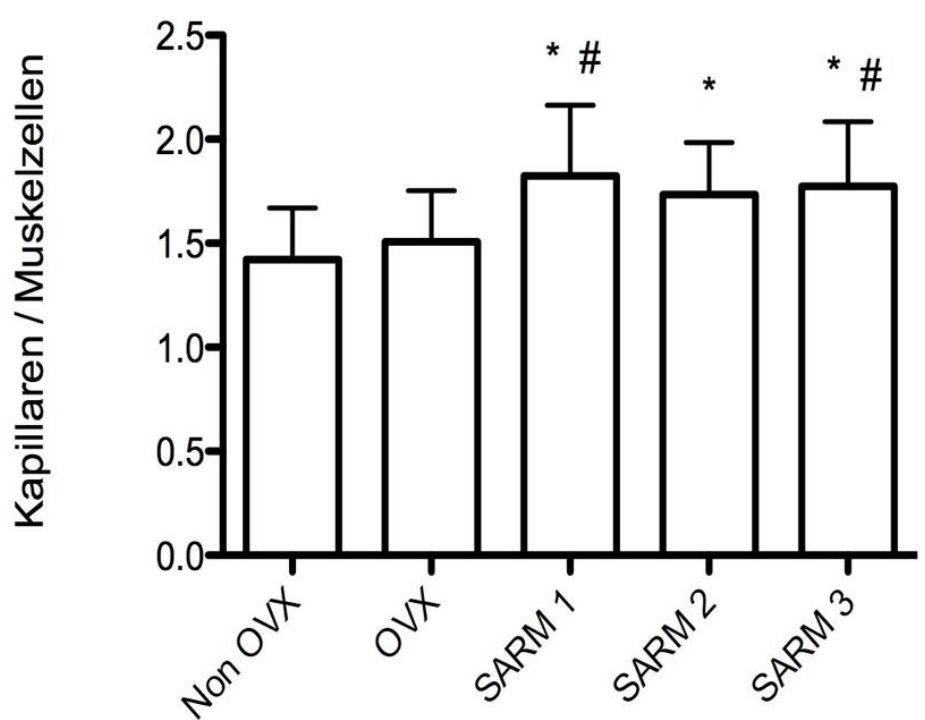

Abbildung 18: Verhältnis von Kapillaren zu Muskelzellen in der Kapillarfärbung des M. Gastrocnemius im Gruppenmittelwert (* vs. Non OVX, \# vs. OVX, p < 0,05, TukeyTest).

Tabelle 13: Verhältnis von Kapillaren zu Muskelzellen in der Kapillarfärbung beim M. Gastrocnemius (im Gruppenmittelwert).

\begin{tabular}{|l|l|l|l|l|l|}
\hline & Non OVX & OVX & SARM 1 & SARM 2 & SARM 3 \\
\hline $\mathrm{M}$ & 1,42 & 1,51 & 1,82 & 1,73 & 1,77 \\
\hline$\pm \mathrm{SD}$ & 0,25 & 0,25 & 0,34 & 0,25 & 0,31 \\
\hline
\end{tabular}

\subsubsection{Ergebnisse der Kapillarfärbung des M. Longissimus}

Im Verhältnis von Kapillaren zu Muskelzellen zeigte der Vergleich von Non OVX mit SARM 2 und SARM 3 einen signifikanten Unterschied ( $p<0,05)$. Der Gruppenvergleich OVX mit SARM 2 zeigte ebenso einen signifikanten Unterschied ( $\mathrm{p}<0,05)$. Auch wies der Vergleich der Gruppe OVX mit SARM 3 einen signifikanten Unterschied ( $p<0,01$ ) auf. Zwischen den anderen Gruppen ergaben sich keine signifikanten Unterschiede (Abbildung 19, Tabelle 14). 


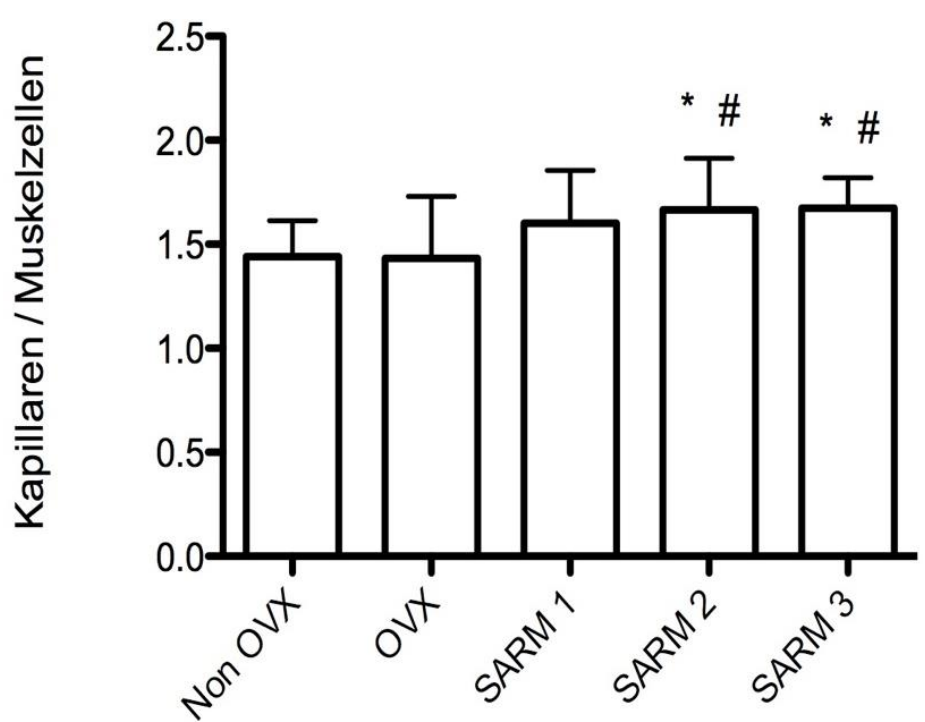

Abbildung 19: Verhältnis von Kapillaren zu Muskelzellen in der Kapillarfärbung des M. Longissimus im Gruppenmittelwert (* vs. Non OVX, \# vs. OVX, p < 0,05, Tukey-Test).

Tabelle 14: Verhältnis von Kapillaren zu Muskelzellen in der Kapillarfärbung beim M. Longissimus (im Gruppenmittelwert).

\begin{tabular}{|l|l|l|l|l|l|}
\hline & Non OVX & OVX & SARM 1 & SARM 2 & SARM 3 \\
\hline M & 1,44 & 1,43 & 1,60 & 1,67 & 1,67 \\
\hline \pm SD & 0,17 & 0,30 & 0,25 & 0,25 & 0,15 \\
\hline
\end{tabular}




\subsubsection{Ergebnisse der Kapillarfärbung des M. Soleus}

Die Gruppenvergleiche beim M. Soleus ergaben keine signifikanten Unterschiede (Abbildung 20, Tabelle 15).

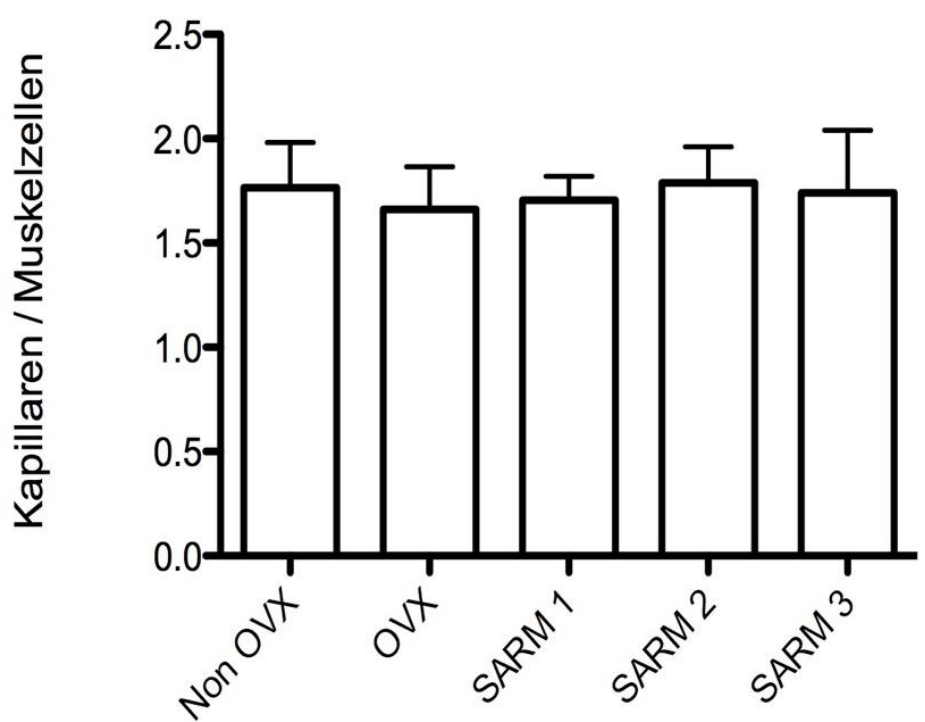

Abbildung 20: Verhältnis von Kapillaren zu Muskelzellen in der Kapillarfärbung des M. Soleus im Gruppenmittelwert.

Tabelle 15: Verhältnis von Kapillaren zu Muskelzellen in der Kapillarfärbung beim M. Soleus (im Gruppenmittelwert).

\begin{tabular}{|l|l|l|l|l|l|}
\hline & Non OVX & OVX & SARM 1 & SARM 2 & SARM 3 \\
\hline M & 1,77 & 1,66 & 1,71 & 1,79 & 1,74 \\
\hline \pm SD & 0,22 & 0,21 & 0,12 & 0,17 & 0,30 \\
\hline
\end{tabular}




\subsection{Ergebnisse der ATPase-Färbung}

\subsubsection{Ergebnisse der ATPase-Färbung des M. Gastrocnemius}

Beim M. Gastrocnemius zeigte sich eine Tendenz zur Größenzunahme der Fläche (Abbildung 21) und des äquivalenten Durchmessers (Abbildung 22) der glykolytischen Zellen unter den Bedingungen SARM 1, SARM 2 und SARM 3 im Vergleich zu Non OVX und OVX. Jedoch waren keine statistisch signifikanten Unterschiede zu verzeichnen (Tabelle 16).

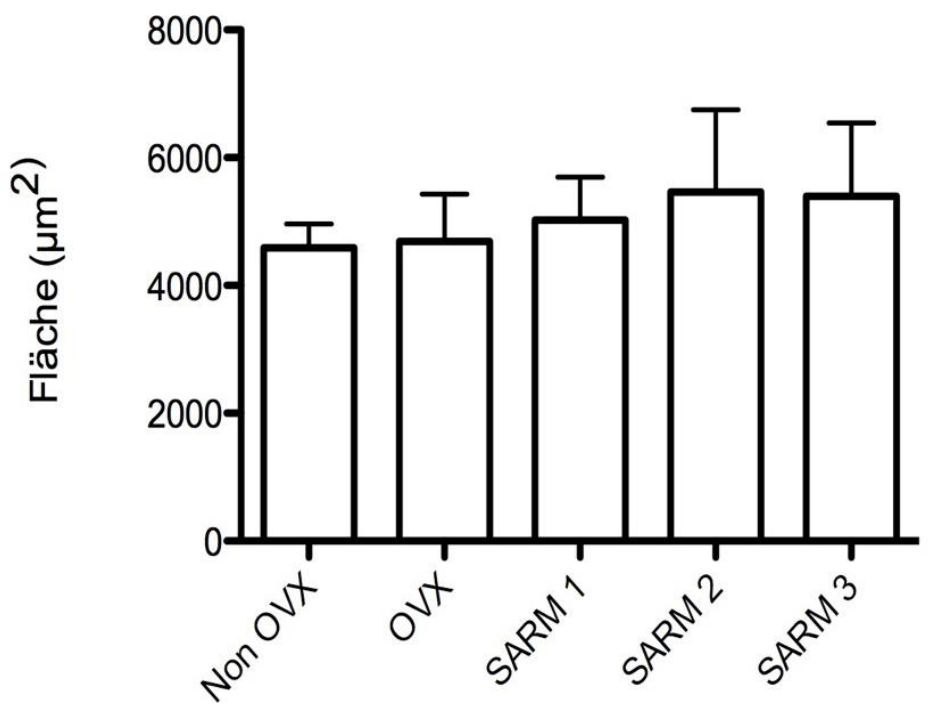

Abbildung 21: Zellfläche der glykolytischen Zellen in der ATPase-Färbung des M. Gastrocnemius im Gruppenmittelwert.

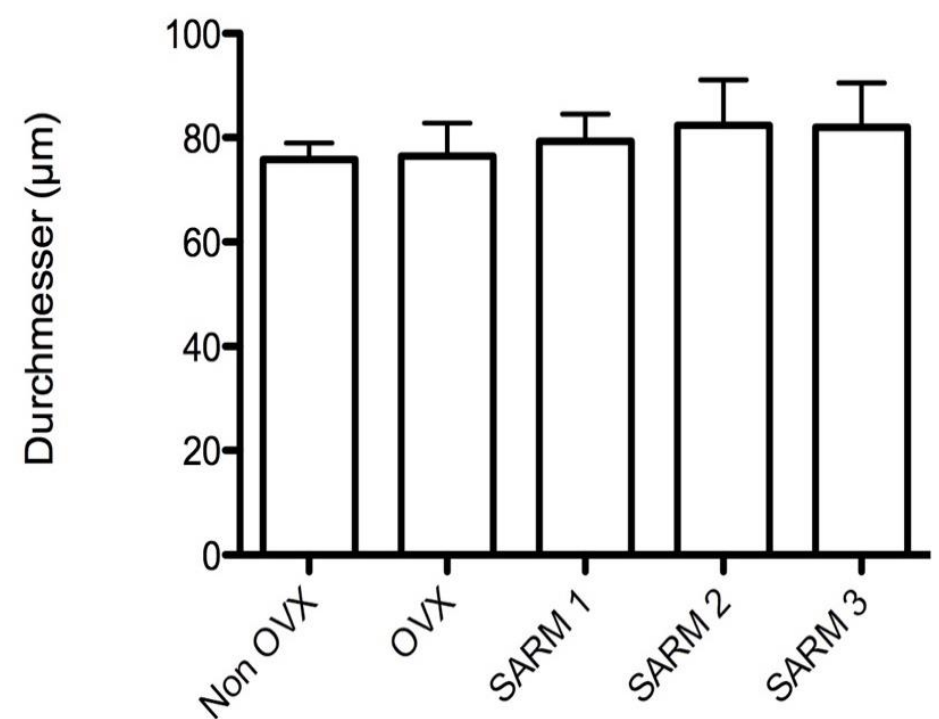

Abbildung 22: Zelldurchmesser der glykolytischen Zellen in der ATPase-Färbung des M. Gastrocnemius im Gruppenmittelwert. 
Tabelle 16: Zellfläche und Zelldurchmesser der glykolytischen Zellen in der ATPaseFärbung beim M. Gastrocnemius (als Gruppenmittelwerte).

\begin{tabular}{|l|l|l|l|l|l|l|}
\hline & & Non OVX & OVX & SARM 1 & SARM 2 & SARM 3 \\
\hline Fläche $\left(\mu \mathrm{m}^{2}\right)$ & $\mathrm{M}$ & 4587,0 & 4692,0 & 5026,0 & 5464,0 & 5398,0 \\
\hline & $\pm \mathrm{SD}$ & 376,4 & 735,2 & 672,3 & 1284,0 & 1147,0 \\
\hline $\begin{array}{l}\text { Durchmesser } \\
(\mu \mathrm{m})\end{array}$ & $\mathrm{M}$ & 75,82 & 76,43 & 79,27 & 82,34 & 81,93 \\
\hline & $\pm \mathrm{SD}$ & 3,18 & 6,34 & 5,31 & 8,77 & 8,65 \\
\hline
\end{tabular}

Es ergaben sich ebenfalls keine signifikanten Unterschiede im Gruppenvergleich des M. Gastrocnemius zwischen den Flächengrößen (Abbildung 23) oder äquivalenten Durchmesser (Abbildung 24) der nicht glykolytischen Zellen im Querschnitt (Tabelle 17).

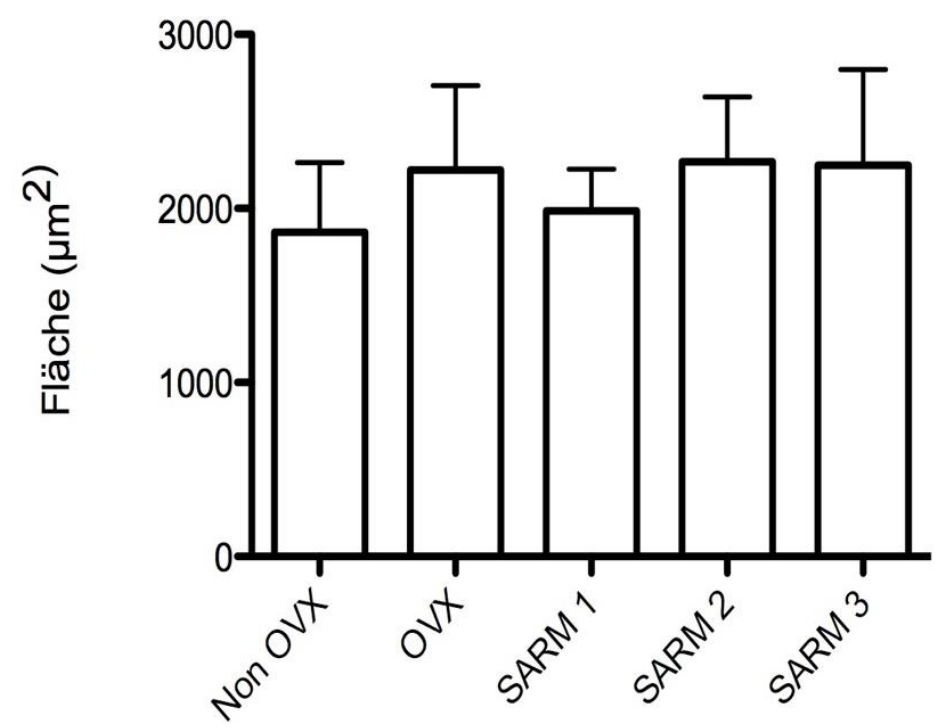

Abbildung 23: Zellfläche der nicht glykolytischen Zellen in der ATPase-Färbung des M. Gastrocnemius im Gruppenmittelwert. 


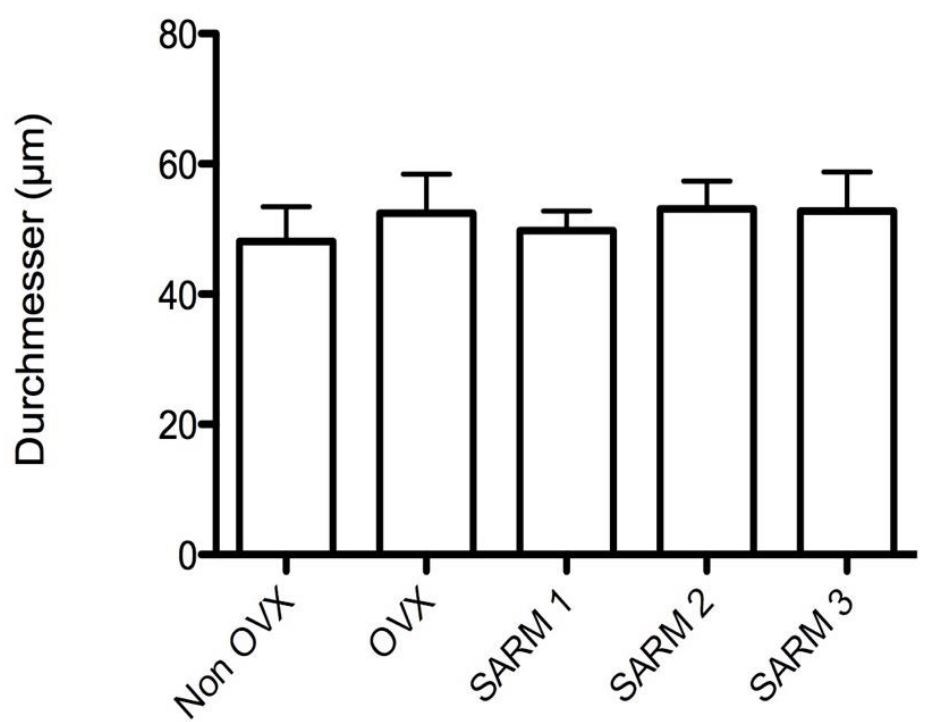

Abbildung 24: Zelldurchmesser der nicht glykolytischen Zellen in der ATPase-Färbung des M. Gastrocnemius im Gruppenmittelwert.

Tabelle 17: Zellfläche und Zelldurchmesser der nicht glykolytischen Zellen in der ATPase-Färbung beim M. Gastrocnemius (im Gruppenmittelwert).

\begin{tabular}{|l|l|l|l|l|l|l|}
\hline & & Non OVX & OVX & SARM 1 & SARM 2 & SARM 3 \\
\hline Fläche $\left(\mu \mathrm{m}^{2}\right)$ & $\mathrm{M}$ & 1863,0 & 2222,0 & 1986,0 & 2269,0 & 2248,0 \\
\hline & $\pm \mathrm{SD}$ & 400,7 & 483,4 & 240,7 & 371,3 & 551,2 \\
\hline $\begin{array}{l}\text { Durchmesser } \\
(\mu \mathrm{m})\end{array}$ & $\mathrm{M}$ & 48,04 & 52,42 & 49,78 & 53,07 & 52,74 \\
\hline & $\pm \mathrm{SD}$ & 5,30 & 5,99 & 3,02 & 4,28 & 6,00 \\
\hline
\end{tabular}




\subsubsection{Ergebnisse der ATPase-Färbung des M. Longissimus}

Beim M. Longissimus zeigte sich ebenfalls eine Tendenz zur Größenzunahme der Fläche (Abbildung 25) und des äquivalenten Durchmessers (Abbildung 26) der glykolytischen Zellen unter den Bedingungen SARM 1, SARM 2 und SARM 3, im Vergleich zu Non OVX und OVX, jedoch keine statistisch signifikanten Unterschiede (Tabelle 18).

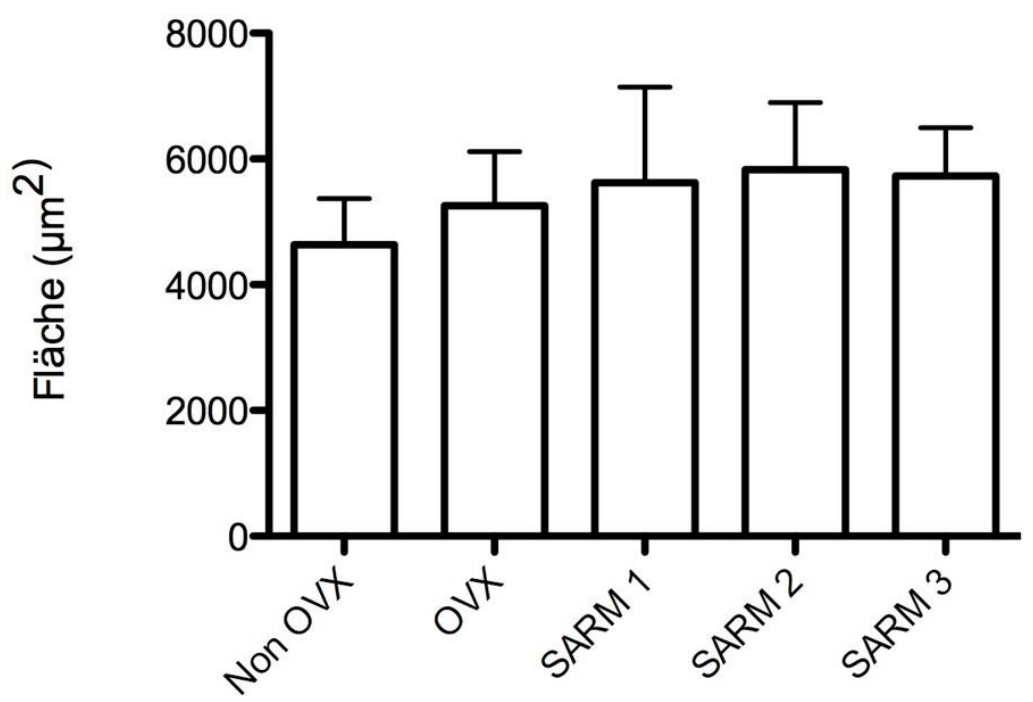

Abbildung 25: Zellfläche der glykolytischen Zellen in der ATPase-Färbung des M. Longissimus im Gruppenmittelwert.

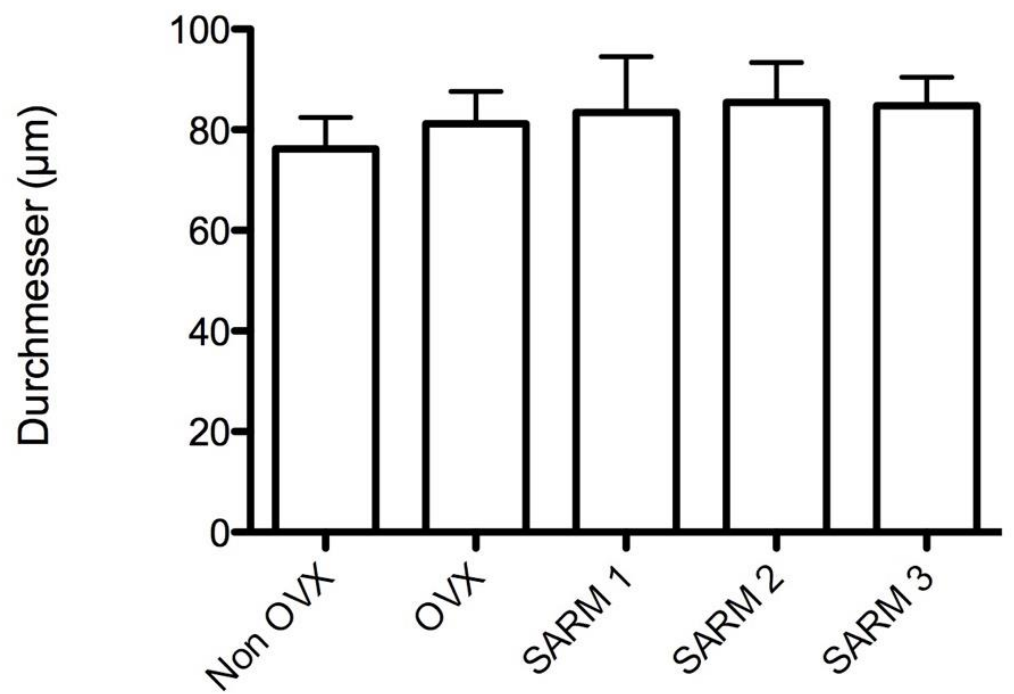

Abbildung 26: Zelldurchmesser der glykolytischen Zellen in der ATPase-Färbung des M. Longissimus im Gruppenmittelwert. 
Tabelle 18: Zellfläche und Zelldurchmesser der glykolytischen Zellen in der ATPaseFärbung beim M. Longissimus (im Gruppenmittelwert).

\begin{tabular}{|l|l|l|l|l|l|l|}
\hline & & $\begin{array}{l}\text { Non } \\
\text { OVX }\end{array}$ & OVX & SARM 1 & SARM 2 & $\begin{array}{l}\text { SARM } \\
\mathbf{3}\end{array}$ \\
\hline Fläche $\left(\mu \mathrm{m}^{2}\right)$ & $\mathrm{M}$ & 4634,0 & 5259,0 & 5625,0 & 5831,0 & 5731,0 \\
\hline & $\pm \mathrm{SD}$ & 734,3 & 858,5 & 1519,0 & 1066,0 & 768,7 \\
\hline $\begin{array}{l}\text { Durchmesser } \\
(\mu \mathrm{m})\end{array}$ & $\mathrm{M}$ & 76,19 & 81,21 & 83,43 & 85,45 & 84,79 \\
\hline & $\pm \mathrm{SD}$ & 6,25 & 6,44 & 11,10 & 7,97 & 5,70 \\
\hline
\end{tabular}

Beim M. Longissimus ergaben sich im Gruppenvergleich keine signifikanten Unterschiede zwischen den Größen der Flächen (Abbildung 27) oder äquivalenten Durchmesser (Abbildung 28) der nicht glykolytischen Zellen im Querschnitt (Tabelle 19).

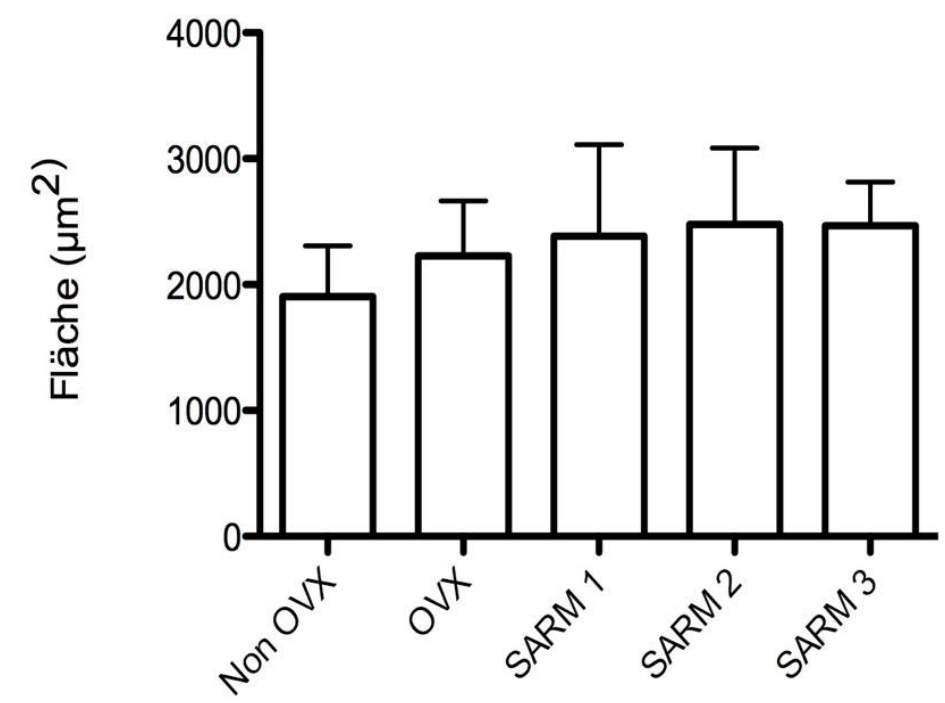

Abbildung 27: Zellfläche der nicht glykolytischen Zellen in der ATPase-Färbung des M. Longissimus im Gruppenmittelwert. 


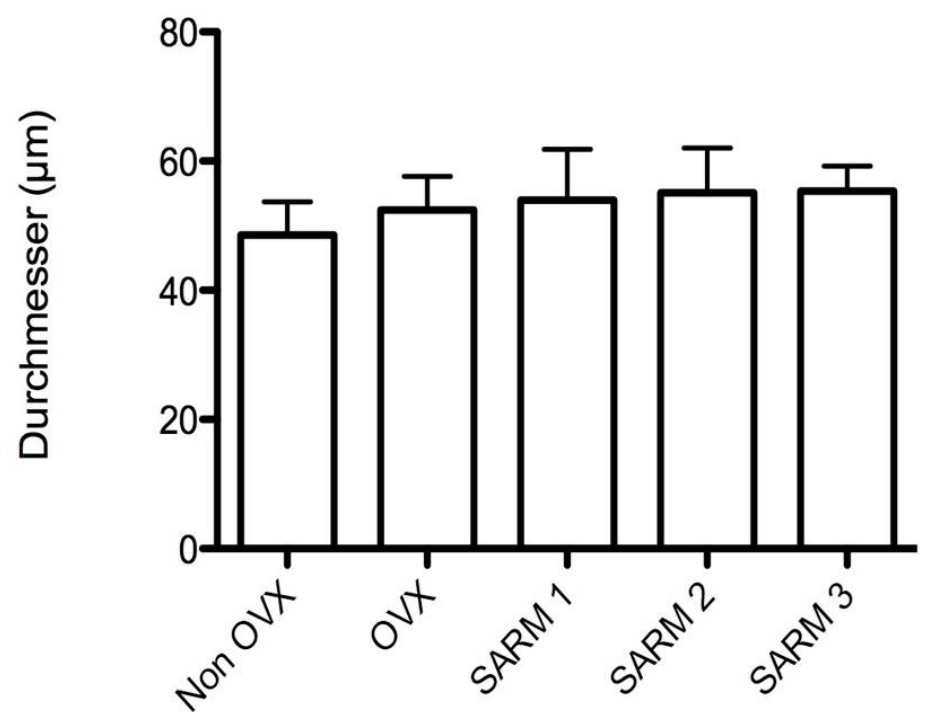

Abbildung 28: Zelldurchmesser der nicht glykolytischen Zellen in der ATPase-Färbung des M. Longissimus im Gruppenmittelwert.

Tabelle 19: Zellfläche und Zelldurchmesser der nicht glykolytischen Zellen in der ATPase-Färbung beim M. Longissimus (im Gruppenmittelwert).

\begin{tabular}{|l|l|l|l|l|l|l|}
\hline & & Non OVX & OVX & SARM 1 & SARM 2 & SARM 3 \\
\hline Fläche $\left(\mu \mathrm{m}^{2}\right)$ & M & 1905,0 & 2227,0 & 2385,0 & 2477,0 & 2470,0 \\
\hline & \pm SD & 404,0 & 437,4 & 725,9 & 608,8 & 345,1 \\
\hline $\begin{array}{l}\text { Durchmesser } \\
(\mu \mathrm{m})\end{array}$ & $\mathrm{M}$ & 48,57 & 52,44 & 53,95 & 55,08 & 55,38 \\
\hline & $\pm \mathrm{SD}$ & 5,11 & 5,22 & 7,90 & 6,94 & 3,87 \\
\hline
\end{tabular}

Im Vergleich der Gruppen beim M. Longissimus ergaben sich keine signifikanten Unterschiede im Verhältnis von glykolytischen zu nicht glykolytischen Zelle pro Fläche $\left(1 \mu \mathrm{m}^{2}\right.$ ) (Abbildung 29, Tabelle 20). 


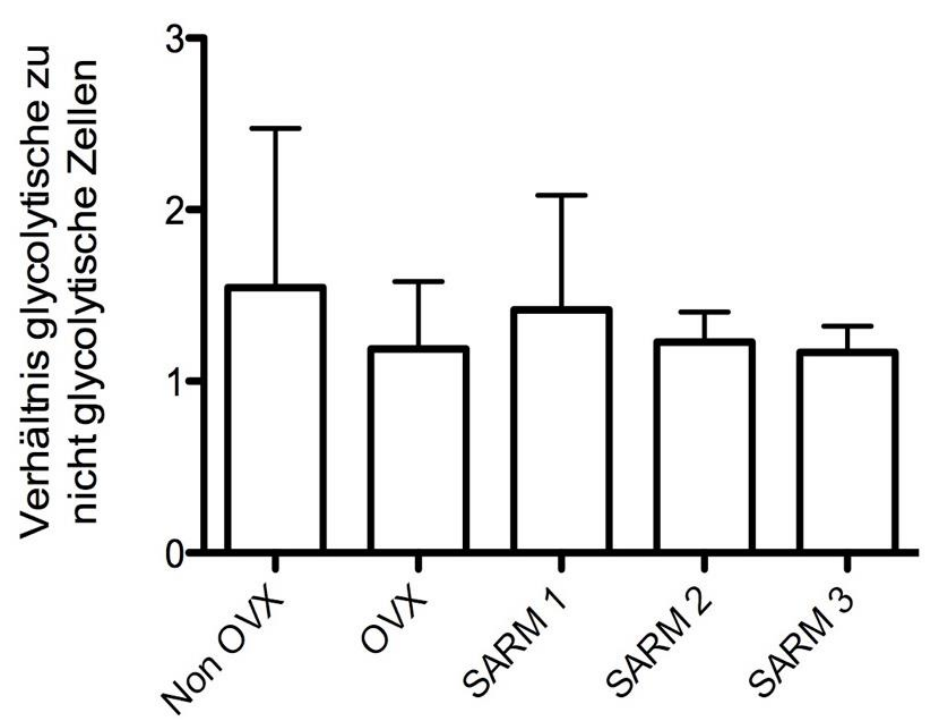

Abbildung 29: Verhältnis von glykolytischen zu nicht glykolytischen Zellen in der ATPase-Färbung des M. Longissimus im Gruppenmittelwert.

Tabelle 20: Verhältnis von glykolytischen zu nicht glykolytischen Zellen in der ATPaseFärbung beim M. Longissimus (im Gruppenmittelwert).

\begin{tabular}{|l|l|l|l|l|l|}
\hline & Non OVX & OVX & SARM 1 & SARM 2 & SARM 3 \\
\hline M & 1,55 & 1,19 & 1,42 & 1,23 & 1,17 \\
\hline \pm SD & 0,93 & 0,40 & 0,67 & 0,18 & 0,15 \\
\hline
\end{tabular}




\subsubsection{Ergebnisse der ATPase-Färbung des M. Soleus}

Beim M. Soleus ergaben sich im Gruppenvergleich keine signifikanten Unterschiede bezüglich der Flächengröße (Abbildung 30) oder des äquivalenten Durchmessers (Abbildung 31) der glykolytischen Zellen im Querschnitt (Tabelle 21).

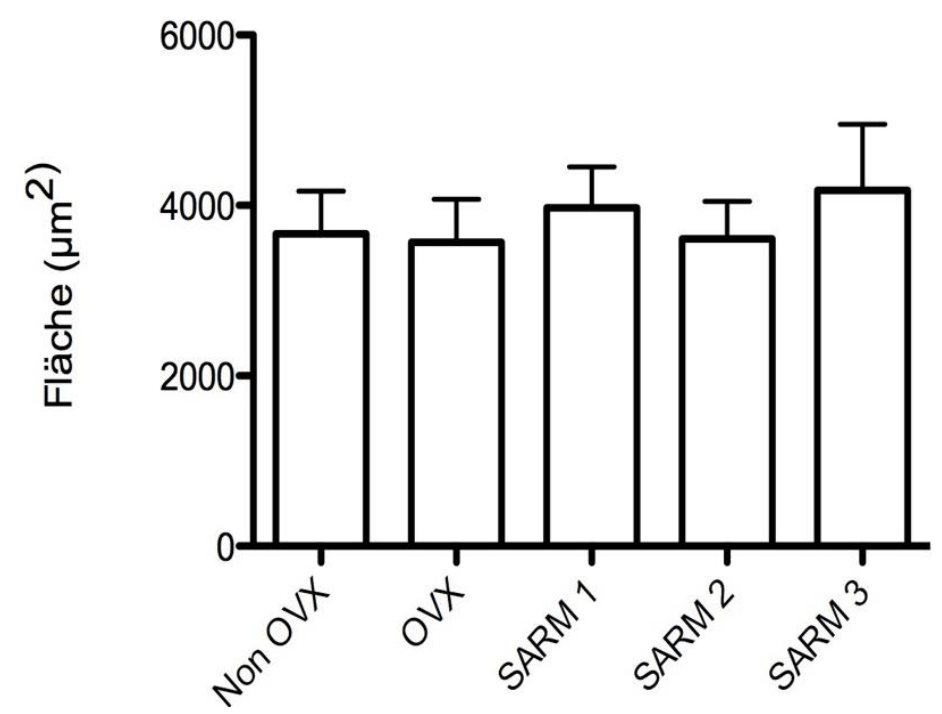

Abbildung 30: Zellfläche der glykolytischen Zellen in der ATPase-Färbung des M. Soleus im Gruppenmittelwert.

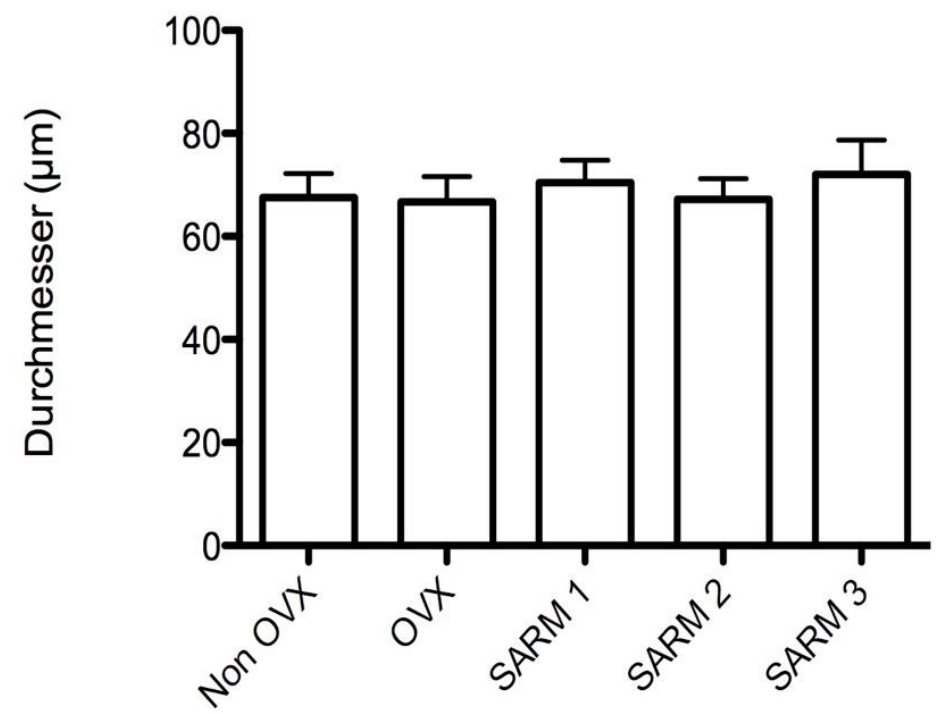

Abbildung 31: Zelldurchmesser der glykolytischen Zellen in der ATPase-Färbung des M. Soleus im Gruppenmittelwert. 
Tabelle 21: Zellfläche und Zelldurchmesser der glykolytischen Zellen in der ATPaseFärbung beim M. Soleus (im Gruppenmittelwert).

\begin{tabular}{|l|l|l|l|l|l|l|}
\hline & & Non OVX & OVX & SARM 1 & SARM 2 & $\begin{array}{l}\text { SARM } \\
\mathbf{3}\end{array}$ \\
\hline Fläche $\left(\mu \mathrm{m}^{2}\right)$ & $\mathrm{M}$ & 3666,0 & 3568,0 & 3973,0 & 3609,0 & 4176,0 \\
\hline & $\pm \mathrm{SD}$ & 501,2 & 506,0 & 478,5 & 438,4 & 779,0 \\
\hline $\begin{array}{l}\text { Durchmesser } \\
(\mu \mathrm{m})\end{array}$ & $\mathrm{M}$ & 67,57 & 66,74 & 70,44 & 67,23 & 72,05 \\
\hline & $\pm \mathrm{SD}$ & 4,66 & 4,85 & 4,37 & 4,01 & 6,66 \\
\hline
\end{tabular}




\subsection{Ergebnisse der Enzymaktivitätsbestimmung}

\subsubsection{Ergebnisse der Enzymaktivitätsbestimmung der Citrat-Synthase}

Im Falle des M. Gastrocnemius ergab sich für die Citrat-Synthase eine Tendenz zur Aktivitätssteigerung der Bedingungen SARM 1, SARM 2 sowie SARM 3 im Vergleich zu Non OVX und OVX. Es ergaben sich jedoch keine signifikanten Unterschiede in der Enzymaktivität zwischen den einzelnen Gruppen (Abbildung 32, Tabelle 22).

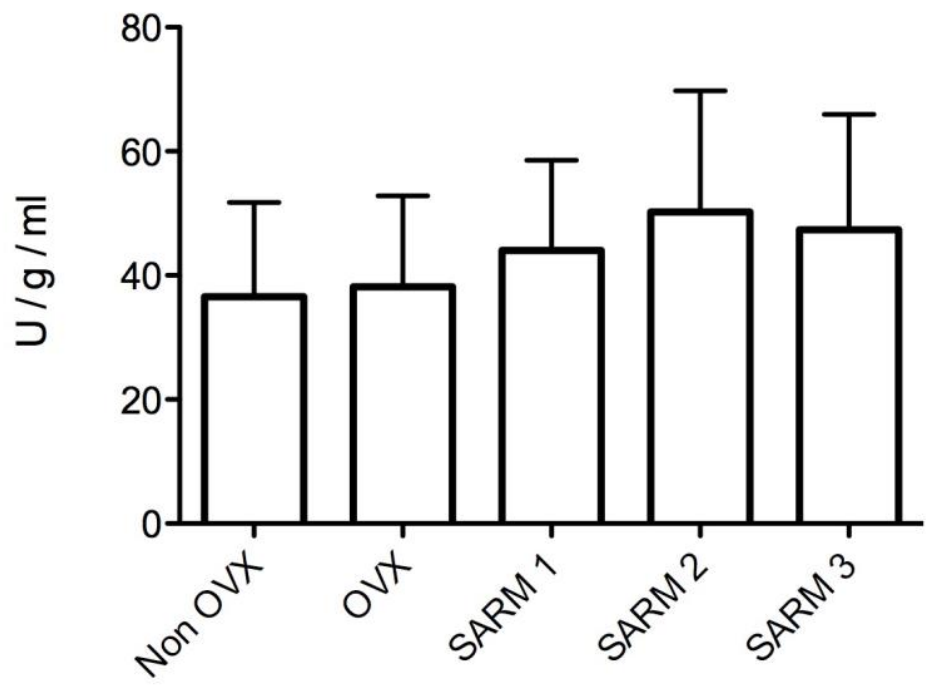

Abbildung 32: Enzymaktivität der Citrat-Synthase des M. Gastrocnemius.

Im Gruppenvergleich beim M. Longissimus zeigte sich ein signifikanter Unterschied der Enzymaktivität zwischen den Gruppen SARM 3 und Non OVX ( $\mathrm{p}<0,05)$. Zwischen den anderen Gruppen fanden sich keine signifikanten Unterschiede (Abbildung 33, Tabelle 22). 


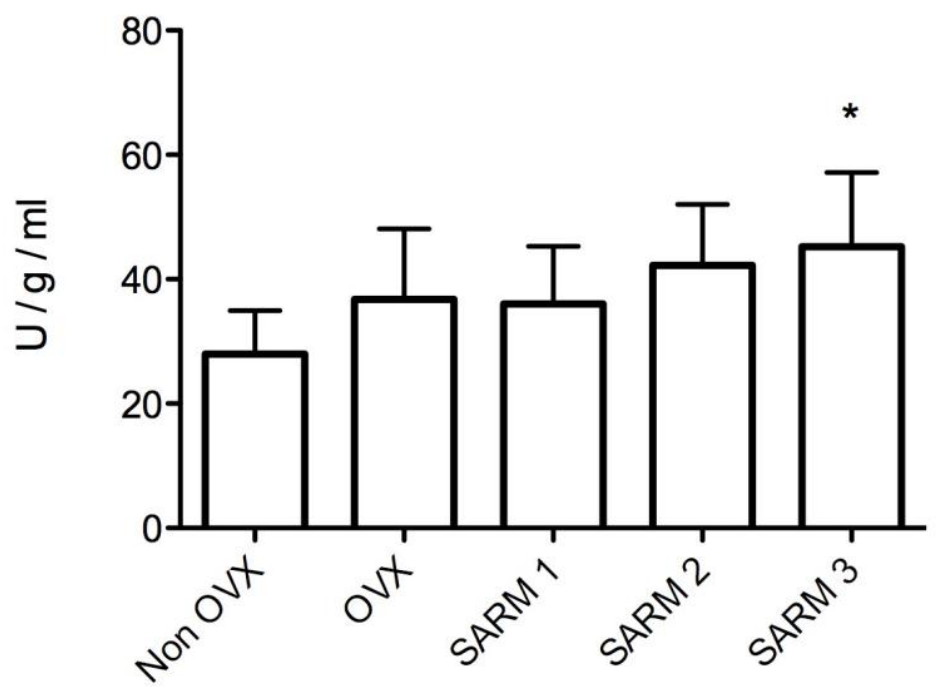

Abbildung 33: Enzymaktivität der Citrat-Synthase des M. Longissimus (*vs. Non OVX, $\mathrm{p}<0,05$, Tukey-Test).

Bei der Citrat-Synthase des M. Soleus ergaben sich keine signifikanten Gruppenunterschiede in der Enzymaktivität (Abbildung 34, Tabelle 22). Es zeigte sich eine Tendenz zur Aktivitätszunahme der Gruppen SARM 1, SARM 2 und SARM 3 im Vergleich zu Non OVX und OVX.

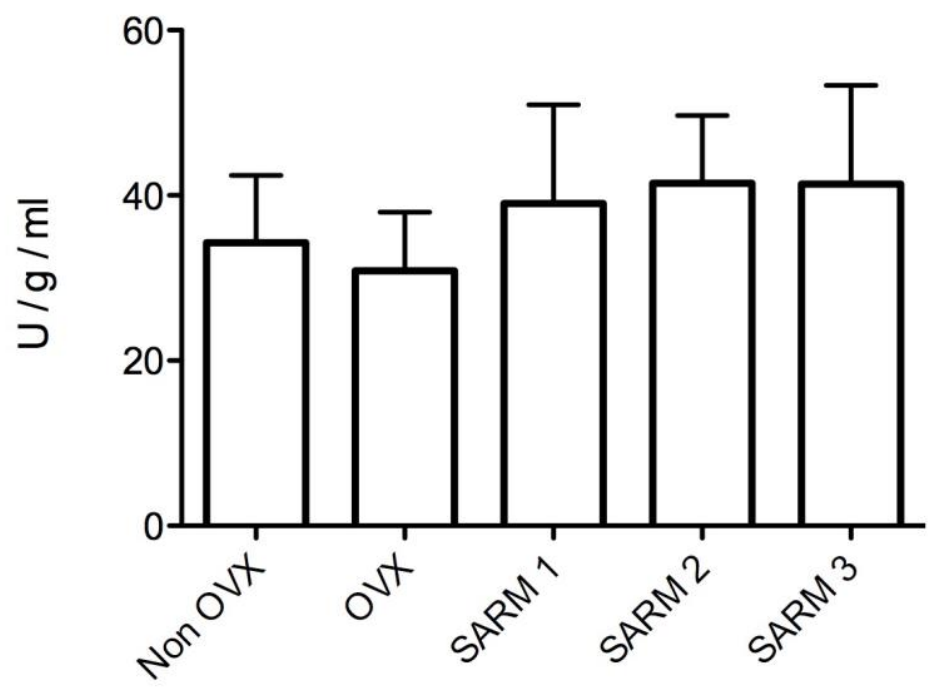

Abbildung 34: Enzymaktivität der Citrat-Synthase des M. Soleus. 
Tabelle 22: Enzymaktivität der Citrat-Synthase des M. Gastrocnemius, M. Longissimus und M. Soleus (U/ mg / ml).

\begin{tabular}{|l|l|l|l|l|l|l|}
\hline & & Non OVX & OVX & SARM 1 & SARM 2 & SARM 3 \\
\hline M. Gastrocnemius & $\mathrm{M}$ & 36,54 & 38,19 & 44,01 & 50,25 & 47,34 \\
\hline & $\pm \mathrm{SD}$ & 15,22 & 14,61 & 14,58 & 19,54 & 18,65 \\
\hline M. Longissimus & $\mathrm{M}$ & 27,96 & 36,77 & 36,01 & 42,25 & 45,22 \\
\hline & $\pm \mathrm{SD}$ & 7,01 & 11,34 & 9,29 & 9,78 & 11,95 \\
\hline M. Soleus & $\mathrm{M}$ & 34,29 & 30,90 & 39,04 & 41,45 & 41,39 \\
\hline & $\pm \mathrm{SD}$ & 8,16 & 7,06 & 11,93 & 8,22 & 11,94 \\
\hline
\end{tabular}

\subsubsection{Ergebnisse der Enzymaktivitätsbestimmung der Laktatdehydrogenase}

Im Vergleich der einzelnen Gruppen in Bezug auf den M. Gastrocnemius ergaben sich keine signifikanten Unterschiede in der Enzymaktivität (Abbildung 35, Tabelle 23).

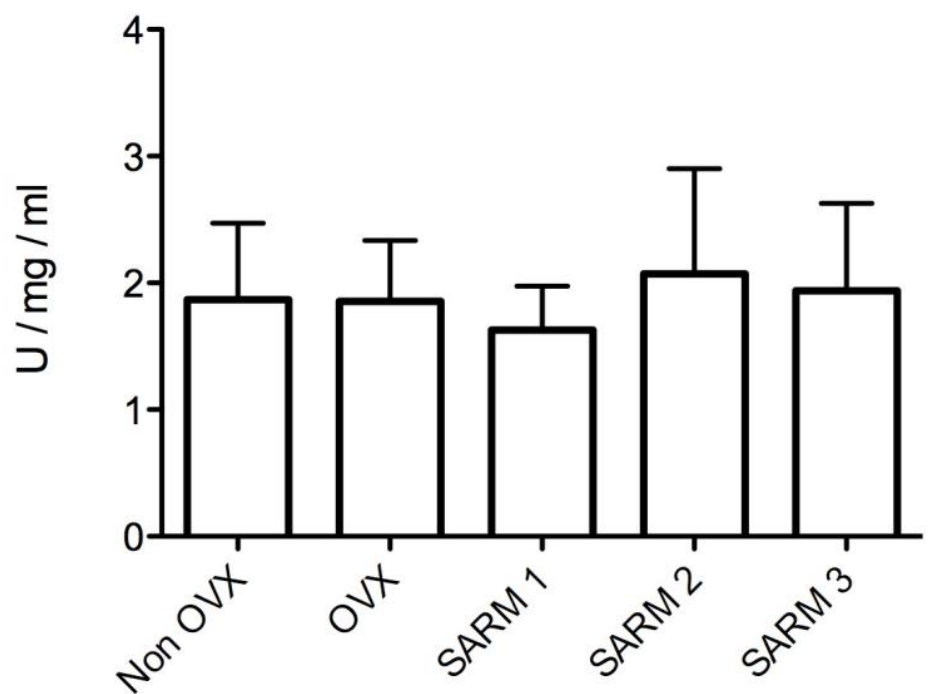

Abbildung 35: Enzymaktivität der Laktatdehydrogenase des M. Gastrocnemius. 
Im Gruppenvergleich des M. Longissimus ergab sich keine signifikanten Unterschiede im Bezug auf die Laktatdehydrogenaseaktivität (Abbildung 36, Tabelle 23).

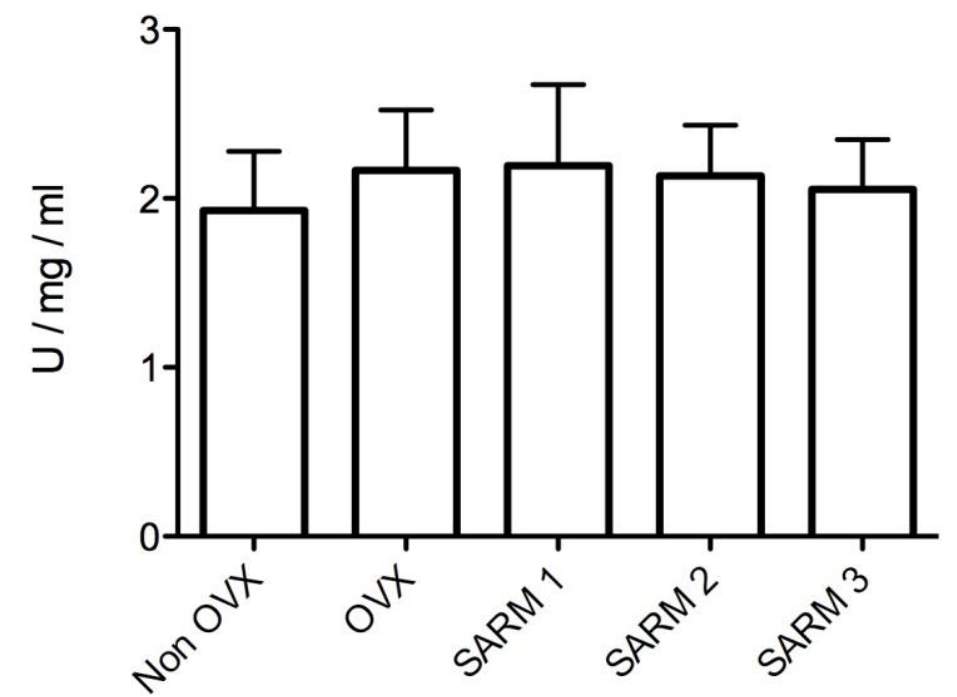

Abbildung 36: Enzymaktivität der Laktatdehydrogenase des M. Longissimus.

Im Falle des M. Soleus fanden sich ebenso keine signifikanten Gruppenunterschiede in der Enzymaktivität der Laktatdehydrogenase (Abbildung 37, Tabelle 23)

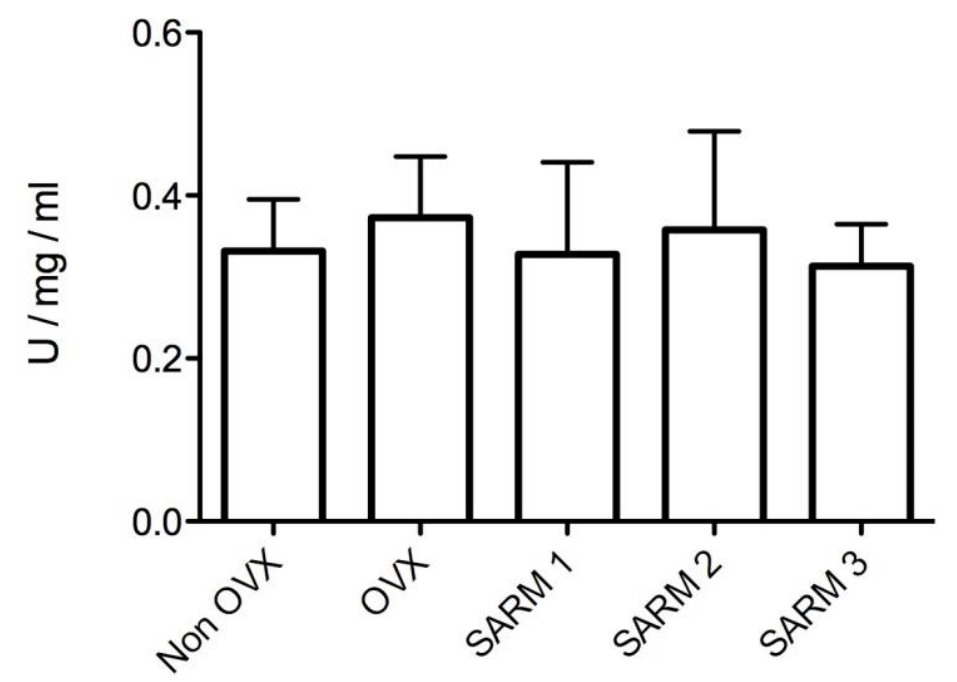

Abbildung 37: Enzymaktivität der Laktatdehydrogenase des M. Soleus. 
Tabelle 23: Enzymaktivität der Laktatdehydrogenase des M. Gastrocnemius, M. Longissimus und M. Soleus (U/g/ ml).

\begin{tabular}{|l|l|l|l|l|l|l|}
\hline & & Non OVX & OVX & SARM 1 & SARM 2 & SARM 3 \\
\hline M. Gastrocnemius & $\mathrm{M}$ & 1,87 & 1,86 & 1,63 & 2,07 & 1,94 \\
\hline & $\pm \mathrm{SD}$ & 0,61 & 0,48 & 0,35 & 0,83 & 0,69 \\
\hline M. Longissimus & $\mathrm{M}$ & 1,93 & 2,17 & 2,19 & 2,13 & 2,06 \\
\hline & $\pm \mathrm{SD}$ & 0,35 & 0,36 & 0,48 & 0,30 & 0,30 \\
\hline M. Soleus & $\mathrm{M}$ & 0,33 & 0,37 & 0,33 & 0,36 & 0,31 \\
\hline & $\pm \mathrm{SD}$ & 0,06 & 0,08 & 0,11 & 0,12 & 0,05 \\
\hline
\end{tabular}

\subsubsection{Ergebnisse der Enzymaktivitätsbestimmung des Komplex-1}

Im Vergleich der Gruppen beim M. Gastrocnemius ergaben sich keine signifikanten Unterschiede zwischen den Gruppen bezüglich der Komplex-1-Enzymaktivität (Abbildung 38, Tabelle 24)

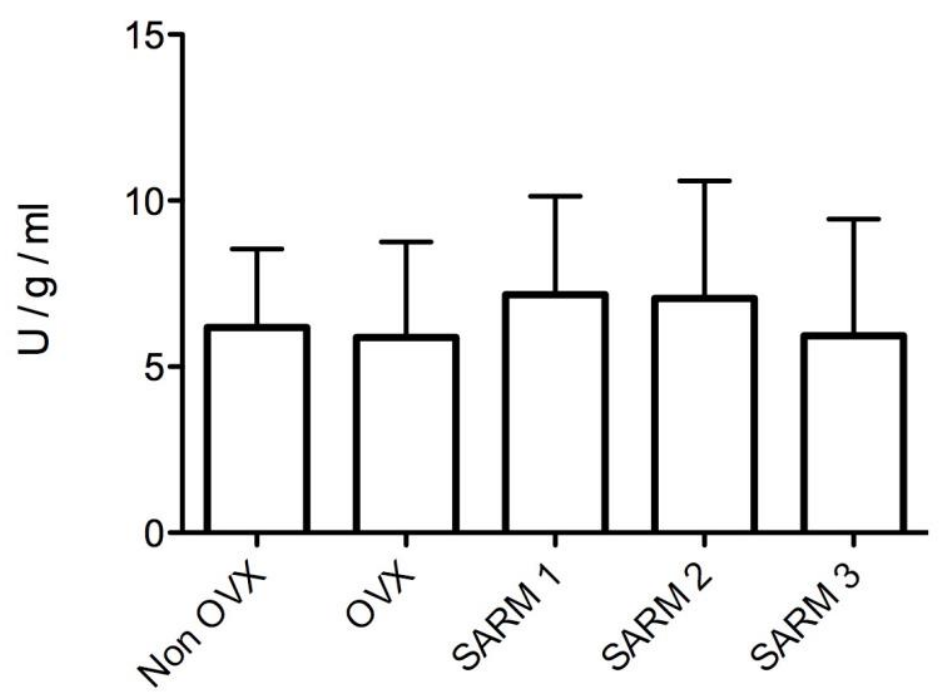

Abbildung 38: Enzymaktivität des Komplex-1 im M. Gastrocnemius. 
In der Auswertung des M. Longissimus ergaben sich keine signifikanten Gruppenunterschiede in der Komplex-1-Enzymaktivität (Abbildung 39, Tabelle 24).

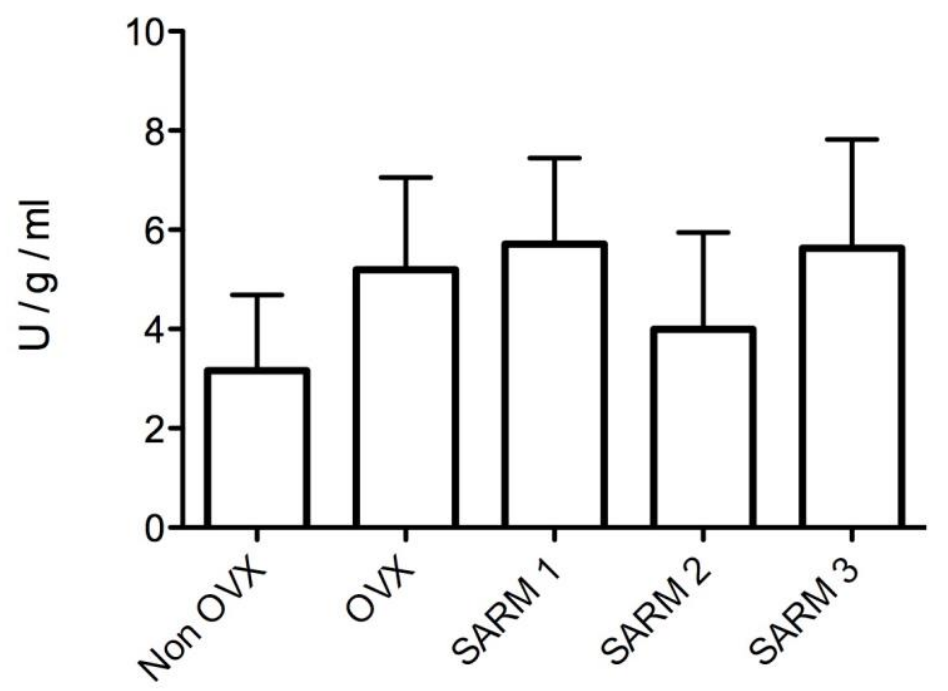

Abbildung 39: Enzymaktivität des Komplex-1 im M. Longissimus.

Im Gruppenvergleich des M. Soleus ergaben sich bezogen auf die Komplex-1Enzymaktivität keine signifikanten Unterschiede (Abbildung 40, Tabelle 24).

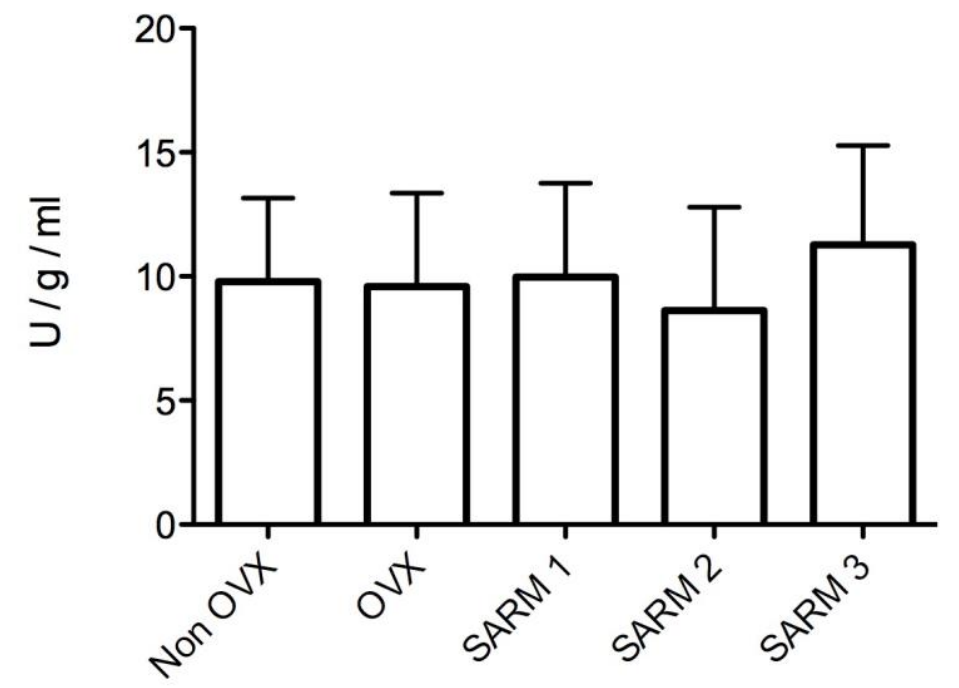

Abbildung 40: Enzymaktivität des Komplex-1 im M. Soleus. 
Tabelle 24: Enzymaktivität von Komplex-1 des M. Gastrocnemius, M. Longissimus und M. Soleus (U/g/ml).

\begin{tabular}{|l|l|l|l|l|l|l|}
\hline & & $\begin{array}{l}\text { Non } \\
\text { OVX }\end{array}$ & OVX & $\begin{array}{l}\text { SARM } \\
\mathbf{1}\end{array}$ & SARM 2 & SARM 3 \\
\hline M. Gastrocnemius & $\mathrm{M}$ & 6,16 & 5,88 & 7,17 & 7,05 & 5,94 \\
\hline & $\pm \mathrm{SD}$ & 2,36 & 2,88 & 2,96 & 3,54 & 3,51 \\
\hline M. Longissimus & $\mathrm{M}$ & 3,17 & 5,20 & 5,72 & 4,00 & 5,63 \\
\hline & $\pm \mathrm{SD}$ & 1,52 & 1,86 & 1,73 & 1,95 & 2,19 \\
\hline M. Soleus & $\mathrm{M}$ & 9,80 & 9,59 & 9,97 & 8,63 & 11,28 \\
\hline & $\pm \mathrm{SD}$ & 3,36 & 3,77 & 3,78 & 4,15 & 3,99 \\
\hline
\end{tabular}

\subsection{Ergebnisse der Serum-Untersuchung}

\subsubsection{Ergebnisse der Serum-Kreatinkinase}

Im Vergleich zeigten sich keine signifikanten Unterschiede zwischen den einzelnen Gruppen (Abbildung 41, Tabelle 25).

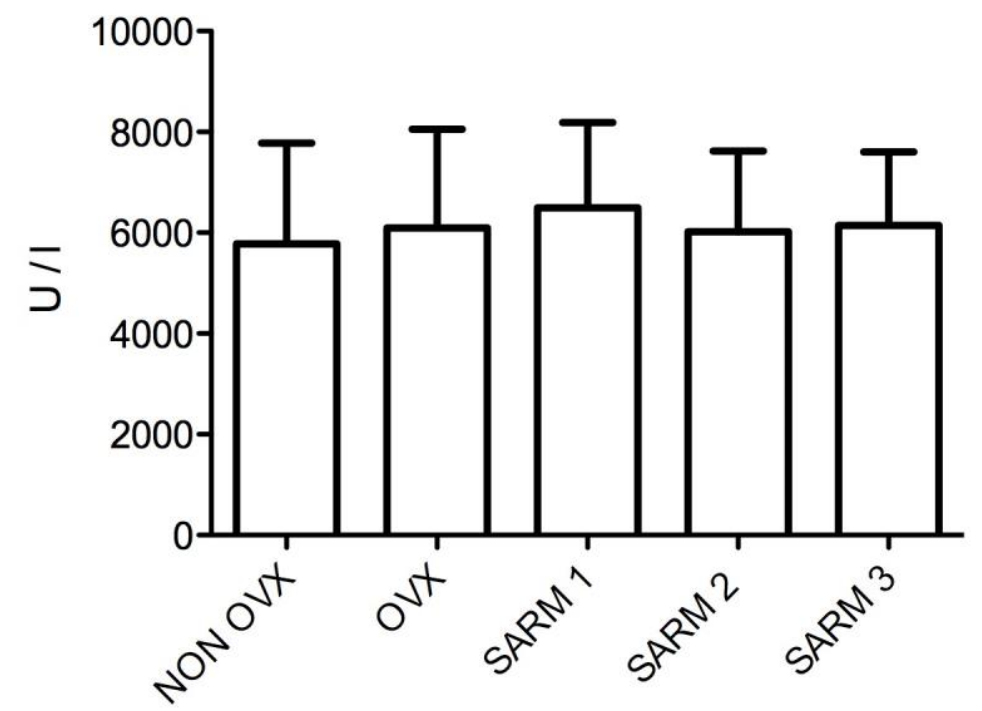

Abbildung 41: Kreatinkinase (CK) aus dem Serum. 


\subsubsection{Ergebnisse des Serum-Magnesiums}

Im Vergleich zeigten sich keine signifikanten Unterschiede zwischen den einzelnen Gruppen (Abbildung 42, Tabelle 25).

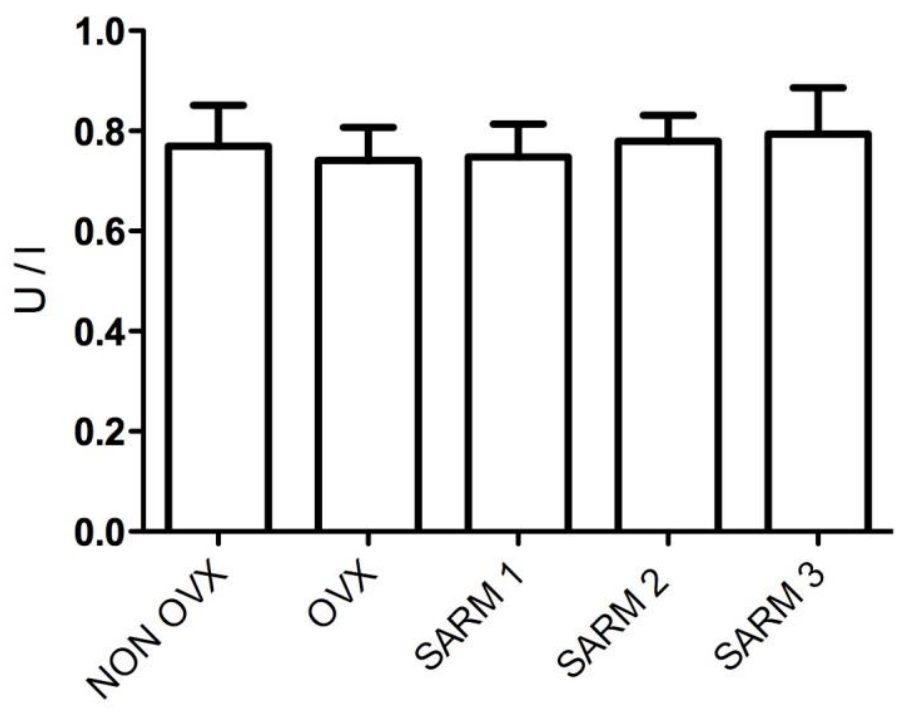

Abbildung 42: Magnesium $\left(\mathrm{Mg}^{2+}\right)$ aus dem Serum.

\subsubsection{Ergebnisse des Serum-Kalziums}

Im Vergleich zeigten sich keine signifikanten Unterschiede zwischen den einzelnen Gruppen (Abbildung 43, Tabelle 25).

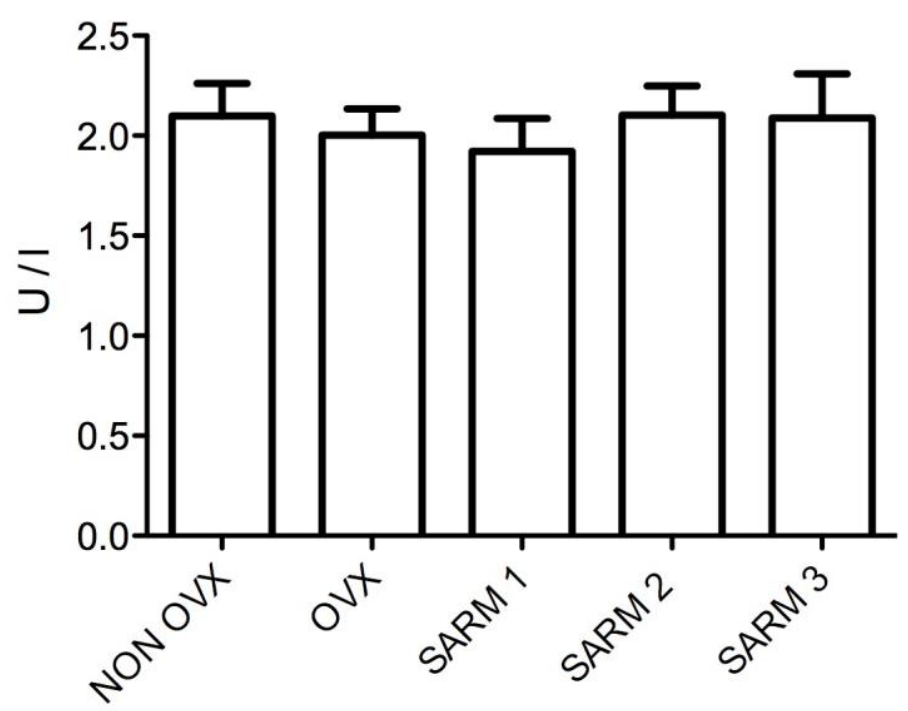

Abbildung 43: Kalzium $\left(\mathrm{Ca}^{2+}\right)$ aus dem Serum. 
Tabelle 25: Kreatinkinase (CK), Magnesium $\left(\mathrm{Mg}^{2+}\right)$ und Kalzium $\left(\mathrm{Ca}^{2+}\right)$ im Serum.

\begin{tabular}{|l|l|l|l|l|l|l|}
\hline & & Non OVX & OVX & SARM 1 & SARM 2 & SARM 3 \\
\hline $\mathrm{CK}(\mathrm{U} / \mathrm{l})$ & $\mathrm{M}$ & 5776 & 6097 & 6492 & 6019 & 6146 \\
\hline & $\pm \mathrm{SD}$ & 2001 & 1961 & 1691 & 1600 & 1456 \\
\hline $\mathrm{Mg}^{2+}(\mathrm{mmol} / \mathrm{l})$ & $\mathrm{M}$ & 0,77 & 0,74 & 0,75 & 0,78 & 0,79 \\
\hline & $\pm \mathrm{SD}$ & 0,08 & 0,07 & 0,07 & 0,05 & 0,09 \\
\hline $\mathrm{Ca}^{2+}(\mathrm{mmol} / \mathrm{l})$ & $\mathrm{M}$ & 2,10 & 2,00 & 1,92 & 2,10 & 2,10 \\
\hline & $\pm \mathrm{SD}$ & 0,16 & 0,13 & 0,17 & 0,15 & 0,22 \\
\hline
\end{tabular}




\subsection{Zusammenfassung der signifikanten Ergebnisse}

Die signifikanten Ergebnisse mit einem $\mathrm{p}$ - Wert $<0,05$ aus allen durchgeführten histologischen und enzymatischen Analysen der Skelettmuskulatur und des Serums, sowie der Gewichtsmessungen der Muskulatur und Uteri lassen sich in tabellarischer Form zusammenfassen (Tabelle 26):

Tabelle 26: Zusammenfassung der signifikanten Ergebnisse.

\begin{tabular}{|c|c|c|c|c|c|}
\hline & Non OVX & OVX & SARM 1 & SARM 2 & SARM 3 \\
\hline Körpergewicht & & 介* & $\Uparrow *$ & $\Uparrow *$ & $\Uparrow *$ \\
\hline Gewicht Uterus & & $\Downarrow *$ & $\Downarrow *$ & $\Uparrow * \#^{\circ}$ & $\Uparrow * \#^{\circ}$ \\
\hline Gewicht M. Gastrocn. & & & $\Uparrow *$ & $\Uparrow *$ & $\Uparrow *$ \\
\hline Kapillaren/Zellen & & & & & \\
\hline M. Gastrocnemius & & & 介*\# & $\Uparrow *$ & 介*\# \\
\hline Kapillaren/Zellen & & & & & \\
\hline M. Longissimus & & & & 介*\# & 介*\# \\
\hline Enzymaktivität (CS) & & & & & \\
\hline M. Longissimus & & & & & 介* \\
\hline
\end{tabular}

介: erhöhter Wert, mit signifikantem Unterschied $(\mathrm{p}<0,05), \downarrow$ : erniedrigter Wert mit signifikantem Unterschied ( $\mathrm{p}<0,05)$. *: vs. Non OVX, \#: vs. OVX, ${ }^{\circ}$ : vs. SARM 1. 


\section{Diskussion}

Ziel dieser Arbeit war es die Wirkung von Enobosarm auf die quergestreifte Skelettmuskulatur am Krankheitsmodell für Osteoporose zur Prävention einer komorbide auftretenden Sarkopenie festzustellen. Die Zusammenschau der Ergebnisse zeigt eine dosisabhängige Wirkung von Enobosarm. Wir konnten zeigen, dass es unter Therapie mittels Enobosarm zu einer Muskelgewichtszunahme, beispielhaft gezeigt am M. Gastrocnemius, kommt. Des Weiteren fanden wir eine zunehmende Kapillarisierung unter Enobosarm Therapie, gezeigt am M. Gastrocnemius und M. Longissimus. Auch die Enzymaktivität der Citrat-Synthase zeigte sich in der höchsten von uns verabreichten Dosis gesteigert. Als Nebeneffekt ist eine Größen- und Gewichtszunahme der Uteri aufgefallen. Diese Effekte zeigten sich ausgeprägter mit zunehmender Wirkstoffdosis. Hinweise für eine sich entwickelnden Sarkopenie zeigen sich histologisch in unserem Modell nicht.

\subsection{Enobosarm}

Die initialen Bestrebungen der Firma GTx Inc. ${ }^{\circledR}$, eine Zulassung von Enobosarm zur Therapie einer Sarkopenie $\mathrm{zu}$ erhalten, wurden trotz gutem Wirkungs- und Nebenwirkungsprofil aufgrund der FDA geforderten Voraussetzungen aufgegeben (Garber und Arbor 2016). Derzeit laufende Studien konzentrieren sich auf den Einsatz bei Tumorkachexie, Stressharninkontinenz, Brustkrebs und Duchenne-Muskeldystrophie (Dalton et al. 2018). Hier verspricht man sich perspektivisch eine einfachere und schnellere Zulassung, da man v. a. bei onkologischen Patienten mit Tumorkachexie und Patienten mit Duchenne-Muskeldystrophie eine progredient abnehmende Muskelmasse und -kraft findet, sowie die kardiovaskulären Langzeitfolgen nicht so stark ins Gewicht bei der Zulassungsentscheidung fallen.

Die Messung mittels Stair-Climb Test zum Nachweis der signifikanten physischen Leistungssteigerung hat bisher $\mathrm{zu}$ keinen studienübergreifenden, signifikanten Ergebnissen geführt. Jede onkologische Erkrankung verläuft individuell und ist im weiteren Verlauf auch stark von begleitenden Komorbiditäten beeinflusst. Bei diesem Patientenkollektiv und den damit assoziierten Problemen kann es im Vergleich zu einer Patientengruppe mit isolierter Sarkopenie schwierig sein eine signifikante Leistungsverbesserung nachzuweisen. Der Stair-Climb Test ist jedoch ein seit langem etablierter Test zur Ermittlung der körperlichen Leistungsfähigkeit. Alternativ ist es 
möglich den 6-Minute-Walk-Test bei identischer Aussagefähigkeit ergänzend durchzuführen (Ahmad et al. 2015).

Diese Arbeit untersucht die Wirkung von Enobosarm auf die Muskulatur an einem Modellorganismus für Osteoporose. In den weiteren Arbeiten unserer Versuchsgruppe wird herausgestellt, ob Enobosarm ebenso anabol auf den Knochen und die Frakturheilung wirkt. Hier konnte in den ersten Ergebnissen eine Zunahme der Knochendichte und Knochenmineraldichte gezeigt werden (Hoffmann et al. 2018). Dieses ist aus dem Aspekt der optimalen Therapie bei Patienten mit einer kombiniert auftretenden Sarko-Osteoporose vielversprechend.

\subsection{Tiermodell}

Das Modell der ovarektomierten Ratte ist ein seit langem etablierter und der häufigste genutzte Modellorganismus zur Erforschung der postmenopausalen Osteoporose (Lelovas et al. 2008). Durch die Ovarektomie wird in den Versuchstieren eine Hormondefizienz induziert, welche mit der hormonellen Situation bei postmenopausalen Frauen vergleichbar ist. Als Resultat kommt es dann zu einem Verlust der Knochenmasse (Kalu 1991).

Diese krankheitstypischen Ausprägungen sollten in der Gruppe OVX, welche als erkrankte Kontrollgruppe diente, im Vergleich zu der gesunden Kontrollgruppe Non OVX am Knochen nachweisbar sein. In der histologischen Untersuchung der Muskeln zeigten sich zwischen diesen beiden Gruppen keine signifikanten Veränderungen. Es kam zu keinen Umbauprozessen, welche für eine Sarkopenie typisch wären.

Es ist vorstellbar, dass die Zeit nach Ovarektomie bis zum Beginn der Behandlung zur Entwicklung der typischen Veränderungen in diesem Versuchsaufbau zu kurz gewesen sein kann. Es ist auch denkbar, dass die Ratten mit einem Alter von drei Monaten noch zu jung für die Ausprägung einer Sarkopenie waren. In Versuchen mit dem primären Fokus auf die Therapie einer Sarkopenie werden bevorzugt gealterte Ratten als Modellorganismen genommen. Man könnte in einem weiteren Versuch ebenso Ratten im fortgeschrittenen Lebensalter verwenden. Andernfalls konnte gezeigt werden, dass Ratten der Gattung Fischer F344/NXBN mit einem Alter von 38 Monaten als Modell zur Sarkopenie durch die Ausbildung ähnlicher Veränderung der Muskelmasse und kontraktilen Eigenschaften als Modellorganismus gut geeignet sind (Rice et al. 2005). 
Fraglich ist jedoch wie gut ältere Versuchstiere die Strapazen der wiederholten Operationen überstehen, da dieses doch eine nicht unerhebliche Belastung darstellt.

Da in diesem Versuch die Wirkung von Enobosarm als prophylaktische Therapie zur Sarkopenie, ergänzend zu Effekten auf die Knochenstruktur und Frakturheilung bei Osteoporose untersucht werden sollte, sind die typischen Veränderungen der Muskulatur, welche im Alter auftreten, in diesem Versuchsaufbau keine zwingende Voraussetzung zum Nachweis der Therapieeffekte. Zur exakten Untersuchung der Effekte von Enobosarm bei Sarkopenie, komorbide auftretend zu einer Osteoporose, wäre beispielsweise eine Voraussetzung die histologische Ausprägung eines typischen Muskelschwundes. Hier muss dann bei dieser Fragestellung über einen angepassten Versuchsaufbau oder einen anderen Modellorganismus nachgedacht werden.

\subsection{Gewichte der Versuchstiere}

Nach Lieferung wurden die Versuchstiere zufällig den fünf Gruppen zugeteilt. Somit konnten gute Voraussetzungen für homogene und vergleichbare Gruppen über den Versuch geschaffen worden.

Es zeigte sich eine stetige Gewichtszunahme der Ratten mit einem ersten Gewichtsmaximum vor Osteotomie in der neunten Woche. Die Gruppe Non OVX zeigte bis zu diesem Zeitpunkt eine geringere Zunahme des Körpergewichtes. Nach Osteotomie nahmen alle Ratten an Körpergewicht ab. Dieser Gewichtsverlust lag bei ca. 7 \% (Non OVX) bzw. $9 \%$ (OVX, SARM 1, SARM 2, SARM 3) im Bezug zum ermittelten Gewicht vor Osteotomie.

Bei ovarektomierten Ratten kommt es im Vergleich zu nicht ovarektomierten Ratten zu einer vermehrten Zunahme des Körpergewichtes und einer gesteigerten Futteraufnahme (Omi und Ezawa 1995). Dieses zeigte sich auch in unserem Versuch. Ursachen sind u. a. die Zunahme des Körperwassers, Körperfettanteils und eine Größenzunahme der Organe nach Ovarektomie (McElroy und Wade 1987). Wiederum führt die Behandlung mit Östrogenen bei weiblichen und Testosteron bei männlichen Ratten zu einer gesteigerten Lipolyse und einer reduzierten Synthese von Fettsäuren (Hansen et al. 1980). Es zeigt sich parallel eine geringere Futteraufnahme, wobei auch ein reduziertes Körpergewicht beobachtet werden kann (Hervey und Hutchinson 1973, Wade und Zucker 1970). Dieses ist auch unter Therapie mit SARMs zu erwarten. 
Bei Therapie mit dem SARM S-4 über 120 Tage konnte im Rattenmodell eine Abnahme des Körpergewichtes und dosisabhängige Reduktion der Fettmasse gezeigt werden (Kearbey et al. 2007). Dieser Effekt ist auch unter Therapie mit Enobosarm denkbar, zeigte sich jedoch in unserem Versuch bei einer Therapiedauer von fünf Wochen nicht. Um die wahrscheinlich nährstoffbedingten Gewichtssteigerungen durch erhöhte Nährstoffzufuhr der OVX Gruppen zu reduzieren, kann man die tägliche Futteraufnahme der Versuchstiere kontrollieren (McCormick et al. 2004). Eine kontrollierte Futteraufnahme wurde in unserem Versuch nicht durchgeführt. Für weitere Versuche ist dieses Prozedere jedoch denkbar, um die futterbedingte Körpergewichtszunahme und Muskelvergrößerung zu kontrollieren. Dieses hätte weniger Einfluss auf Therapieeffekte und würde den Effekt der getesteten Medikation mittels Enobosarm klarer hervorheben.

Für den postoperativen Gewichtsverlust können unterschiedliche Ursachen diskutiert werden. Zum einen zeigt sich die Aktivität der Versuchstiere nach Osteotomie leicht reduziert (Komrakova et al. 2009), was in einer Atrophie der Muskulatur (Machida und Booth 2004) oder Knochenmasse (Everett und Gilligan 1991) resultieren kann. Ursachen dafür können die peri- und postoperative Medikation oder auch postinterventionelle Schmerzen sein. Trotz der Belastung durch die Osteotomie erholen sich die Versuchstiere beachtlich schnell, was einen großen Effekt durch Immobilität für unwahrscheinlich erscheinen lässt. Es zeigte sich parallel eine reduzierte Futteraufnahme (siehe Kapitel 4.3), was ebenso zu einer Gewichtsreduktion führen kann und hier als wichtigste Ursache für die postoperative Gewichtsabnahme diskutiert werden muss (Komrakova et al. 2009). In den folgenden fünf Wochen bis zum Versuchsende stabilisierte sich das Gewicht aller Versuchstiere wieder und erreichte gegen Ende das Niveau vor Osteotomie bzw. überstieg dieses.

\subsection{Nahrungsverhalten und Wirkstoffaufnahme}

Vor Osteotomie schwankte die tägliche Futteraufnahme der Gruppen OVX, SARM 1, SARM 2 und SARM 3 zwischen 26 g und 30,5 g. Die Gruppe Non OVX nahm im Vergleich nur zwischen 19,8 g und $23 \mathrm{~g}$ Futter zu sich. Im direkten Vergleich zeigte sich somit eine geringere Futteraufnahme der Gruppe Non OVX zu den anderen Gruppen. Dieses ist ein bekannter Effekt nach Ovarektomie (Omi und Ezawa 1995).

Gleichzeitig zur beobachteten Gewichtsabnahme zeigte sich in der Woche nach Osteotomie eine ebenso sprunghafte Abnahme der Futteraufnahme, gemessen pro Woche 
und Käfig. Die Futteraufnahme der Gruppe Non OVX reduzierte sich um $54 \%$. Die anderen Gruppen zeigten eine Reduktion um 65 \% im Vergleich zum Fressverhalten vor Osteotomie. In den folgenden Wochen stieg dieses dann wieder an.

Die Zugabe des Wirkstoffes Enobosarm begann nach Osteotomie für den Zeitraum von fünf Wochen. Alle Gruppen zeigten eine wöchentlich zunehmende Wirkstoffaufnahme, welche mit der steigenden Futteraufnahme korrelierte. Die Gruppe SARM 1 nahm im Verlauf zwischen 0,006 mg und 0,012 mg Wirkstoff pro Tier zu sich. SARM 2 zeigte eine anfängliche Wirkstoffaufnahme von $0,054 \mathrm{mg}$, welche sich auf 0,14 mg steigerte. Die Tiere der Gruppe SARM 3 nahmen in der ersten Woche durchschnittlich 0,5 mg, in der letzten Woche 1,4 mg des Wirkstoffes täglich zu sich.

Bezogen auf den Mittelwert hat keine der Behandlungsgruppen die geplante Wirkstoffaufnahme (SARM1: 0,014 mg/Tier, SARM2: 0,14 mg/Tier, SARM3: 1,4 mg/Tier) über die gesamte Versuchsdauer erreicht. Der geplanten täglichen Aufnahme von Enobosarm, kamen die Ratten vor allem in der zweiten Hälfte des Therapiezeitraumes nahe oder erreichten diese (Tabelle 27). Bei einer durchschnittlichen Standardabweichung der Körpergewichte von $23 \mathrm{~g}$, bezogen auf die durchschnittlichen Gewichte der Versuchstiere, schließt dieses nicht aus, dass einzelne Tiere im Zielbereich lagen.

Um diesem Problem entgegenzuwirken, wäre eine Möglichkeit die Dosierung entsprechend der Differenz zum Zielbereich, v. a. in den ersten beiden Therapiewochen nach Osteotomie, im Futter zu erhöhen. Um den präventiven Effekt von Enobosarm auf die Muskulatur zu untersuchen, ist es empfehlenswert so früh wie möglich mit der Therapie zu beginnen. Andernfalls wäre es denkbar erst eine Woche nach Osteotomie mit einer oralen Therapie zu starten. Dadurch könnte man die v. a. in dieser Woche auftretende verringerte Wirkstoffaufnahme umgehen und eine stabilere Konzentration gewährleisten. Als weitere Variante ist es denkbar, den Wirkstoff über die ersten Therapiewochen nach Operation subkutan $\mathrm{zu}$ applizieren. Somit ist die Wirkstoffaufnahme nicht vom Nahrungsverhalten abhängig. Diese doch sehr reduzierte, schwankende und von der Nahrungsaufnahme abhängige Wirkstoffaufnahme muss als ein großer limitierender Faktor dieser Arbeit gesehen werden. Die Futter- und somit auch die Wirkstoffaufnahme jedes Tieres ist nicht durch uns kontrolliert worden und wird nur gemittelt für einen Käfig über das verbleibende Futtergewicht gemessen. Es ist nicht eruierbar welches individuelle Tier wirklich wie viel Wirkstoff zu sich genommen hat. 
Enobosarm hat jedoch eine gute orale Bioverfügbarkeit und wird aus diesem Grund über das Futter verabreicht (Dalton et al. 2011). Andere Applikationsformen wie z. B. s. c., i. m. oder i. v. würden die Zieldosis sicher und ohne relevante Wirkstoffschwankungen über den gesamten Versuchsablauf erreichen. Um Aussagen bezüglich der oralen Wirkung auf einen Organismus machen zu können, sollte man auch unter experimentellen Bedingungen diese Form der Applikation wählen. Ein Nachteil anderer Applikationsformen ist der erhöhte Stress, eine erhöhte Invasivität und Schmerzen bei den Versuchstieren durch ggf. mehrmals tägliche Gabe.

\subsection{Uterusgewichte}

Nach Dekapitation wurden die Uteri der Ratten entfernt und gewogen. Es zeigten sich signifikante Gewichtsreduktionen der Gruppen OVX, SARM 1, SARM 2 und SARM 3 im Vergleich zu der Gruppe Non OVX. Die Uteri der Ratten aus der Gruppe SARM 1 befanden sich im Gewichtsbereich der OVX Gruppe. Die Gruppen SARM 2 und SARM 3 konnten im Vergleich zu OVX und SARM 1 signifikante Gewichtszunahmen aufweisen. Jedoch konnte nicht das Niveau der gesunden Ratten erreicht werden. Dies deutet auf eine dosisabhängige Wirkung von Enobosarm hin. Mit steigender Dosis zeigte sich eine stärkere Annäherung zum Uterusgewicht gesunder Ratten.

Die Dokumentation der Gewichte der Uteri diente der Kontrolle einer erfolgreichen Ovarektomie. Diese wird durch eine Uterusatrophie angezeigt (McElroy und Wade 1987, Komrakova et al. 2010). Die Uterusgewichte der Gruppen SARM 2 und SARM 3 nahmen signifikant zu. Diese Größen- und Gewichtszunahme zeigte sich vergleichbar auch unter Therapie mit Östrogenen (Komrakova et al. 2009).

Es konnte eine zyklusabhängige Expression von Androgenrezeptoren (AR) im Endometrium und Myometrium bei Frauen nachgewiesen werden. Die Gabe von Androgenen führt zusätzlich zu einer gesteigerten AR-Expression (Mertens et al. 2001). Eine Umwandlung in 5- $\alpha$-Dihydrotestosteron oder Estradiol im Uterus, wie in anderen Geweben fehlt jedoch (Giannopoulos 1973). Es ist vorstellbar das Enobosarm über AR im Uterus zu einer Zunahme der Größe und Gewichte geführt hat. Dieses könnte als Therapienebenwirkung bei Frauen auch zu weiteren, bisher noch unklaren Effekten führen und sollte weiter untersucht werden, da die Entwicklung eines Malignoms als Langzeitfolge unter länger andauernder Therapie durch eine derartige ProliferationsStimulation nicht ausgeschlossen werden kann. Um diese und weitere Auswirkungen auf 
die AR-Expression zu verstehen, wäre es in einem weiteren Versuch sinnvoll, dieses unter verschiedenen Wirkstoffkonzentrationen zu untersuchen.

\subsection{Muskelgewichte}

Der M. Gastrocnemius zeigte eine signifikante Gewichtszunahme der Gruppen SARM 1 SARM 2 und SARM 3 im Vergleich zu Non OVX. Dieses geht mit den Beschreibungen der Zunahme der fettfreien Körpermasse einher (Dalton et al. 2011).

Zwischen den Gruppen Non OVX und OVX zeigte sich kein signifikanter Gewichtsunterschied. Zur Gewichtsentwicklung nach Ovarektomie mit resultierendem Östrogenmangel gibt es gegenläufige Angaben. Man konnte zeigen, dass es zu einer Gewichtszunahme kommt, welche sich unter Östrogentherapie zurückbildet (Moran et al. 2007). Unter kontrollierter Futteraufnahme zeigte sich jedoch kein Effekt auf das Muskelgewicht (McCormick et al. 2004). Diese Gewichtszunahme kann in einer vermehrten Ansammlung von extrazellulärer Flüssigkeit begründet sein (Moran et al. 2007). Da bei unserem Versuch keine kontrollierte Futteraufnahme erfolgte, können diese Effekte durch den Östrogenmangel und die folgend vermehrte Futteraufnahme begründet sein, auch wenn sich zwischen den Gruppen Non OXV und OVX keine signifikanten Unterschiede zeigen.

Im Vergleich der Gruppen bezüglich des M. Soleus konnten keine signifikanten Gewichtsunterschiede gezeigt werden. Auch am M. Soleus wäre unter Therapie, wie auch im Falle des M. Gastrocnemius, eine Zunahme des Muskelgewichtes zu erwarten. Dieses zeigte sich nur tendenziell. Bei längerer Therapiedauer und stabiler Wirkstoffaufnahme könnte eine signifikante Gewichtszunahme resultieren. Therapie-effekte, wie eine Gewichtsabnahme unter Östrogentherapie, konnten beispielsweise bereits bei einer Therapiedauer von 28 Tagen gezeigt werden (McCormick et al. 2004).

\subsection{Verhältnis von Kapillaren zu Muskelzellen}

Im Falle des M. Gastrocnemius zeigte sich in den Gruppen SARM 1, SARM 2 und SARM 3, im Vergleich zu Non OVX, eine zunehmende Kapillarisierung, gemessen auf einer Querschnittsfläche von $0,5 \mathrm{~mm}^{2}$. Dies zeigte sich ebenso signifikant zwischen OVX und SARM 1 bzw. SARM 3.

Im Falle des M. Longissimus konnte ebenfalls eine signifikante Zunahme der Kapillarisierung der Gruppen SARM 2 und SARM 3 im Vergleich zu Non OVX und 
OVX gezeigt werden. Bei dem M. Soleus kam es zu keinen signifikanten Veränderungen. Wie auch im Falle der Uteri, lässt dieses eine dosisabhängige Wirkung vermuten. Es ergibt sich kein signifikanter Unterschied zwischen den Gruppen Non OVX und OVX. Bei einer Sarkopenie kommt es zur Abnahme der Kapillardichte und Reduktion von Faktoren zur Angiogenese. Die histologische Veränderung betroffener Muskeln konnte an unterschiedlichen Modellorganismen gezeigt werden (Ambrose 2015). Da sich dieser Unterschied bei uns nicht findet, muss dieses als ein weiterer Hinweis für dich nichtAusprägung Sarkopenie-typischer Veränderungen interpretiert werden.

Es konnte gezeigt werden, dass Östrogene und Androgene (Testosteron, DHT) die Angiogenese stimulieren (Kyriakides et al. 2001). Dies konnte u. a. durch Applikation von DHT an männlichen Mäusen (Sieveking et al. 2009) und Prostatazellen nachgewiesen werden (Eisermann et al. 2013). Androgene führen über ihre Interaktion mit Androgenrezeptoren zu einer Hochregulation des Faktors VEGF. Als Resultat kommt es zu einer zunehmenden Angiogenese. Die Zunahme der Kapillardichte und VEGFKonzentration kann ebenso durch körperliches Training bewirkt werden. Es zeigt sich, dass mit steigender VEGF-Konzentration auch die Kapillarisierung der Muskelfasern zunimmt (Gavin et al. 2007). In unserem Versuch konnten wir keine Aktivitätssteigerung der Versuchstiere unter Enobosarm-Therapie beobachten. Es wurde unsererseits jedoch kein Aktivitätsprotokoll angefertigt. Um eine durch Enobosarm induzierte Aktivitätssteigerung mit resultierender Mehrbelastung und Muskelhypertrophie auszuschließen ist, dieses jedoch eine denkbare Möglichkeit.

Enobosarm führte zu einer zunehmenden Kapillardichte in der Skelettmuskulatur, beispielhaft gezeigt am M. Gastrocnemius und M. Longissimus. In Folgeuntersuchungen wäre eine Bestimmung der VEGF-Konzentration im Muskel-gewebe unter Therapie mit Enobosarm in verschiedenen Wirkstoffkonzentrationen sinnvoll. Somit könnten weitere Hinweise über den genauen Wirkmechanismus der Angiogenese unter EnobosarmTherapie gesammelt werden. Diese Wirkung könnte dem physiologischen Alterseffekt, mit abnehmenden Faktoren für Angiogenese und der reduzierten Kapillardichte bei Sarkopenie, entgegenwirken. Durch die verbesserte Versorgung sind optimale Bedingungen für eine Muskelhypertrophie geschaffen. Als prophylaktische Therapie wirkt es zudem auf den intakten und gesunden Muskel und könnte dem Auftreten dieser Veränderungen vorbeugen. 


\subsection{Verhältnis von glykolytischen zu nicht glykolytischen Zellen}

Gezeigt am M. Longissimus konnten keine signifikanten Unterschiede im Verhältnis von glykolytischen zu nicht glykolytischen Zellen beobachtet werden. Es konnte nachgewiesen werden, dass es im Alter zu einem überwiegenden Verlust von Typ-2Muskelfasern mit resultierendem Anstieg des Typ-1/Typ-2-Verhältnisses kommt (Larsson 1978). Diese Veränderung konnte in der Gruppe OVX nicht beobachtet werden. Es zeigten sich ebenso keine signifikanten Unterschiede zu der gesunden Kontrollgruppe Non OVX. Auch dieses weist darauf hin, dass es zu keiner Sarkopenie-typischen Veränderung im Rahmen dieses Versuchsaufbaus kommt. Sinha-Hikim konnte im Jahre 2002 zeigen, dass die Therapie mit Testosteron zu keiner Veränderung im Verhältnis von Typ-1 zu Typ-2 Fasern führt. Ebenso hat die Therapie mit Enobosarm, da es über die gleichen Androgenrezeptoren wirkt, in diesem Versuch keinen Effekt auf eine Umwandlung der Muskelfasern gezeigt. Dieses haben wir im Rahmen dieses Versuches auch nicht erwartet. Ergänzend ist es denkbar über eine Gelelektrophorese (SDS-Page) mit darauf folgender Silberfärbung die Expression der MHC-Isoformen zu quantifizieren, worüber Rückschlüsse auf die Muskelfaserzusammensetzung möglich sind (McCormick et al. 2004). Hierdurch wäre es möglich Veränderungen der Komposition von schnellund langsam kontrahierenden Muskelfasern $\mathrm{zu}$ erkennen, die wir in unserer histologischen Analyse nicht nachweisen können.

\subsection{Zellflächen und Zelldurchmesser}

Weder bezogen auf die Fläche noch auf den Durchmesser konnten signifikante Veränderungen der glykolytischen oder nicht glykolytischen Muskelfasern unter Therapie mit Enobosarm gezeigt werden. Dieses bezieht sich sowohl auf den M. Gastrocnemius als auch den M. Longissimus und M. Soleus. Es zeigten sich ebenso keine Unterschiede zwischen der gesunden Gruppe Non OVX und der erkrankten, nicht behandelten Gruppe OVX. Dieses lässt vermuten, dass Östrogen bzw. Östrogenmangel in diesem Modell keinen Effekt auf den Querschnitt der einzelnen Muskelfasern hat.

Im Gegensatz dazu gibt es Daten, bei denen es nach Ovarektomie zu einer Größenzunahme der Muskelfasern kommt. Dieser Effekt konnte über alle Fasertypen gezeigt werden. Eine Östrogen-Applikation führte dann wieder zu einer Abnahme der Muskelfasergröße (Kobori und Yamamuro 1989). Es wird diskutiert, ob die Ursache 
dieses Effektes im Östrogenmangel oder der erhöhten Nährstoffaufnahme der ovarektomierten Ratten liegt (McCormick et al. 2004).

Ein Testosteronmangel führt bei kastrierten Ratten in unterschiedlichem Ausmaße zur Gewichtsreduktion der Skelettmuskulatur. Dieses zeigte sich an betroffenen Muskeln histologisch in der Abnahme der Muskelfaserdurchmesser (Souccar et al. 1982). Im histologischen Bild eines sarkopenen Muskels ist mit einer Atrophie der Muskelfasern zu rechnen. Es kommt zu einer Abnahme des Muskelquerschnittes mit assoziierter Reduktion der Kreatininexkretion (Young et al. 1984). Dieser Verlust betrifft im Alter zwischen 20 und 60 Jahren überwiegend Typ-2 Muskelfasern, wobei ca. $26 \%$ des Querschnittes verloren geht (Lexell et al. 1988). Die Therapie mit Testosteron führt dann dosisabhängig zu einer Hypertrophie der Typ-1 und Typ-2 Muskelfasern (Sinha-Hikim 2002). Die Muskelfasern der OVX Gruppe zeigten im Vergleich zu Non OVX keine Anzeichen für eine Faseratrophie. Bei der Untersuchung zur Prävention vor Sarkopenie muss zu diesem Zeitpunkt kein nachweisbarer Effekt aufgetreten sein. Wenn man jedoch die Effektivität der Therapie mit Enobosarm auf einen bereits sarkopenen Muskel komorbide $\mathrm{zu}$ einer Osteoporose eruieren möchte, wäre dieses aufgrund dieser Voraussetzungen nicht möglich. Die Sarkopenie ist auch eine Funktionelle Störung mit Reduktion von z. B. Kraft und Ausdauer. Auch wenn es histologisch keine Hinweise gibt, kann es zu funktionellen Beeinträchtigungen gekommen sein. Dieses haben wir nicht getestet.

Wir hätten jedoch unter optimalen Bedingungen eine Zunahme der Muskelfasergröße und des -durchmessers erwartet. Als Ursache für das Fehlen dieses Effektes muss die geringe Wirkstoffkonzentration über die Therapiedauer in Betracht gezogen werden. Alternativ kann, im Vergleich zu Testosteron, die abweichende intrazelluläre Signaltransduktion zu anderen Effekten führen.

Im Falle des M. Gastrocnemius zeigte sich eine tendenzielle Größenzunahme der glykolytischen Muskelfasern in den Gruppen SARM 2 und SARM 3 im Vergleich zu Non OVX und OVX. Im Vergleich zu Non OVX und OVX zeigte sich statistisch außerdem eine zunehmende Standardabweichung. Dieses gibt Hinweise auf eine größere Zellvariabilität. Es ist denkbar, dass nicht alle Zellen zur gleichen Zeit und in unterschiedlichem Maße beginnen zu hypertrophieren. Dieses hängt $\mathrm{u}$. a. von der Versorgung mit Nährstoffen, neuronaler Stimuli und der effektiven Wirkstoffkonzentration ab. 
Diese Tendenz fand sich ebenso im Bezug auf den M. Longissimus im Vergleich mit den Gruppen SARM 1, SARM 2 und SARM 3 bei den glykolytischen Zellen zu Non OVX und OVX. Auch hier zeigten sich keine signifikanten Unterschiede zwischen den Gruppen Non OVX und OVX. Unter Therapie mit Enobosarm kam es nur zu einer tendenziellen, jedoch zu keiner signifikanten Hypertrophie der Muskelfasern. Bei längerer Studiendauer könnte eine signifikante Hypertrophie resultieren. Da selektive Androgenrezeptor-Modulatoren über die gleichen Androgenrezeptoren wie Testosteron wirken, sollten in Folge auch beide Muskelfasertypen Merkmale einer Hypertrophie aufweisen. Diese Tendenzen konnten beispielhaft am M. Gastrocnemius und M. Longissimus gezeigt werden.

\subsection{Enzymaktivitäten}

Um den Einfluss von Enobosarm auf den Zellmetabolismus zu untersuchen, wurden die Aktivitäten ausgewählter Enzyme gemessen. Beispielhaft aus der Glykolyse wurde die Laktatdehydrogenase, aus dem Citrat-Zyklus, die Citrat-Synthase und aus der oxidativen Phosphorylierung der Komplex-1 gewählt. Die Citrat-Synthase (CS) bildet Citrat im Citratzyklus aus Oxalacetat und Acetyl-CoA (Rassow et al. 2012). Sie wird als Marker für die aerobe Kapazität und Mitochondriendichte im Skelettmuskel eingesetzt (Leek et al. 2001).

Bezüglich der Enzymaktivitätsbestimmung der Citrat-Synthase im M. Longissimus konnte ein signifikanter Anstieg in der Gruppe SARM 3 im Vergleich zu Non OVX gezeigt werden. Zusätzlich gab es einen nicht signifikanten Aktivitätsanstieg im Vergleich zu OVX und SARM 1. Tendenziell stieg auch die Aktivität der Gruppe SARM 2 im Vergleich zu Non OVX, OVX und SARM 1 an. Auch beim M. Gastrocnemius und M. Soleus gab es nicht signifikante Aktivitätssteigerungen der CS im Vergleich von SARM 1, SARM 2 und SARM 3 zu Non OVX und OVX. Die erhöhte Aktivität, v. a. in den Gruppen SARM 3 und SARM 2, lässt auf einen dosisabhängigen Effekt schließen, wobei mit höherer Dosis auch die Enzymaktivität stieg.

An kastrierten männlichen Modellorganismen wurde nachgewiesen, dass die Aktivität der CS im Urogenitaltrakt bei reduziertem Testosteronspiegel eine ebenso reduzierte Aktivität aufweist (Juan et al. 2007). Es ist denkbar, dass erhöhte Testosteronspiegel bei Hormonersatztherapie oder die Therapie mit selektiven Androgenrezeptor-Modulatoren 
zu einer gesteigerten CS-Aktivität führen. Eine Steigerung der CS-Aktivität kann beispielsweise auch durch körperliches Training induziert werden (Leek et al. 2001).

Die Laktatdehydrogenase (LDH) hat fünf gewebespezifische Isoenzyme (LDH 1-5). Sie katalysieren jeweils die Hin- und Rückreaktion bei Umwandlung von Pyruvat in Laktat am Ende der Glykolyse. Laktat kann, über die Blutbahn abgegeben, dann von Leber und Herzmuskel weiterverarbeitet werden (Rassow et al. 2012). Die NADH-UbichinonOxidoreduktase (Komplex-1) ist Bestandteil der Atmungskette im Mitochondrium. Es nimmt Elektronen von NADH auf und überträgt sie auf Ubichinon (Rassow et al. 2012).

Die Bestimmung der Enzymaktivität der Laktatdehydrogenase oder Komplex-1 zeigt keine signifikanten Unterschiede im Gruppenvergleich, sowohl beim M. Longissimus, als auch beim M. Gastrocnemius oder M. Soleus. Auch hier zeigten sich zwischen den Gruppen Non OVX und OVX keine signifikanten Aktivitätsunterschiede der Enzyme. Dieses Ergebnis lässt den Schluss zu, dass eine Reduktion des Östrogenspiegels, in unserem Fall nach Ovarektomie, zu keiner Veränderung der Enzymaktivitäten von CS, LDH und Komplex-1 führt.

An kastrierten Ratten konnte gezeigt werden, dass die Aktivität der Laktatdehydrogenase (LDH) im Muskel, im Vergleich zu gesunden Tieren, nach zwölf Wochen abnimmt. Dieser Effekt konnte unter ebenso zwölfwöchiger Substitution von Testosteron rückgängig gemacht werden (Krotkiewski et al. 1980).

Bei längerer Therapiedauer mit Enobosarm wäre eine Aktivitätssteigerung der CS, LDH und Komplex-1 zu erwarten. Dieses könnte in einem modifizierten Versuch mit längerer Therapiedauer weiter untersucht werden.

\subsection{Serumkonzentrationen}

Die Bestimmung der Kreatinkinase (CK), des Magnesiums $\left(\mathrm{Mg}^{2+}\right)$ und Kalziums $\left(\mathrm{Ca}^{2+}\right)$ ergab keine signifikanten Konzentrationsveränderungen im Serum.

Die Untersuchung der Kreatinkinase erlaubt Rückschlüsse über den Muskelstatus. Eine Veränderung der CK-Konzentration ist je nach Situation in unterschiedlichem Ausmaß zu erwarten. Im Alter nimmt diese mit abnehmender Muskelmasse ebenfalls ab. Mit zunehmender Muskelmasse, z. B. bei körperlichem Training oder bei Zellschäden, würde diese zunehmen (Brancaccio et al. 2007). Es zeigten sich keine signifikanten Veränderungen zwischen den Gruppen Non OVX und OVX. Dementsprechend ist nicht 
von einem relevanten Verlust der Muskelmasse in der ovarektomierten Kontrollgruppe auszugehen. Ebenso kam es zu keinem signifikanten Anstieg der Muskelmasse in den Therapiegruppen. Durch die ausbleibende Veränderung der CK-Konzentration im Serum kann davon ausgegangen werden, dass es zu keinen relevanten Zellschäden der Skelettmuskulatur unter Therapie mit Enobosarm gekommen ist.

Magnesium ist ein v. a. intrazellulär vorkommendes Ion, welches zu $65 \%$ im Knochen lokalisiert ist. Im Blut wird es zu $65 \%$ als freies $\mathrm{Mg}^{2+}$ transportiert. Es dient als Co-Faktor für viele Enzyme. Durch seine strukturelle Ähnlichkeit zu Kalzium können sich die beiden Ionen gegenseitig beeinflussen. Bei einem Magnesiummangel kommt es zu neuromuskulären Störungen, welche sich u. a. im klinischen Bild einer Tetanie zeigen. Kalzium wird zu 99 \% im Knochen, in Form von Hydroxylapatit, gespeichert. Dort befindet es sich in einer Bindung mit Phosphat. Eine $\mathrm{zu}$ hohe Konzentration an $\mathrm{Ca}^{2+}$ Ionen kann sich negativ auf die neuronale Signaltransduktion auswirken (Rassow et al. 2012).

Es zeigten sich weder in der Gruppe OVX noch in den Therapiegruppen relevante Veränderungen der $\mathrm{Mg}^{2+}$ - oder $\mathrm{Ca}^{2+}$-Serumspiegel. Von einer Veränderung des Magnesium-Serumspiegels sind wir vor dem Versuch ebenso nicht ausgegangen.

\subsection{Schlussfolgerung und Ausblick}

Insgesamt zeigt sich ein Therapieeffekt von Enobosarm im Osteoporose-Rattenmodell, im Sinne einer Muskelgewichtszunahme, einer Zunahme der Kapillarisierung, sowie einer Steigerung der enzymatischen Aktivität. Dementsprechend ist Enobosarm auch im Kontext einer komorbide auftretenden Osteoporose ein vielversprechender Wirkstoff um anabole Effekte auf die quergestreifte Skelettmuskulatur zu erzielen und die Muskelfunktion zu verbessern.

Die Gewichtszunahme der Muskulatur kann in diesem Versuchsaufbau nicht sicher in Korrelation mit Enobosarm gestellt werden. Hierzu muss die Futteraufnahme der Versuchstiere reglementiert werden, da es nach Ovarektomie unter Östrogenmangel zu einem gesteigerten Futterverhalten kommt. In weiteren Versuchen könnte an eine definierte tägliche und individuelle Futtergabe gedacht werden, um eine sicherere Aussage bezüglich des Effektes von Enobosarm auf das Muskelgewicht treffen zu können. 
Die orale Gabe von Enobosarm zeigt sich im Nachhinein nach bilateraler Osteotomie als Problem, da die Wirkstoffaufnahme direkt mit der Futteraufnahme zusammenhängt. Die unter dem Zielbereich liegende Wirkstoffaufnahme kann sich negativ auf sich ergebene Effekte auswirken. Somit sollte in Folgestudien das Applikationskonzept entweder zugunsten einer s. c. Therapie angepasst, oder die Dosis in den ersten Wochen dementsprechend gesteigert werden.

Es zeigte sich keine Veränderung im Verhältnis der Muskelfasertypen oder eine signifikant veränderte Zellgröße. Eine Größenzunahme wäre unter optimalen Bedingungen mit konstanter Wirkstoffaufnahme im Zielbereich und ggf. auch unter länger andauernder Therapie zu erwarten. Auch hier kann die effektive Dosis v. a. in der ersten Therapiehälfte zu gering gewesen sein um unter diesen Voraussetzungen Effekte zu erzielen. Auch unter diesem Aspekt muss bei fünf Wochen geplanter Therapiedauer ggf. an ein anderes Applikationskonzept gedacht, oder die Therapiedauer entsprechend verlängert werden.

Histologisch zeigt sich unter Therapie sowohl keine Atrophie der Muskulatur, als auch laborchemisch keine Hinweise auf eine Schädigung der Muskulatur. Dementsprechend kann davon ausgegangen werden, dass die Muskulatur unter Therapie mit Enobosarm keinen Schaden nimmt.

Aussagen bezüglich der Wirkung auf die Muskulatur unter dem Hintergrund einer SarkoOsteoporose sind in diesem Modell nicht möglich, da sich keine histologischen Veränderungen der Muskulatur in Richtung Sarkopenie zeigen. Wenn dieses untersucht werden soll muss in Folge ggf. an einen anderen Modellorganismus, wie z. B. die gealterte Ratte gedacht werden.

Um einen detaillierteren Eindruck über die Effekte von Enobosarm zu erhalten sind in Folgeversuchen weiterführende Untersuchungen zur VEGF-Expression sowie eine Gelelektrophorese (SDS-Page) möglich. Somit können Rückschlüsse auf die Ursache der gesteigerten Vaskularisierung in der quergestreiften Skelettmuskulatur und eventuelle Veränderungen der Zusammensetzung der MHC-Komplexe gezogen werden.

Nach bilateraler Ovarektomie kommt es nach operativem Erfolg typischerweise zu einer Atrophie des Uterus. Die Größenzunahme der Uteri unter Therapie mit hochdosiertem Enobosarm deutet auf eine androgensensitive Proliferation hin. Dieses kann auch in Folge zu ungewollter Gewebeproliferation und Malignomen führen. Auch hier sollte der genaue Mechanismus weiter untersucht werden. 
Perspektivisch kann mit geringen Modifikationen des Versuchsaufbaus eine exaktere Aussage bezüglich der Wirkung von Enobosarm auf die Muskulatur getroffen werden. Dazu kann in erster Linie an die Möglichkeit einer kontinuierlichen Wirkstoffaufnahme im festgelegten Zielbereich gedacht werden. Des Weiteren an eine kontrollierte Futtergabe pro Tag, um futterbedingte Hypertrophie-Effekte $\mathrm{zu}$ minimieren. Das Konzept der kombinierten Therapie des Knochens und der Muskulatur durch nur einen Wirkstoff bei komorbider Sarko-Osteoporose ist bei steigendem Lebensalter und zunehmender Zahl der betroffenen jedoch sehr interessant und sollte unbedingt weiterverfolgt werden. Hier konnte eine positive Wirkung auf die Knochenstuktur in unserem Versuch am Modellorganismus der osteoporotischen Ratte gezeigt werden (Hoffmann et al. 2018).

Im Rahmen weiterführender klinischer Studien könnte darüber nachgedacht werden bei Onkologischen Patienten mit Sarkopenie ergänzend eine Knochendichtemessung durchzuführen um den Effekt auf die Knochenqualität zu erheben. Bei diesem Patientenkollektiv ist es äußerst sinnvoll die Lebensqualität und eigenständige Mobilität so lange es möglich ist zu erhalten. Hierzu zählt auch das zunehmende Risiko für Stürze durch Muskelaufbau (mittels Training, oder durch Arzneimittel) und sturzassoziierte Frakturen zu reduzieren. Dafür muss so lange es möglich ist sowohl die Knochenqualität als auch die Muskelkraft erhalten bleiben.

Da das Bestreben der Zulassung für die Therapie von Sarkopenie von der Firma GTx Inc. ${ }^{\circledR}$ zu Gunsten anderer Einsatzgebiete verlassen wurde (Garber und Arbor 2016), ist es fraglich, ob zukünftig auch eine Zulassung für die Therapie von Osteoporose und Sarko-Osteoporose bei an sonst gesunden Personen in naher Zukunft ohne vorige kardiovaskuläre-Sicherheitsstudien absehbar ist. Realistischer scheint es auch hier die Wirkung von Enobosarm bei Tumor- und Chemotherapie-Assoziierter Osteoporose, Sarkopenie und Sarko-Osteoporose weiter zu verfolgen. Des Weiteren sollte man sich bei einem solch komplexen Patientenkollektiv über eine andere Messmethode zur Ermittlung des Therapieerfolges Gedanken machen. Der Stair-Climb Test scheint diesbezüglich kein erfolgreiches Mittel zu sein. Denkbar wäre das ganze mit z. B. dem 6-Minute-Walk-Test, Aktivitätsprotokollen und Lebensqualitätsfragebögen zu kombinieren. Des Weiteren könnte man die fettfreie Körpermasse und Muskelumfänge ergänzend ermitteln. Eine Kombination verschiedener Verfahren zur Ermittlung des Therapieerfolges könnte signifikante Ergebnisse liefern. 


\section{$5 \quad$ Zusammenfassung}

Sarkopenie ist eine oft unterdiagnostizierte Erkrankung welche häufig komorbide zur Osteoporose auftritt. Wir untersuchten die Wirkung des selektiven AndrogenrezeptorModulators (SARM) Enobosarm auf die Skelettmuskulatur am Modell der ovariektomierten Ratte. Drei Monate alte Sprague Dawley Ratten wurden in fünf Gruppen unterteilt. Vier Gruppen wurden ovarektomiert um postmenopausale Bedingungen zu schaffen. An drei der ovarektomierten Versuchstiergruppen (SARM $1(\mathrm{n}=11), \quad 2(\mathrm{n}=10)$, und $3(\mathrm{n}=11))$ wurde Enobosarm in den folgenden Wirkstoffdosierungen $0,04 \mathrm{mg} / \mathrm{kg} / \mathrm{KG}, 0,4 \mathrm{mg} / \mathrm{kg} / \mathrm{KG}$ und 4,0 mg/kg/KG getestet. Die vierte ovariektomierte Gruppe (OVX $(\mathrm{n}=9))$ diente als kranke, die nicht ovariektomierte Gruppe fünf (Non OVX $(n=10)$ ) als gesunde Kontrollgruppe. Acht Wochen nach Ovariektomie bekamen die Gruppen SARM 1 bis 3 für insgesamt fünf Wochen eine Therapie mit Enobosarm über sojafreies Futter. Nach fünfwöchiger Behandlung wurden der M. Gastrocnemius, M. Soleus, ein Teil des M. Longissimus und die Uteri entnommen, sowie die jeweiligen Gewichte ermittelt. Aus dem Blut wurden die Kreatinkinase, Magnesium- und Kalzium-Konzentrationen bestimmt. Aus den Muskelproben wurden mit Hilfe eines Kryotoms $12 \mu \mathrm{m}$ Dünnschnitte angefertigt und histologische Untersuchungen durchgeführt. Das Verhältnis von Kapillaren zu Muskelfasern, das Verhältnis der Muskelfasertypen und die Muskelfasergrößen wurden in Folge bestimmt. Zusätzlich wurden die Enzymaktivitäten der Citrat-Synthase, Laktatdehydrogenase und Komplex-1 in der Skelettmuskulatur analysiert.

Die Uteri der Gruppen OVX und SARM 1 waren signifikant leichter im Vergleich zu Non OVX, was sich durch den reduzierten Östrogenspiegel nach Ovariektomie erklären lässt. Die Uteri der Gruppen SARM 2 und SARM 3 zeigten eine signifikante Gewichtszunahme im Vergleich zu OVX und SARM 1. Sie haben jedoch nicht das Gewicht der gesunden Vergleichsgruppe Non OVX erreicht. Dieses spricht für eine dosisabhängige Wirkung am Uterus über dort vorhandene Androgenrezeptoren. Hinterfragen muss man hier drohende Langzeitfolgen mit einer im schlimmsten Fall hormonell stimulierten Malignom-Entwicklung im Bereich des Uterus.

In der Muskulatur, beispielhaft gezeigt am M. Gastrocnemius und M. Longissimus, kam es unter Therapie zu einer zunehmenden Kapillarisierung. Dieser Effekt stieg mit steigender Wirkstoffdosierung. Eine zunehmende Angiogenese unter Therapie mit Enobosarm lässt sich über eine vergleichbare Wirkung von Testosteron erklären. 
Es zeigten sich keine signifikanten Änderungen im Verhältnis von Typ-1- zu Typ-2Muskelfasern unter Therapie mit Enobosarm. Dieses wurde auch nach TestosteronTherapie berichtet. Bezüglich der Muskelfaserflächen und -durchmesser ergaben die Auswertungen eine tendenzielle Größenzunahme der glykolytischen Muskelzellen. Von einer Zunahme der Muskelkraft und der fettfreien Körpermasse, unter Therapie mit SARMs, ist bereits früher berichtet worden. Eine fünf Wochen dauernde Therapie, wie in unserem Versuch, ist anscheinend nicht ausreichend um einen signifikanten Effekt auf die Muskelfasergrößen zu erzielen.

Die Aktivität der Citrat-Synthase der Gruppe SARM 3 war im M. Longissimus signifikant erhöht gegenüber der Gruppe Non OVX. Im Falle der anderen Muskeln konnte eine tendenzielle Aktivitätssteigerung der CS-Aktivität, v. a. in den Therapiegruppen SARM 2 und SARM 3 gezeigt werden. Diese spricht wiederum für eine dosisabhängige Wirkung, wie auch schon beispielhaft am Uterus gezeigt und deutet auf einen aktivitätssteigernden Effekt von Enobosarm auf den Zellmetabolismus hin. Bezüglich der Laktatdehydrogenase und des Komplex-1 konnten keine signifikanten Aktivitätsunterschiede nachgewiesen werden. Es erscheint, dass Enobosarm keinen messbaren Effekt auf die Glykolyse und Atmungskette in unserem Modell unter den gegebenen Voraussetzungen hat.

In der Analyse des Serums fanden sich keine signifikanten Veränderungen von Magnesium, Kalzium und der Kreatinkinase (CK). Der fehlende Anstieg der CKAktivität spricht gegen einen durch Enobosarm induzierten Muskelzellschaden. Der Elektrolythaushalt im Serum blieb ebenfalls unverändert.

Enobosarm zeigte insgesamt eine dosisabhängige anabole Wirkung auf die Skelettmuskulatur und den Zellmetabolismus. Es kam $\mathrm{zu}$ einer verbesserten Blutversorgung der Muskulatur durch eine zunehmende Kapillarisierung und einer Enzymaktivitätssteigerung (gezeigt an der Citrat-Synthase). Tendenziell lässt sich ebenfalls eine Größenzunahme der Muskelfasern erkennen. Bei länger andauernder Therapie wären noch größere Effekte zu erwarten. Diese Effekte könnten durch die Analyse weiterer Faktoren, wie der vaskulären endothelialen Wachstumsfaktoren sowie einer Gelelektrophorese der Isoformen der Myosinschwerketten im Skelettmuskel und einer Analytik der Androgenrezeptoren im Uterus, weiter untersucht werden. Dieses könnte Gegenstand weiterer Forschungsarbeiten mit Enobosarm sein. Fraglich stellt sich die perspektivische Zulassung von Enobosarm für die Indikation der Sarkopenie, Osteoporose und einer komorbiden Sarko-Osteoporose, da das Bestreben der Firma GTx Inc. ${ }^{\circledR}$ bezüglich einer Zulassung bei Sarkopenie verworfen und auf andere Erkrankungen, 
wie u. a. die Tumorassoziierte-Kachexie bei onkologischen Patienten verlagert wurde. Diese Patienten leiden häufig nicht nur an Sarkopenie, sondern auch an einer Osteoporose. Unsere Studie bezieht sich jedoch auf die präventive Wirkung bezüglich einer Sarkopenie, am Modellorganismus der für postmenopausale Bedingungen. Bei ggf. folgenden Studien sollte dieser Aspekt bedacht werden, auch mit dem Hintergrund weiterer noch unbekannter Nebenwirkungen an anderen Organen, wie z. B. dem Herzen, dem Uterus und der Leber. 


\section{$6 \quad$ Anhang}

Tabelle 27: Körpergewichte (in g, SARM 1 - 3 im Mittelwert) und geplante (Soll), sowie erreichte (Ist) Wirkstoffaufnahme über die Therapiedauer, gezeigt für jede Therapiewoche (in mg/Tier).

\begin{tabular}{|l|l|l|l|l|l|}
\hline & $\begin{array}{l}\text { Woche 1 } \\
\text { Ist / Soll } \\
\text { (mg/Tier) }\end{array}$ & $\begin{array}{l}\text { Woche 2 } \\
\text { Ist / Soll } \\
(\mathbf{m g} / \text { Tier) }\end{array}$ & $\begin{array}{l}\frac{\text { Woche 3 }}{\text { Ist / Soll }} \\
\text { (mg/Tier) }\end{array}$ & $\begin{array}{l}\frac{\text { Woche 4 }}{\text { Ist / Soll }} \\
\text { (mg/Tier) }\end{array}$ & $\begin{array}{l}\frac{\text { Woche 5 }}{\text { Ist / Soll }} \\
(\mathbf{m g} / \text { Tier) }\end{array}$ \\
\hline SARM 1 & $0,006 / 0,014$ & $0,01 / 0,014$ & $0,011 / 0,014$ & $0,012 / 0,014$ & $0,012 / 0,014$ \\
\hline SARM 2 & $0,054 / 0,14$ & $0,099 / 0,14$ & $0,11 / 0,14$ & $0,13 / 0,14$ & $0,14 / 0,14$ \\
\hline SARM 3 & $0,51 / 1,4$ & $1 / 1,4$ & $1,12 / 1,4$ & $1,3 / 1,4$ & $1,4 / 1,4$ \\
\hline Gewicht & $330 \mathrm{~g} \pm 21,2$ & $343 \mathrm{~g} \pm 20,6$ & $357 \mathrm{~g} \pm 23,9$ & $366 \mathrm{~g} \pm 25,6$ & $379 \mathrm{~g} \pm 25,7$ \\
\hline
\end{tabular}

Tabelle 28: Übersicht entwickelter SARMs (Thevis und Schänzer 2017).

\begin{tabular}{|l|l|l|}
\hline SARM & Formel & Gruppe \\
\hline S-1 & C17H14F4N2O5 & arylpropionamid \\
\hline S-4(Andarine) & C19H18F3N3O6 & arylpropionamid \\
\hline S-22(Ostarine) & C17H14ClF3N2O5 & arylpropionamid \\
\hline S-23 & C18H13ClF4N2O3 & arylpropionamid \\
\hline S-24 & C18H14F4N2O3 & arylpropionamid \\
\hline LGD-2226 & C14H9F9N2O & quinolinone \\
\hline LGD-2941 & C17H16F6N2O2 & quinolinone \\
\hline LGD-3303 & C16H14C1F3N2O & quinolinone \\
\hline LG-121071 & C15H15F3N2O & quinolinone \\
\hline S-40503 & C15H23N3O3 & tetrahydroquinoline \\
\hline S-101479 & C26H24F2N4O3 & tetrahydroquinoline \\
\hline S-49288 & C25H26N4O & tetrahydroquinoline \\
\hline JNJ-28330835 & C14H10F6N4O & phenyl-pyrazol-carboxamide \\
\hline BMS-564929 & C14H12C1N3O3 & hydantoin \\
\hline JNJ-37654032 & C11H7Cl2F3N2O & benzoimidazole \\
\hline SARM & Formel & Gruppe \\
\hline RAD140 & C20H16ClN5O2 & phenyl-oxadiazole \\
\hline
\end{tabular}




\begin{tabular}{|l|l|l|}
\hline AC262536 & C18H18N2O & tropanol \\
\hline ACP-105 & C16H19C1N2O & tropanol \\
\hline LGD-4033/VK 5211 & C14H12F6N2O & pyrrolidinyl-benzonitrile \\
\hline RAD35010 & C13H11ClF3NO & indole \\
\hline Ly2452473 & C23H23N3O2 & indole \\
\hline FTBU-1 & C19H16FN5OS & benzoimidazole \\
\hline 2-FPA & C17H19FN2O & pyridinylmethanamide \\
\hline Compound 6 & C14H17ClN2O & cyclopentyl-benzonitrile \\
\hline Compound 15 & C19H17FN2O3 & phenoxypropanoyl-indoline \\
\hline Compound 17h & C16H16N2O & pyrrolidinyl-naphthonitrile \\
\hline Compound 17j & C17H18N2O & pyrrolidinyl-naphthonitrile \\
\hline Compound 17m & C16H16N2O & pyrrolidinyl-naphthonitrile \\
\hline GLPG0492 (DT-200) & C19H14F3N3O3 & diarylhydantoin \\
\hline GLPG0634 & C19H14F3N3O3 & diarylhydantoin \\
\hline MK-3984 & C17H12F7NO2 & phenylmethanamide \\
\hline NEP28 & C10H10BrF3N2S & thiophene \\
\hline MK-0773 & C27H34FN5O2 & steroidal \\
\hline Cl-4-AS-1 & C26H33ClN2O2 & steroidal \\
\hline TFM-4AS-1 & C27H33F3N2O2 & steroidal \\
\hline YK-11 & C25H34O6 & steroidal \\
\hline S-42 & C21H28O & steroidal \\
\hline
\end{tabular}


Tabelle 29: Protokoll der Amylase-PAS-Kapillarfärbung.

\begin{tabular}{|l|l|l|}
\hline Arbeitsschritt & Zeit & Besonderheiten \\
\hline 1.) Fixierlösung (A) & $\begin{array}{l}\text { a) } 1 \text { Stunde } \\
\text { b) } 10 \text { Minuten }\end{array}$ & $\begin{array}{l}\text { a) bei } 4{ }^{\circ} \mathrm{C} \\
\text { b) bei Raumtemperatur }\end{array}$ \\
\hline 2.) Aqua destillata & & $10 \times$ spülen \\
\hline 3.) Amylase (B) & 25 Minuten & bei $37^{\circ} \mathrm{C}$ \\
\hline 4.) Aqua destillata & & $10 \times$ spülen \\
\hline 5.) Perjodsäure (C) & 30 Minuten & \\
\hline 6.) Aqua destillata & & $10 \times$ spülen \\
\hline 7.) Schiff' s Reagenz (D) & 25 Minuten & \\
\hline 8.) SO2-Wasser (E) & 30 Minuten & \\
\hline 9.) Leitungswasser & 10 Minuten & unter fließendem Wasser \\
\hline 10.) Aqua destillata & 3 Minuten & \\
\hline
\end{tabular}

Tabelle 30: Rezepturen der Amylase-PAS-Kapillarfärbung.

\begin{tabular}{|l|l|l|}
\hline & Lösung & Menge \\
\hline A) & Fixierlösung & \\
\hline & $\begin{array}{l}\text { Ethanol } \\
\text { Chloroform } \\
\text { Essigsäure }\end{array}$ & $\begin{array}{l}43 \mathrm{ml} \\
8 \mathrm{ml} \\
2,7 \mathrm{ml}\end{array}$ \\
\hline B) & Amylase Lösung & \\
\hline & Amylase & $185 \mathrm{mg}$ \\
& Aqua destillata & $60 \mathrm{ml}$ \\
\hline C) & Perjodsäure & $0,6 \mathrm{~g}$ \\
\hline & $\begin{array}{l}\text { Perjodsäure } \\
\text { Aqua destillata }\end{array}$ & $60 \mathrm{ml}$ \\
\hline D) & Schiffs Reagenz & $600 \mathrm{ml}$ \\
\hline & Fertig gemischt geliefert & $30 \mathrm{ml}$ \\
\hline E) & SO -Wasser & $30 \mathrm{ml}$ \\
\hline & $\begin{array}{l}\text { Aqua destillata } \\
\text { Kaliumdisulfitlösung } \\
\text { HCL, 1 N }\end{array}$ & \\
\hline
\end{tabular}


Tabelle 31: Protokoll der ATPase-Färbung.

\begin{tabular}{|c|c|c|}
\hline Arbeitsschritt & Zeit & Besonderheiten \\
\hline 1.) Fixierung nach Meier (A) & 1 Minute & $\mathrm{pH}: 6,3-6,6$ \\
\hline 2.) Aqua destillata & 5 Minuten & \\
\hline 3.) Aqua destillata & 5 Minuten & \\
\hline 4.) Diaphorase-Inkubation (B) & 60 Minuten & bei $37^{\circ} \mathrm{C}$ \\
\hline 5.) Aqua destillata & 15 Minuten & \\
\hline 6.) Saure Vorinkubation (C) & 15 Minuten & $\mathrm{pH}: 4,2$ \\
\hline 7.) Tris-CaCl 2 -Lsg. (D) & 2 Minuten & $\mathrm{pH}: 7,8$ \\
\hline 8.) ATPase-Inkubationslösung (E) & 30 Minuten & $\begin{array}{l}\text { bei } 37^{\circ} \mathrm{C} \\
\mathrm{pH}: 9,4\end{array}$ \\
\hline 9.) $\mathrm{CaCl}_{2}$-Waschlösung & 30 Sekunden & \\
\hline 10.) $\mathrm{CaCl}_{2}$-Waschlösung & 30 Sekunden & \\
\hline 11.) $\mathrm{CaCl}_{2}$-Waschlösung & 30 Sekunden & \\
\hline 12.) Kobaltchloridlösung (F) & 2 Minuten & \\
\hline 13.) Aqua destillata & 45 Sekunden & \\
\hline 14.) Aqua destillata & 45 Sekunden & \\
\hline 15.) Aqua destillata & 45 Sekunden & \\
\hline 16.) Ammoniumsulfidlösung (G) & 2 Minuten & \\
\hline 17.) Leitungswasser & 10 Minuten & \\
\hline 18.) Aqua destillata & 5 Minuten & \\
\hline
\end{tabular}


Tabelle 32: Rezeptur der ATPase-Färbung.

\begin{tabular}{|c|c|c|}
\hline & Lösung & Menge \\
\hline \multirow[t]{2}{*}{ A) } & Fixierungslösung nach Meier & \\
\hline & $\begin{array}{l}\text { Paraformaldehyd }\left(\mathrm{Fa} . \text { Roth }{ }^{\circledR}, 0335.1\right) \\
\mathrm{CaCl}_{2} \text {-2-hydrat }\left(\mathrm{Fa} . \text { Fluka }{ }^{\circledR}, 21100\right) \\
\text { Saccharose }\left(\mathrm{Fa} \text {. AppliChem }{ }^{\circledR}, \mathrm{A} 4734,1000\right) \\
\text { Aqua destillata }\end{array}$ & $\begin{array}{l}0,6 \mathrm{~g} \\
0,588 \mathrm{~g} \\
3,6 \mathrm{~g} \\
60 \mathrm{ml}\end{array}$ \\
\hline \multirow[t]{2}{*}{ B) } & Diaphorase-Inkubationslösung & \\
\hline & $\begin{array}{l}\left.\text { NADH-Dinatriumsalz (AppliChem }{ }^{\circledR}, \mathrm{A} 1393,0005\right) \\
\text { Phospatpuffer }(0,1 \mathrm{M}, \mathrm{pH}: 7,4) \\
\text { Nitro-BT } \\
\text { Aqua destillata }\end{array}$ & $\begin{array}{l}13 \mathrm{mg} \\
2,08 \mathrm{ml} \\
2,6 \mathrm{ml} \\
3,12 \mathrm{ml}\end{array}$ \\
\hline \multirow[t]{2}{*}{ C) } & Saure Vorinkubation & \\
\hline & $\begin{array}{l}\text { CaCl2-Stammlösung } \\
\left.\text { Eisessig (Fa. Merck® }{ }^{\circledR}, 63\right) \\
\text { Aqua destillata }\end{array}$ & $\begin{array}{l}6,67 \mathrm{ml} \\
0,27 \mathrm{ml} \\
60 \mathrm{ml} \\
\end{array}$ \\
\hline \multirow[t]{2}{*}{ D) } & Tris-CaCl 2 Stammlösung & \\
\hline & $\begin{array}{l}\text { Tris } \\
\mathrm{CaCl}_{2} \text {-Stammlösung } \\
\text { Aqua destillata }\end{array}$ & $\begin{array}{l}0,74 \mathrm{~g} \\
6,1 \mathrm{ml} \\
55 \mathrm{ml}\end{array}$ \\
\hline \multirow[t]{2}{*}{ E) } & ATPase-Inkubationslösung & \\
\hline & $\begin{array}{l}\mathrm{KCl}\left(\mathrm{Fa} . \text { Merck }{ }^{\circledR}, 4936, \mathrm{M}=75 \mathrm{~g} / \mathrm{mol} \text { ) }\right. \\
\text { ATP (Adenosin-5'-triphosphat, M=551,2 g/mol) Glycinpuffer } \\
\mathrm{CaCl}_{2} \text {-Stammlösung } \\
\text { Glycinpuffer }\end{array}$ & $\begin{array}{l}226 \mathrm{mg} \\
93 \mathrm{mg} \\
55 \mathrm{ml} \\
6,1 \mathrm{ml} \\
\end{array}$ \\
\hline \multirow[t]{2}{*}{ F) } & Kobaltchlorid Lösung & \\
\hline & $\begin{array}{l}\text { Kobaltchlorid }\left(\mathrm{CoCl}_{2} \mathrm{X}_{6} \mathrm{H}_{2} \mathrm{O}\right) \\
\text { Aqua destillata }\end{array}$ & $\begin{array}{l}1,2 \mathrm{~g} \\
60 \mathrm{ml} \\
\end{array}$ \\
\hline \multirow[t]{2}{*}{ G) } & Ammoniumsulfid-Lösung & \\
\hline & $\begin{array}{l}\text { Ammoniumsulfid (Fa. Merck } ®, 1.05442 .1000) \\
\text { Aqua destillata }\end{array}$ & $\begin{array}{l}0,08 \mathrm{ml} \\
60 \mathrm{ml}\end{array}$ \\
\hline
\end{tabular}


Tabelle 33: Rezeptur des Chappel-Perry-Mediums.

\begin{tabular}{|c|c|}
\hline Chappel-Perry-Medium (pH: 7.5) & Menge (für 1 Liter) \\
\hline 0,1 M KCL $($ Merck $\circledast, 4936)$ & $7,456 \mathrm{~g}$ \\
\hline 0,05 M Tris $(\mathrm{Biomol} \circledast, 080003)$ & $6,057 \mathrm{~g}$ \\
\hline $0,01 \mathrm{M} \mathrm{MgCl}+6 \mathrm{H}_{2} 0\left(\right.$ Sigma $\left.{ }^{\circledR}, \mathrm{M}-9272\right)$ & $2,0 \mathrm{~g}$ \\
\hline 1mM EGTA (AppliChem ${ }^{\circledR}$, A0878, 0005) & $0,38 \mathrm{~g}$ \\
\hline
\end{tabular}

Tabelle 34: Testansatz Citrat-Synthase.

\begin{tabular}{|l|l|l|}
\hline Chemikalie & Leerwert & Probe \\
\hline $\begin{array}{l}\text { Tris-Mannitol-Puffer } \\
\left.50 \mathrm{mM} \text { Tris-HCl (AppliChem }{ }^{\circledR}, \mathrm{A} 1087,0250\right): 0,788 \mathrm{~g} \\
\left.200 \mathrm{mM} \text { Mannitol (AppliChem }{ }^{\circledR}, \mathrm{A} 5292,0250\right): 3,64 \mathrm{~g}\end{array}$ & $830 \mu \mathrm{l}$ & $810 \mu \mathrm{l}$ \\
\hline $\begin{array}{l}\text { Triton 5,1\% } \\
\text { DTNB Dithiobis (2-Nitro-benzoic Acid), } 2 \mathrm{mM}\end{array}$ & $20 \mu \mathrm{l}$ & $20 \mu \mathrm{l}$ \\
\hline $\begin{array}{l}\left.\text { AppliChem }{ }^{\circledR}, \mathrm{A} 3378,0001\right) \\
\left.\text { Acethyl-CoA, 2 mM (AppliChem }{ }^{\circledR}, \mathrm{A} 3753,0010\right)\end{array}$ & $50 \mu \mathrm{l}$ & $50 \mu \mathrm{l}$ \\
\hline Homogenat & $50 \mu \mathrm{l}$ & $50 \mu \mathrm{l}$ \\
\hline
\end{tabular}

Tabelle 35: Testansatz Laktatdehydrogenase.

\begin{tabular}{|l|l|l|}
\hline Chemikalie & Leerwert & Probe \\
\hline Tris-HCl 0,05 M (AppliChem $\left.{ }^{\circledR}, \mathrm{A} 1087,0250\right)$ & $935 \mu \mathrm{l}$ & $915 \mu \mathrm{l}$ \\
\hline EDTA 0,25 M (Merck $\left.{ }^{2}, 8418\right)$ & $20 \mu \mathrm{l}$ & $20 \mu \mathrm{l}$ \\
\hline NADH 10 mM (AppliChem $\left.{ }^{2}, \mathrm{~A} 1393,0001\right)$ & $15 \mu \mathrm{l}$ & $15 \mu \mathrm{l}$ \\
\hline Homogenat & $0 \mu \mathrm{l}$ & $20 \mu \mathrm{l}$ \\
\hline
\end{tabular}


Tabelle 36: Testansatz Komplex-1.

\begin{tabular}{|l|l|l|}
\hline Chemikalie & Leerwert & Probe \\
\hline Messpuffer & $920 \mu \mathrm{l}$ & $900 \mu \mathrm{l}$ \\
\hline Kaliumcyanid $50 \mathrm{mM}$ & $20 \mu \mathrm{l}$ & $20 \mu \mathrm{l}$ \\
\hline Antimycin A $50 \mu \mathrm{M}$ & $20 \mu \mathrm{l}$ & $20 \mu \mathrm{l}$ \\
\hline Homogenat & $0 \mu \mathrm{l}$ & $20 \mu \mathrm{l}$ \\
\hline
\end{tabular}




\section{Literaturverzeichnis}

Abu EO, Horner A, Kusec V, Triffitt JT, Compston JE (1997): The localization of androgen receptors in human bone. J Clin Endocrinol Metab 2, 3493-3497

Ahmad S, Brown AW, King C, Shlobin O, Weir N, Stayrook S, Nathan S (2015): The six minute walk test comparison to a stair climb test. Eur Respir J 46, 2239

Allolio B, Schulte HM: Praktische Endokrinologie. 2. Auflage; Urban \& Fischer Verlag/Elsevier, München 2010

Ambrose C (2015): Muscle weakness during aging: a deficiency state involving declining angiogenesis. Ageing Res Rev 23, 139-153

Andersen (1975): Capillary Density in Skeletal Muscle of Man. Acta physiol scand 95, 203205

Bartl R: Osteoporose: Prävention, Diagnostik, Therapie. 4. Auflage; Georg Thieme Verlag, Stuttgart 2010

Basaria S, Coviello AD, Travison TG, Storer TW, Farwell WR, Jette AM, Eder R, Tennstedt S, Ulloor J, Zhang A, et al. (2010): Adverse Events Associated with Testosterone Administration. N Engl J of Med 363, 109-122

Bauer JM (2011): Ernährung im Alter: Grundlage für den Erhalt von Funktionalität und Lebensqualität. Internist 52, 946-954

Bauer JM, Wirth R, Volkert D, Werner H, Sieber CC (2008): Malnutrition, Sarkopenie und Kachexie im Alter - Von der Pathophysiologie zur Therapie. Dtsch Med Wochenschr $133,305-310$

Baumgartner RN, Koehler KM, Gallagher D, Romero L, Heymsfield SB, Ross RR, Garry PJ, Lindeman RD (1998): Epidemiology of Sarcopenia among the Elderly in New Mexico. Am J Epidemiol 147, 755-763

Beaudart C, McCloskey E, Bruyère O, Cesari M, Rolland Y, Rizzoli R, Araujo de Carvalho I, Amuthavalli Thiyagarajan J, Bautmans I, Bertière M-C, et al. (2016): Sarcopenia in daily practice: assessment and management. BMC Geriatr $\underline{16}, 170$

Behrends JC, Bischofberger J, Deutzmann R, Ehmke H, Frings S, Grissmer S, Hoth M, Kurtz A, Leipziger J, Müller F, et al.: Physiologie. 2. Auflage; Thieme, Stuttgart 2012 Bhasin S, Jasuja R (2009): Selective Androgen Receptor Modulators (SARMs) as Function Promoting Therapies. Curr Opin Clin Nutr Metab Care 12, 232-240

Bhasin S, Storer TW, Berman N, Yarasheski KE, Clevenger B, Phillips J, Lee WP, Bunnell TJ, Casaburi R (1997): Testosterone Replacement Increases Fat-Free Mass and Muscle Size in Hypogonadal Men. J Clin Endocrinol Metab 2ㅜ 407-413 
Bhasin S, Calof OM, Storer TW, Lee ML, Mazer NA, Jasuja R, Montori VM, Gao W, Dalton JT (2006): Drug Insight: testosterone and selective androgen receptor modulators as anabolic therapies for chronic illness and aging. Nat Clin Pract Endocrinol Metab 2, 146-159

Bhasin S, Woodhouse L, Casaburi R, Singh AB, Mac RP, Lee M, Yarasheski KE, SinhaHikim I, Dzekov C, Dzekov J et. Al (2005): Older Men are as Responsive as Young Men to the Anabolic Effects of Graded Doses of Testosterone on the Skeletal Muscle. J Clin Endocrinol Metab 90, 678-688

Binkley N, Krueger D, Buehring B (2013): What's in a name revisited: Should osteoporosis and sarcopenia be considered components of „dysmobility syndrome?“. Osteoporosis Int 24, 2955-2959

Biressi S, Molinaro M, Cossu G (2007): Cellular heterogeneity during vertebrate skeletal muscle development. Dev Biol $\underline{308}$, 281-293

Bischoff-Ferrari HA, Dietrich T, Orav EJ, Hu FB, Zhang Y, Karlson EW, Dawson-Hughes B (2004): Higher 25-hydroxyvitamin D concentrations are associated with better lowerextremity function in both active and inactive persons aged $\geq 60 \mathrm{y}$. Am J Clin Nutr $\underline{80}$, $752-758$

Bonaiuti D, Shea B, Iovine R, Negrini S, Welch V, Kemper H, Wells GA, Tugwell P, Cranney A (2002): Exercise for preventing and treating osteoporosis in postmenopausal women. Cochrane Database Syst Rev 2002, CD000333

Brancaccio P, Maffulli N, Limongelli FM (2007): Creatine kinase monitoring in sport medicine. Br Med Bull $\underline{81}-\underline{82}$, 209-230

Brandsch T: Einfluss der intermittierenden PTH-Applikation (hPTH 1-34) auf die Frakturheilung des metaphysären Knochens der orchiektomierten Ratte. Med. Diss. Göttingen 2011

Brotto M, Bonewald L (2015): Bone and muscle: Interactions beyond mechanical. Bone $\underline{80}$, $109-114$

Brown WF (1972): A method for estimating the number of motor units in thenar muscles and the changes in motor unit count with ageing. J Neurol Neurosurg Psychiatry $\underline{35}, 845$ 852

Buehring B, Krueger D, Binkley N (2013): Effect of including historical height and radius BMD measurement on sarco-osteoporosis prevalence. J Cachexia Sarcopenia Muscle $\underline{4}$, $47-54$ 
Chen J, Kim J, Dalton JT (2005): Discovery AND Therapeutic Promise OF Selective Androgen Receptor Modulators. Mol Interv ㅁ, 173-188

Chen Y, Zajac JD, MacLean HE (2005): Androgen regulation of satellite cell function. J Endocrinol 186, 21-31

Cheng C, Wentworth K, Shoback DM (2019): New Frontiers in Osteoporosis Therapy. Annu Rev Med 71, annurev-med-052218-020620

Chung HY, Cesari M, Anton S, Marzetti E, Giovannini S, Seo AY, Carter C, Yu BP, Leeuwenburgh C (2009): Molecular inflammation: Underpinnings of aging and agerelated diseases. Ageing Res Rev $\underline{8}, 18-30$

Cilotti A, Falchetti A (2009): Male osteoporosis and androgenic therapy: from testosterone to SARMs. Clin Cases Miner Bone Metab ㅁ, 229-233

Clark RV, Walker AC, Miller RR, O’Connor-Semmes RL, Ravussin E, Cefalu WT (2018): Creatine (methyl $-\mathrm{d}_{3}$ ) dilution in urine for estimation of total body skeletal muscle mass: accuracy and variability vs. MRI and DXA. Journal of Applied Physiology 124, 1-9

Clarke BL, Khosla S (2009): New Selective Estrogen and Androgen Receptor Modulators. Curr Opin Rheumatol 21, 374-379

Compston JE, Watts NB, Chapurlat R, Cooper C, Boonen S, Greenspan S, Pfeilschifter J, Silverman S, Díez-Pérez A, Lindsay R, et al. (2011): Obesity Is Not Protective against Fracture in Postmenopausal Women: GLOW. The American Journal of Medicine 124, $1043-1050$

Coss CC, Jones A, Dalton JT (2016): Pharmacokinetic drug interactions of the selective androgen receptor modulator GTx-024(Enobosarm) with itraconazole, rifampin, probenecid, celecoxib and rosuvastatin. Invest New Drugs 34, 458-467

Crawford J, Prado CMM, Johnston MA, Gralla RJ, Taylor RP, Hancock ML, Dalton JT (2016): Study Design and Rationale for the Phase 3 Clinical Development Program of Enobosarm, a Selective Androgen Receptor Modulator, for the Prevention and Treatment of Muscle Wasting in Cancer Patients (POWER Trials). Curr Oncol Rep $\underline{18}$, 37

Cruz-Jentoft AJ, Baeyens JP, Bauer JM, Boirie Y, Cederholm T, Landi F, Martin FC, Michel J-P, Rolland Y, Schneider SM, et al. (2010): Sarcopenia: European consensus on definition and diagnosisReport of the European Working Group on Sarcopenia in Older People. Age Ageing $\underline{39}$, 412-423 
Cruz-Jentoft AJ, Bahat G, Bauer J, Boirie Y, Bruyère O, Cederholm T, Cooper C, Landi F, Rolland Y, Sayer AA, et al. (2019): Sarcopenia: revised European consensus on definition and diagnosis. Age and Ageing $\underline{48}, 16-31$

Cummings SR, Martin JS, McClung MR, Siris ES, Eastell R, Reid IR, Delmas P, Zoog HB, Austin M, Wang A, et al. (2009): Denosumab for Prevention of Fractures in Postmenopausal Women with Osteoporosis. New Engl J Med $\underline{361}$, 756-765

Dalton JT (2017): The long an winding road for selective androgen receptor modulators. $\mathrm{Br}$ J Clin Pharmacol 83, 2131-2133

Dalton JT, Barnette KG, Bohl CE, Hancock ML, Rodriguez D, Dodson ST, Morton RA, Steiner MS (2011): The selective androgen receptor modulator GTx-024 (enobosarm) improves lean body mass and physical function in healthy elderly men and postmenopausal women: results of a double-blind, placebo-controlled phase II trial. J Cachexia Sarcopenia Muscle 2, 153-161

Deutz NEP, Bauer JM, Barazzoni R, Biolo G, Boirie Y, Bosy-Westphal A, Cederholm T, CruzJentoft A, Krznariç Z, Nair KS, et al. (2014): Protein intake and exercise for optimal muscle function with aging: Recommendations from the ESPEN Expert Group. Clinical Nutrition $\underline{33}, 929-936$

Dobs AS, Nguyen T, Pace C, Roberts CP (2002): Differential Effects of Oral Estrogen versus Oral Estrogen-Androgen Replacement Therapy on Body Composition in Postmenopausal Women. J Clin Endocrinol Metab 7, 1509-1516

Dobs AS, Boccia RV, Croot CC, Gabrail NY, Dalton JT, Hancock ML, Johnston MA, Steiner MS (2013): Effects of enobosarm on muscle wasting and physical function in patients with cancer: a double-blind, randomised controlled phase 2 trial. The Lancet Oncology $14,335-345$

Döll CJ: Einfluss der vertikalen Ganzkörpervibration unterschiedlicher Frequenz auf den osteoporotischen Lendenwirbelkörper der Ratte. Med. Diss. Göttingen 2010

DVO (2017): Prophylaxe, Diagnostik und Therapie der Osteoporose bei postmenopausalen Frauen und bei Männern. Leitlinie des Dachverbandes der deutschsprachigen wissenschaftlichen osteologischen Gesellschaften e.V.

Edgerton VR, Smith JL, Simpson DR (1975): Muscle fibre type populations of human leg muscles. Histochem J $\underline{7}, 259-266$

Eisermann K, Broderick CJ, Bazarov A, Moazam MM, Fraizer GC (2013): Androgen upregulates vascular endothelial growth factor expression in prostate cancer cells via an Sp1 binding site. Molecular Cancer 12, 1-12 
Ettinger B, Black DM, Mitlak BH, Knickerbocker RK, Nickelsen T, Genant HK, Christiansen C, Delmas PD, Zanchetta JR, Stakkestad J, et al. (1999): Reduction of Vertebral Fracture Risk in Postmenopausal Women With Osteoporosis Treated With Raloxifene: Results From a 3-Year Randomized Clinical Trial. JAMA 282, 637-645 Evans WJ (2010): Skeletal muscle loss: cachexia, sarcopenia, and inactivity. Am J Clin Nutr 91, 1123-1127

Everett LS, Gilligan C (1991): Physical activity affects on bone metabolism. Calcif Tissue Int $49,50-54$

Ferlay J, Autier P, Boniol M, Heanue M, Colombet M, Boyle P (2007): Estimates of the cancer incidence and mortality in Europe in 2006. Ann Oncol 18, 581-592

Ferrucci L, Baroni M, Ranchelli A, Lauretani F, Maggio M, Mecocci P, Ruggiero C (2014): Interaction Between Bone and Muscle in Older Persons with Mobility Limitations. Curr Pharm Des 20, 3178-3197

Forsberg AM, Nilsson E, Werneman J, Bergström J, Hultman E (1991): Muscle composition in relation to age and sex. Clin Sci $\underline{81}, 249-256$

Freiberger E, Goisser S, Porzel S, Volkert D, Kemmler W, Sieber C, Bollheimer C (2015): Sarcopenic obesity and complex interventions with nutrition and exercise in communitydwelling older persons \&ndash; a narrative review. CIA 1267

Frontera WR, Hughes VA, Fielding RA, Fiatarone MA, Evans WJ, Roubenoff R (2000): Aging of skeletal muscle: a 12-yr longitudinal study. J Appl Physiol 묘, 1321-1326

Gao W, Dalton JT (2007): Expanding the therapeutic use of androgens via selective androgen receptor modulators (SARMs). Drug Discov Today 12, 241-248

Garber K, Arbor A (2016): No longer going to waste. Nat Biotechnol 34, 458-461

Gavin TP, Ruster RS, Carrithers JA, Zwetsloot KA, Kraus RM, Evans CA, Knapp DJ, Drew JL, McCartney JS, Garry JP, Hickner RC (2007): No difference in the skeletal muscle angiogenic response to aerobic exercise training between young and aged men. $\mathrm{J}$ Physiol 585, 231-239

Giannopoulos G (1973): Binding of Testosterone to Uterine Components of the Immature Rat. J Biol Chem 248, 1004-1010

Gillespie WJ, Gillespie LD, Parker MJ (2010): Hip protectors for preventin hip fractures in older people. Cochrane Database Syst Rev 2010, CD001255

Girgis CM (2015): Integrated Therapies for Osteoporosis and Sarcopenia: From Signaling Pathways to Clinical Trials. Calcif Tissue Int $\underline{96}$, 243-255 
Goisser S, Kob R, Sieber CC, Bauer JM (2019): Update zur Diagnose und Therapie der Sarkopenie. Internist $\underline{60}, 141-148$

Hadji P, Klein S, Gothe H, Häussler B, Kless T, Schmidt T, Steinle T, Verheyen F, Linder R (2013): The Epidemiology of Osteoporosis. Deutsches Aerzteblatt Online

Hansen FM, Fahmy N, Nielsen JH (1980): The influence of sexual hormones on lipogenesis and lipolysis in rat fat cells. Acta Endocrinol 95, 566-570

Hatefi Y, Rieske JS (1967): The Preparation and properties of DPNH-cytochrome c reductase (complex I-III oft he respiratory chain). Methods Enzymol 10, 225-231

Häussler B, Gothe H, Göl D, Glaeske G, Pientka L, Felsenberg D (2007): Epidemiology, treatment and costs of osteoporosis in Germany-the BoneEVA Study. Osteoporos Int $\underline{18}, 77-84$

Hervey GR, Hutchinson I (1973): The effects of testosterone on body weight and composition in the rat. J Endocrinol 57, 24-25

Hoffmann DB, Komrakova M, Pflug S, von Oerzen M, Saul D, Weiser L, Walde TA, Wassmann M, Schilling AF, Lehmann W, Sehmisch S (2018): Evaluation of ostarine as a selective androgen receptor modulator in a rat model of postmenopausal osteoporosis. J Bone Miner Metab

Horak V (1983): A Successive Histochemical Staining for Succinate Dehydrogenase an „Reversed“-ATPase in a Single Section for the Skeletal Muscle Fibre Typing. Histochemistry $\underline{78}, 545-553$

Ibrahim K, May C, Patel HP, Baxter M, Sayer AA, Roberts H (2016): A feasibility study of implementing grip strength measurement into routine hospital practice (GRImP): study protocol. Pilot Feasibility Stud 2, 27

Janssen HC, Samson MM, Verhaar HJ (2002): Vitamin D deficiency, muscle function, and falls in elderly people. Am J Clin Nutr $\underline{75}, 611-615$

Jähn K, Lara-Castillo N, Brotto L, Mo C, Johnson M, Brotto M, Bonewald L (2012): Skeletal muscle secreted factors prevent glucocorticoid-induced osteocyte apoptosis through activation of $\beta$-catenin. eCM $\underline{24}, 197-210$

Juan Y-S, Onal B, Broadaway S, Cosgrove J, Leggett RE, Whitbeck C, De E, Sokol R, Levin RM (2007): Effect of castration on male rabbit lower urinary tract tissue enzymes. Mol Cell Biochem 301, 227-233

Kalu DN (1991): The ovariectomized rat model of postmenopausal bone loss. Bone and Mineral 15, 175-191 
Kanis JA, McCloskey EV, Johansson H, Cooper C, Rizzoli R, Reginster J-Y (2013):

European guidance for the diagnosis and management of osteoporosis in postmenopausal women. Osteoporos Int 24, 23-57

Kanis JA, McCloskey EV, Johansson H, Oden A, Ström O, Borgström F (2010): Development and use of FRAX $®$ in osteoporosis. Osteoporos Int 21, 407-413

Kanis JA, Melton LJ, Christiansen C, Johnston CC, Khaltaev N (1994): The diagnosis of osteoporosis. J Bone Miner Res $\underline{9}, 1137-1141$

Katznelson L, Finkelstein JS, Schoenfeld DA, Rosenthal DI, Anderson EJ, Klibanski A (1996): Increase in bone density and lean body mass during testosterone administration in men with acquired hypogonadism. J Clin Endocrinol Metab 81, 4358-4365

Kearbey JD, Gao W, Narayanan R, Fisher SJ, Wu D, Miller DD, Dalton JT (2007): Selective Androgen Receptor Modulator (SARM) Treatment Prevents Bone Loss and Reduces Body Fat in Ovariectomized Rats. Pharm Res 24, 328-335

Khor SC, Abdul Karim N, Wan Ngah WZ, Mohd Yusof YA, Makpol S (2014): Vitamin E in Sarcopenia: Current Evidences on Its Role in Prevention and Treatment. Oxid Med Cell Longev, 2014, 1-16

Khosla S, Riggs BL (2005): Pathophysiology of Age-Related Bone Loss and Osteoporosis. Clin Endocrinol Metab $\underline{34}, 1015-1030$

Kiesswetter E (2015): Optimierte Ernährung bei Sarkopenie. Schweiz Z Ernährungsmed 13(5):6-11

Kim S, Won CW, Kim BS, Choi HR, Moon MY (2014): The Association between the Low Muscle Mass and Osteoporosis in Elderly Korean People. J Korean Med Sci 29, 995 1000

Kling JH: Einfluss des Lipoxygenaseinhibitors Baicalein in unterschiedlicher Dosierung auf den Skelettmuskel der ovariektomierten Ratte. Med. Diss. Göttingen 2016

Kobori M, Yamamuro T (1989): Effects of Gonadectomy and Estrogen Administration on Rat Skeletal Muscle. Clin Orthop 243, 306-311

Komrakova M, Werner C, Wicke M, Nguyen BT, Sehmisch S, Tezval M, Stuermer KM, Stuermer EK (2009): Effect of daidzein, 4-methylbenzylidene camphor or estrogen on gastrocnemius muscle of osteoporotic rats undergoing tibia healing period. J Endocrinol $\underline{201}, 253-262$ 
Komrakova M, Stuermer EK, Werner C, Wicke M, Kolios L, Sehmisch S, Tezval M, Daub F, Martens T, Witzenhausen P, et al. (2010): Effect of human parathyroid hormone $\mathrm{hPTH}(1-34)$ applied at different regimes on fracture healing and muscle in ovariectomized and healthy rats. Bone $\underline{47}, 480-492$

Komrakova M, Hoffmann DB, Nuehnen V, Stueber H, Wassmann M, Wicke M, Tezval M, Stuermer KM, Sehmisch S (2016): The Effect of Vibration Treatments Combined with Teriparatide or Strontium Ranelate on Bone Healing and Muscle in Ovariectomized Rats. Calcif Tissue Int 99, 408-422

Kousteni S, Chen J-R, Bellido T, Han L, Ali AA, O’Brien CA, Plotkin L, Fu Q, Mancino AT, Wen Y, et al. (2002): Reversal of Bone Loss in Mice by Nongenotropic Signaling of Sex Steroids. Science 298, 843-846

Krotkiewski M, Kral JG, Karlsson J (1980): Effects of castration and testosterone substitution on body composition and muscle metabolism in rats. Acta Physiol Scand $\underline{109}, 233-237$

Kyriakides ZS, Petinakis P, Kaklamanis L, Sbarouni E, Karayannakos P, Iliopoulos D, Dontas I, Kremastinos DT (2001): Intramuscular administration of estrogen may promote angiogenesis and perfusion in a rabbit model of chronic limb ischemia. Cardiovasc Res $\underline{49}, 626-633$

Landi F, Liperoti R, Russo A, Giovannini S, Tosato M, Capoluongo E, Bernabei R, Onder G (2012): Sarcopenia as a risk factor for falls in elderly individuals: Results from the ilsirente study. Clin Nutr $\underline{31}, 652-658$

Larsson L (1978): Morphological and functional characteristics of the aging skeletal muscle in man. Acta Physiol Scand $\underline{457}, 1-36$

Lauretani F, Russo CR, Bandinelli S, Bartali B, Cavazzini C, Iorio AD, Corsi AM, Rantanen T, Guralnik JM, Ferrucci L (2003): Age-associated changes in skeletal muscles and their effect on mobility: an operational diagnosis of sarcopenia. J Appl Physiol $\underline{95}$, $1851-1860$

Leek BT, Mudaliar SRD, Henry R, Mathieu-Costello O, Richardson RS (2001): Effect of acute exercise on citrate synthase activity in untrained and trained human skeletal muscle. Am J Physiol Regul Integr Comp Physiol 280, 441-447

Leifke E, Körner HC, Link TM, Behre HM, Peters PE, Nieschlag E (1998): Effects of testosterone replacement therapy on cortical and trabecular bone mineral density, vertebral body area and paraspinal musle area in hypogonadal men. Eur J Endocrinol $\underline{138}, 51-58$ 
Lelovas PP, Xanthos TT, Thoma SE, Lyritis GP, Dontas IA (2008): The Laboratory Rat as an Animal Model for Osteoporosis Research. Comparative medicine 424-430

Leslie WD, Adler RA, El-Hajj Fuleihan G, Hodsman A, Kendler DL, McClung M, Miller PD, Watts NB (2006): Application of the 1994 WHO Classification to Populations Other Than Postmenopausal Caucasian Women: The 2005 ISCD Official Positions. Journal of Clinical Densitometry $\underline{9}, 22-30$

Lexell J (1995): Human aging, muscle mass, and fiber type composition. J Gerontol A Biol Sci Med Sci. $\underline{50}, 1-16$

Lexell J, Taylor CC, Sjöström M (1988): What is the cause of the ageing atrophy?: Total number, size and proportion of different fiber types studied in whole vastus lateralis muscle from 15- to 83-year-old men. J Neurol Sci $\underline{84}$, 275-294

Li G, Zhang L, Wang D, AIQudsy L, Jiang JX, Xu H, Shang P (2019): Muscle-bone crosstalk and potential therapies for sarco-osteoporosis. J Cell Biochem 120, 14262-14273

Li X, Ominsky MS, Warmington KS, Morony S, Gong J, Cao J, Gao Y, Shalhoub V, Tipton B, Haldankar R, et al. (2009): Sclerostin Antibody Treatment Increases Bone Formation, Bone Mass, and Bone Strength in a Rat Model of Postmenopausal Osteoporosis. J Bone Miner Res 24

Lüllmann-Rauch R: Taschenlehrbuch Histologie. 3. Auflage; Georg Thieme Verlag, Stuttgart 2009

Machida S, Booth F (2004): Regrowth of Skeletal Muscle Atrophied from Inactivity. Med Sci Sports Exerc 36, 52-59

Maetzler W, Drey M, Jacobs AH (2015): Sarkopenie und Frailty in der Neurologie. Nervenarzt $\underline{86}, 420-430$

Maggio M, Ceda GP, Ticinesi A, De Vita F, Gelmini G, Costantino C, Meschi T, Kressig RW, Cesari M, Fabi M, Lauretani F (2016): Instrumental and Non-Instrumental Evaluation of 4-Meter Walking Speed in Older Individuals. PLoS ONE 11

Malmstrom TK, Miller DK, Simonsick EM, Ferrucci L, Morley JE (2016): SARC-F: a symptom score to predict persons with sarcopenia at risk for poor functional outcomes: SARC-F. Journal of Cachexia, Sarcopenia and Muscle $\underline{7}, 28-36$ Mauro A (1961): Satellite Cell of Skeletal Muscle Fibers. J Biophys Biochem Cytol $\underline{9}, 493-$ 495

McComas AJ: Skeletal muscle: Form and Function. Champaign, Human Kinetics 1996 
McCormick KM, Burns KL, Piccone CM, Gosselin LE, Brazeau GA (2004): Effects of ovariectomy and estrogen on skeletal muscle function in growing rats. J Muscle Res Cell Motil 25, 21-27

McElroy JF, Wade GN (1987): Short- and long-term effects of ovariectomy on food intake, body weight, carcass composition, and brown adipose tissue in rats. Physiol Behav $\underline{39}$, $361-365$

Meijer AE (1970): Histochemical method for the demonstration of myosin adenosine triphosphatase in muscle tissues. Histochemie 22, 51-58

Mertens HJMM, Heineman MJ, Theunissen PHMH, de Jong FH, Evers JLH (2001): Androgen, estrogen and progesterone receptor expression in the human uterus during the menstrual cycle. Eur J Obstet Gyn and R B 98, 58-65

Michael YL, Whitlock EP, Lin JS, Fu R, O’Connor EA, Gold R (2010): Primary CareRelevant Interventions to Prevent Falling in Older Adults: A Systematic Evidence Review for the U.S. Preventive Services Task Force. Ann Intern Med 153, 815 Moline SW, Glenner GG (1964): Ultrarapid Tissue Freezing In Liquid Nitrogen. J Histochem Cytochem $\underline{12}, 777-783$

Mooradian AD, Morley JE, Korenman SG (1987): Biological Actions of Androgens. Endocr $\operatorname{Rev} \underline{8}, 1-28$

Moore KL, Persaud TVN, Viebahn C: Embryologie: Entwicklungsstadien - Frühentwicklung - Organogenese - Klinik. 5. Auflage; Urban \& Fischer Verlag/Elsevier, München 2007

Morales A, Heaton JPW, Carson CC (2000): Andropause: A Misnomer For a True Clinical Entity. J Urol 163, 705-712

Moran AL, Nelson SA, Landisch RM, Warren GL, Lowe DA (2007): Estradiol replacement reverses ovariectomy-induced muscle contractile and myosin dysfunction in mature female mice. J Appl Physiol 102, 1387-1393

Morley JE (2016): Pharmacologic Options for the Treatment of Sarcopenia. Calcif Tissue Int 98, 319-333

Morley JE, Baumgartner RN, Roubenoff R, Mayer J, Nair KS (2001): Sarcopenia. J Lab Clin Med 137, 231-243

Narayanan R, Coss CC, Dalton JT (2018): Development of Selective Androgen Receptor Modulators (SARMs). Mol Cell Endocronol 465, 123-142

Narayanan R, Mohler ML, Bohl CE, Miller DD, Dalton JT (2008): Selective androgen receptor modulators in preclinical and clinical development. Nucl Recept Signal $\underline{6}, 1-26$ 
Negro-Vilar A (1999): Selective Androgen Receptor Modulators (SARMs): A Novel Approach to Androgen Therapy for the New Millennium. J Clin Endocrinol Metab 84, $3459-3462$

Newman AB, Kupelian V, Visser M, Simonsick E, Goodpaster B, Nevitt M, Kritchevsky SB, Tylavsky FA, Rubin SM, Harris TB, on behalf of the Health ABC Study Investigators (2003): Sarcopenia: Alternative Definitions and Associations with Lower Extremity Function. J Am Geriatr Soc 51, 1602-1609

NIH Consensus Development Panel on Osteoporosis Prevention, Diagnosis, and Therapy (2001): Osteoporosis prevention, diagnosis, and therapy. JAMA $\underline{285}$, 785-795

Omi N, Ezawa I (1995): The effect of ovariectomy on bone metabolism in rats. Bone 17, $163-168$

Pahor M, Manini T, Cesari M (2009): Sarcopenia: Clinical evaluation, biological markers and other evaluation tools. J Nutr Health Aging $\underline{13}$, 724-728

Pette D, Staron RS (1997): Mammalian Skeletal Muscle Fiber Type Transitions. Int Rev Cytol, 170, 143-223

Pfeilschifter J, Diel IJ (2000): Osteoporosis Due to Cancer Treatment: Pathogenesis and Management. J Clin Oncol 18, 1570-1593

Philippou A, Maridaki M, Halapas A, Koutsilieris M (2007): The Role of the Insulin-like Growth Factor 1 (IGF-1) in Skeletal Muscle Physiology. In Vivo 21, 45-54

Ponnusamy S, Sullivan RD, Thiyagarajan T, Tillmann H, Getzenberg RH, Narayanan R (2017): Tissue Selective Androgen Receptor Modulators (SARMs) Increase Pelvic Floor Muscle Mass in Ovariectomized Mice. J Cell Biochem 118, 640-646

Rassow J, Hauser K, Netzker R, Deutzmann R (Hrsg.): Biochemie. 3. Auflage; Georg Thieme Verlag, Stuttgart 2012

Reginster JY, Seeman E, De Vernejoul MC, Adami S, Compston J, Phenekos C, Devogelaer JP, Curiel MD, Sawicki A, Goemaere S, et al. (2005): Strontium Ranelate Reduces the Risk of Nonvertebral Fractures in Postmenopausal Women with Osteoporosis:

Treatment of Peripheral Osteoporosis (TROPOS) Study. The Journal of Clinical Endocrinology \& Metabolism 90, 2816-2822

Rice KM, Linderman JK, Kinnard RS, Blough ER (2005): The Fischer 344/NNiaHSd X Brown Norway/BiNia is a Better Model of Sarcopenia than the Fischer 344/NNiaHSd: a Comparative Analysis of Muscle Mass and Contractile Properties in Aging Male Rat Models. Biogerontology $\underline{6}, 335-343$ 
Rizzoli R (2008): Nutrition: its role in bone health. Best Pract Res Clin Endocrinol Metab 22, $813-829$

Rizzoli R, Burlet N, Cahall D, Delmas PD, Eriksen EF, Felsenberg D, Grbic J, Jontell M, Landesberg R, Laslop A, et al. (2008): Osteonecrosis of the jaw and bisphosphonate treatment for osteoporosis. Bone $42,841-847$

Rizzoli R, Reginster J-Y, Boonen S, Bréart G, Diez-Perez A, Felsenberg D, Kaufman J-M, Kanis JA, Cooper C (2011): Adverse Reactions and Drug-Drug Interactions in the Management of Women with Postmenopausal Osteoporosis. Calcif Tissue Int $\underline{89}, 91-$ 104

Rizzoli R, Reginster J-Y, Arnal J-F, Bautmans I, Beaudart C, Bischoff-Ferrari H, Biver E, Boonen S, Brandi M-L, Chines A, et al. (2013): Quality of Life in Sarcopenia and Frailty. Calcif Tissue Int $\underline{93}, 101-120$

Roessner A, Pfeifer U, Müller-Hermelink HK: Allgemeine Pathologie und Grundlagen der Speziellen Pathologie: 11. Auflage; Urban \& Fischer Verlag/Elsevier, München 2008 Rosenberg IH (1997): Sarcopenia: Origins and Clinical Relevance. J Nutr 127, 990-991

Rossouw JE, Anderson GL, Prentice RL, LaCroix AZ, Kooperberg C, Stefanick ML, Jackson RD, Beresford SAA, Howard BV, Johnson KC, et al. (2002): Risks and benefits of estrogen plus progestin in healthy postmenopausal women: principal results From the Women's Health Initiative randomized controlled trial. JAMA 288, 321-333 Roubenoff R (2000): Sarcopenia and ist implications for the elderly. Eur J Clin Nutr $\underline{54}$, 4047

Roubenoff R, Parise H, Payette HA, Abad LW, D'Agostino R, Jacques PF, Wilson PWF, Dinarello CA, Harris TB (2003): Cytokines, insulin-like growth factor 1, sarcopenia, and mortality in very old community-dwelling men and women: the Framingham Heart Study. Am J Med 115, 429-435

Santesso N, Carrasco-Labra A, Brignardello-Petersen R (2014): Hip protectors for preventing hip fractures in older people. 83

Sayer AA, Syddall HE, Gilbody HJ, Dennison EM, Cooper C (2004): Does Sarcopenia Originate in Early Life? Findings From the Hertfordshire Cohort Study. J Gerontol A Biol Sci Med Sci 59, 930-934

Schaap LA, Pluijm SMF, Deeg DJH, Harris TB, Kritchevsky SB, Newman AB, Colbert LH, Pahor M, Rubin SM, Tylavsky FA, Visser M (2009): Higher Inflammatory Marker Levels in Older Persons: Associations With 5-Year Change in Muscle Mass and Muscle Strength. J Gerontol A Biol Sci Med Sci 64, 1183-1189 
Schaap LA, van Schoor NM, Lips P, Visser M (2018): Associations of Sarcopenia Definitions, and Their Components, With the Incidence of Recurrent Falling and Fractures: The Longitudinal Aging Study Amsterdam. The Journals of Gerontology: Series A $\underline{73}, 1199-120$

Schauder P, Ollenschläger G: Ernährungsmedizin: Prävention und Therapie. 3. Auflage; Urban \& Fischer Verlag/Elsevier GmbH, München 2006

Scheidt-Nave C, Banzer D, Abendroth K (1997): Schlussbericht Multizentrische Studie zu Verteilung,Determination und prädiktivem Wert der Knochendichte in der deutschen Bevölkerung Förderprojekt des Bundesministeriums für Forschung und Technologie Förderkennzeichen 01KM 9304/0; 1-45

Schwerzmann K, Hoppeler H, Kayar SR, Weibel ER (1989): Oxidative capacity of muscle and mitochondria: correlation of physiological, biochemical, and morphometric characteristics. Proc Natl Acad Sci $\underline{86}(5), 1583-1587$

Scott W, Stevens J, Binder-Macleod SA (2001): Human Skeletal Muscle Fiber Type Classifications. Phys Ther $\underline{81}, 1810-1816$

Seidell JC, Björntorp P, Sjöström L, Kvist H, Sannerstedt R (1990): Visceral fat accumulation in men is positively associated with insulin, glucose, and C-peptide levels, but negatively with testosterone levels. Metabolism $\underline{39}$, 897-901

Shrader SP, Ragucci KR (2005): Parathyroid Hormone (1-84) and Treatment of Osteoporosis. Ann Pharmacother $\underline{39}, 1511-1516$

Sieveking DP, Lim P, Chow RW, Dunn LL, Bao S, McGrath KC, Heather AK, Handelsman DJ, Celermajer DS, Ng MK (2009): A Sex-Specific Role for Androgens in Angiogenesis. Circulation 120, 1140-1140

Singh R, Artaza JN, Taylor WE, Gonzalez-Cadavid NF, Bhasin S (2003): Androgens Stimulate Myogenic Differentiation and Inhibit Adipogenesis in C3H 10T1/2 Pluripotent Cells through an Androgen Receptor-Mediated Pathway. Endocrinology $\underline{144}, 5081-5088$

Sinha-Hikim I, Artaza J, Woodhouse L, Gonzalez-Cadavid N, Singh AB, Lee MI, Storer TW, Casaburi R, Shen R, Bhasin S (2002): Testosterone-induced increase in muscle size in healthy young men is associated with muscle fiber hypertrophy. Am J Physiol Endocrinol Metab 283, 154-164

Sirola J, Kröger H (2011): Similarities in Acquired Factors Related to Postmenopausal Osteoporosis and Sarcopenia. J Osteoporos 2011, 1-14 
Souccar C, Lapa AJ, do Valle JR (1982): The influence of testosterone on neuromuscular transmission in hormone sensitive mammalian skeletal muscles. Muscle Nerve 5, 232237

Srinath R, Dobs A (2014): Enobosarm (GTx-024, S-22): a potential treatment for cachexia. Future Oncol $\underline{10}, 187-194$

Srinivas-Shankar U, Wu FC (2006): Drug insight: testosterone preparations. Nat Clin Pract Urol $\underline{3}, 653-665$

Stanley HL, Schmitt BP, Poses RM, Deiss WP (1991): Does Hypogonadism Contribute to the Occurrence of a Minimal Trauma Hip Fracture in Elderly Men? J Am Geriatr Soc $\underline{39}, 766-771$

Stepan JJ, Lachman M, Zvěřina J, Pacovský V, Baylink DJ (1989): Castrated Men Exhibit Bone Loss: Effect of Calcitonin Treatment on Biochemical Indices of Bone Remodeling. J Clin Endocrinol Metab $\underline{69}$, 523-527

Stevenson M, Lloyd Jones M, De Nigris E, Brewer N, Davis S, Oakley J (2005): A systematic review and economic evaluation of alendronate, etidronate, risedronate, raloxifene and teriparatide for the prevention and treatment of postmenopausal osteoporosis. Health Technol Assess $\underline{9}$

Studenski SA, Peters KW, Alley DE, Cawthon PM, McLean RR, Harris TB, Ferrucci L, Guralnik JM, Fragala MS, Kenny AM, et al. (2014): The FNIH Sarcopenia Project:

Rationale, Study Description, Conference Recommendations, and Final Estimates. The Journals of Gerontology: Series A $\underline{69}, 547-558$

Stuermer EK, Sehmisch S, Rack T, Wenda E, Seidlova-Wuttke D, Tezval M, Wuttke W, Frosch KH, Stuermer KM (2010): Estrogen and raloxifene improve metaphyseal fracture healing in the early phase of osteoporosis. A new fracture-healing model at the tibia in rat. Langenbecks Arch Surg 395, 163-172

Tenover JL (1997): Testosterone and the Aging Male. J Androl 18, 103-106

Thevis M, Schänzer W (2017): Detection of SARMs in doping control analysis. Mol Cell Endocrinol $464,34-45$

Torgerson DJ, Bell-Syer SEM (2001): Hormone Replacement Therapy and Prevention of Nonvertebral Fractures: A Meta-analysis of Randomized Trials. JAMA 285, 2891 Tucker H, Crook JW, Chesterson GJ (1988): Nonsteroidal antiandrogens. Synthesis and structure-activity relationships of 3-substituted derivatives of 2-hydroxypropionanilides. J Med Chem 31, 954-959 
van der Klift M, de Laet CE, McCloskey EV, Johnell O, Kanis JA, Hofman A, Pols HA (2004): Risk Factors for Incident Vertebral Fractures in Men and Women: The Rotterdam Study. J Bone Miner Res $\underline{19}, 1172-1180$

Vanderschueren D, Vandenput L, Boonen S, Lindberg MK, Bouillon R, Ohlsson C (2004): Androgens and Bone. Endocr Rev 25, 389-425

Volkert D (2009): Die Rolle der Ernährung zur Prävention von Sarkopenie und Frailty. Schweizer Zeitschrift für Ernährungsmedizin 4, 25-30

Volpato S, Bianchi L, Cherubini A, Landi F, Maggio M, Savino E, Bandinelli S, Ceda GP, Guralnik JM, Zuliani G, Ferrucci L (2014): Prevalence and Clinical Correlates of Sarcopenia in Community-Dwelling Older People: Application of the EWGSOP Definition and Diagnostic Algorithm. J Gerontol A Biol Sci Med Sci 69, 438-446

Wade GN, Zucker I (1970): Modulation of food intake and locomotor activity in female rats by diencephalic hormone implants. J Comp Physiol Psychol 72(2) 328-336

Wakley GK, Schutte HD, Hannon KS, Turner RT (1991): Androgen treatment prevents loss of cancellous bone in the orchidectomized rat. J Bone Miner Res $\underline{6}, 325-330$

Walsh MC, Hunter GR, Livingstone MB (2006): Sarcopenia in premenopausal and postmenopausal women with osteopenia, osteoporosis and normal bone mineral density. Osteoporos Int $\underline{17}, 61-67$

Welsch U, Deller T: Sobotta Lehrbuch Histologie: Unter Mitarbeit von Thomas Deller. 3. Auflage; Urban \& Fischer Verlag/Elsevier, München 2010

Wilson S, Sharp CA, Davie MWJ (2012): Health-related quality of life in patients with osteoporosis in the absence of vertebral fracture: a systematic review. Osteoporos Int $\underline{23}, 2749-2768$

Wülker N, Kluba T, Roetman B, Rudert M: Taschenlehrbuch Orthopädie und Unfallchirurgie. 3. Auflage; Thieme, Stuttgart 2015

Yin D, Gao W, Kearbey JD, Xu H, Chung K, He Y, Marhefka CA, Veverka KA, Miller DD, Dalton JT (2003): Pharmacodynamics of Selective Androgen Receptor Modulators. J Pharmacol Exp Ther 304, 1334-1340

Young A, Stokes M, Crowe M (1984): Size and strength of the quadriceps muscles of old and young women. Eur J Clin Invest 14, 282-287

Ziaaldini MM, Marzetti E, Picca A, Murlasits Z (2017): Biochemical Pathways of Sarcopenia and Their Modulation by Physical Exercise: A Narrative Review. Front Med $\underline{4}, 167$ 
Internetquellen

1: Bulk MK-2866, Androgem Ingredients, unter:

http://androgem.com/products/mk-2866; Zugriff am 19.02.2017

2: Selektive Androgenrezeptor Modulatoren, Doping, unter:

http://www.dopinginfo.de/rubriken/00_home/00_sar.html; Zugriff am 19.02.2017

3: Deutsche Gesellschaft für Ernährung (DGE) (2016) Referenzwerte für die Nährstoffzufuhr: Protein Unter:

https://www.dge.de/wissenschaft/referenzwerte/protein; Zugriff am 01.09.2019

4: European Medicines Agency, unter:

https://www.ema.europa.eu/en/medicines/human/EPAR/osseor; Zugriff am 03.09.2019 


\section{Danksagung}

Ich möchte mich ganz herzlich bei dem ehemaligen Leiter, Prof. Dr. med. Klaus Michael Stürmer, und Prof. Dr. med. Wolfgang Lehmann, dem aktuellen Klinikleiter, für die Ermöglichung dieses Projektes bedanken.

Des Weiteren geht ein großes Dankeschön an Herrn Prof. Dr. med. Stephan Sehmisch, der als Doktorvater bei Fragen immer ansprechbar war und mir mit konstruktiven Ratschlägen zur Seite stand.

Ein ganz besonderer Dank geht an das Laborteam um Dr. rer. nat. Marina Komrakova, Ramona Castro-Machguth und Annette Witt. Bei allen aufkommenden Fragen wurde ich immer sehr gut betreut. Somit blieben zur keiner Zeit Fragen offen, sei es bezüglich der experimentellen Durchführung oder im Rahmen der Korrekturen dieser Arbeit.

Auch möchte ich all denjenigen Danken, welche sich die Zeit genommen haben, um diese Arbeit Korrektur zu lesen und mich bei der grafischen Umsetzung unterstützt haben. 